Portland State University

PDXScholar

$6-3-2020$

\title{
Addressing Structural Inequalities in Planning \\ Processes: a Case Study of an Equity Lens
}

Marta Conklé McGuire

Portland State University

Follow this and additional works at: https://pdxscholar.library.pdx.edu/open_access_etds

Part of the Public Affairs Commons

Let us know how access to this document benefits you.

\section{Recommended Citation}

McGuire, Marta Conklé, "Addressing Structural Inequalities in Planning Processes: a Case Study of an Equity Lens" (2020). Dissertations and Theses. Paper 5474.

https://doi.org/10.15760/etd.7346

This Dissertation is brought to you for free and open access. It has been accepted for inclusion in Dissertations and Theses by an authorized administrator of PDXScholar. Please contact us if we can make this document more accessible: pdxscholar@pdx.edu. 
Addressing Structural Inequalities in Planning Processes:

A Case Study of an Equity Lens

\author{
By \\ Marta Conklé McGuire
}

A dissertation submitted in partial fulfillment of the requirements for the degree of

\author{
Doctor of Philosophy \\ in \\ Public Affairs and Policy
}

Dissertation Committee:

Jennifer H. Allen, Chair

Billie Sandberg

Craig Shinn

Marisa Zapata

Portland State University

2020 
(C) 2020 Marta Conklé McGuire 


\begin{abstract}
The use of equity lenses is growing rapidly in the public sector as a means to reform institutional practices that produce racialized outcomes; yet, organizations are interpreting and using an equity lens in different ways, leaving open questions on the extent to which a lens addresses structural inequalities. This dissertation focuses on an indepth case study of a planning process that incorporated an equity lens in the development of a large scale urban system plan in Portland (OR) to build understanding of how an equity lens may change the institutional planning process. Insights from the study suggest an equity lens addresses structural inequalities in the planning process in three main ways: 1) by shifting underlying values for decision making by taking into account social structural relations that provide for differences in social identity, power and opportunity and attributing value to the "lived experience" in policy deliberation; 2) by providing special treatment for oppressed groups in decision making including appointed representation and compensation; and 3) by positioning these groups at the onset of the planning process and in advance of each decision point, allowing them to interact directly with decision makers rather than later as a review body. While the potential for the use of an equity lens to address structural inequalities appears substantial, the case study suggests factors such as organizational policies and values within the institutional environment that may either constrain or support the use of an equity lens.
\end{abstract}




\section{Dedication}

To Mom and Dad - For my foundation and inspiration.

To Elle and Ian - For the change you will bring to this world.

And to Matt - For your unrelenting support. 


\section{Acknowledgements}

I would like to extend my deepest gratitude and appreciation to the many people that have supported, encouraged and guided me through my academic journey and the process of writing this dissertation. First, I would like to thank all the individuals that participated in this study and their willingness to share their experience and insights. Thank you to my committee for guiding and supporting me throughout this process. I am grateful for my dissertation chair Dr. Jennifer Allen for being my advisor during my entire journey in this program. Thank you for being there at every turn, providing guidance and clarity whenever I needed it and helping me connect my two worlds of being an academic and practitioner. You never missed an email, a meeting or left a question unanswered. Thank you for always making me feel supported on this journey. Thank you to my committee members including Dr. Billie Sandberg for thoughtful guidance and invaluable insights; to Dr. Craig Shinn for your continual encouragement to push myself on this intellectual journey and helping provide a roadmap when I needed it; and to Dr. Marisa Zapata for sharing your expertise in this field and counsel during the course of this process.

I will be forever grateful to my mom and dad for supporting me on this journey. You both have shaped me, my view of the world and always set the sky as the limit for achievement. To my dad, who set a high bar for work ethic and drive, thank you for showing me that you can do anything you put your mind to accomplish. My fierce determination and drive reflects the constant example you set for us. To my mom, who gave me the insights to understand privilege, the necessity of advocating for yourself and how to find strength and optimism in adversity, thank you for instilling upon me a view 
of the world oriented in eternal optimism and the desire to make this world better. Thank you for every opportunity and sacrifice you made to allow your children to access greater opportunity and for always being someone I aspire to be as a mother, spouse and individual. I will forever be grateful to you both for all the school pick-ups, warm dinners, folded laundry baskets and love and hugs you gave my family in my absence to allow me to pursue this journey.

I also could not have completed this journey without the support of my life-long love, Matt and our two children Elle and Ian. There really are no words or enough pages to express my gratitude for your support in this journey. It was longer than we planned and there were many sacrifices that I know you all felt, but you did so with understanding, constant encouragement and belief in my achievement even when I experienced doubts. To Elle and Ian, you will always be my proudest achievement, thank you for understanding the late night classes and long weekends spent studying and writing, thank you for all the hugs and kisses of encouragement. To Matt, thank you for inspiring me to go back to school, joining me on this journey, finding time to copy edit all my papers and carrying so many more responsibilities to allow me to pursue this lifelong goal. I could not have done this without you and I will be forever grateful.

I would also like to thank my dear colleagues and friends, Rosalynn and Rob, for your endless support, enthusiasm and belief in me. You are both fierce, brilliant advocates that I admire. Thank you for your constant counsel, always making me feel valued and giving me encouragement to push forward. Finally, to all my friends and family not yet mentioned, you are so dear to me, thank you for your support and encouragement you showed me throughout this process. 


\section{Table of Contents}

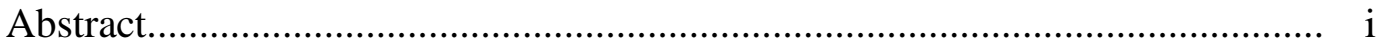

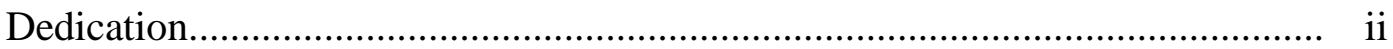

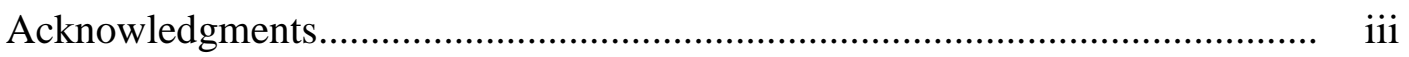

List of Tables........................................................................................... vii

List of Figures....................................................................................... viii

Chapter 1. Study Overview....................................................................... 1

1.1 A Legacy of Discrimination................................................... 1

1.2 Significance................................................................... 9

1.3 Study Purpose................................................................ 10

1.4 Research Questions.............................................................. 11

1.5 Structure of Dissertation......................................................... 11

Chapter 2. Literature Review............................................................. 13

2.1 Introduction.................................................................... 13

2.2 Planning Process Theories...................................................... 13

2.3 Theories of Justice................................................................ 29

2.4 Equity Lens....................................................................... 37

2.5 Summary and Review of Key Gaps in the Literature.................. 49

Chapter 3. Theoretical Framework........................................................ 54

3.1 Introduction....................................................................... 54

3.2 Theoretical Basis and Key Concepts...................................... 55

Chapter 4. Research Approach........................................................... 63

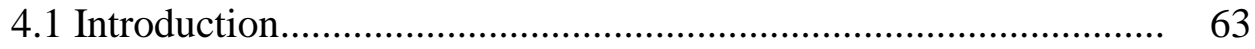

4.2 Research Questions.......................................................... 63

4.3 Research Design.................................................................. 63

4.4 Case Selection................................................................... 68

4.5 Data Collection....................................................................... 70

4.6 Data Analysis Process.................................................................. 76

4.7 Validity and Reliability..................................................... 83

4.8 Limitations.................................................................... 84

4.8 Ethical Considerations....................................................... 87 
Chapter 5. Equity Lens Case Study ……………….............................. 88

5.1 Introduction....................................................................... 88

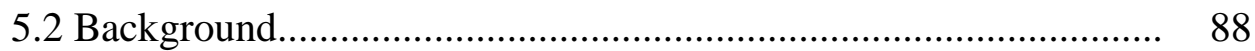

5.2.1 Metro Regional Government......................................... 88

5.2.2 2030 Regional Waste Plan Overview................................. 90

5.2.3 History and Legal Foundation of Regional Waste Plan.... 92

5.2.4 Planning Process for the 2030 Regional Waste Plan....... 94

5.2.5 Project Organization........................................ 97

5.2.6 Decision Making Structures............................. 100

5.3 Research Findings...................................................................... 101

5.3.1 How is an equity lens defined by planners, policy makers and participants in the planning process? .......................... 103

5.3.2 How are social groups identified and selected for special representation as a part of the equity lens in the planning process?

5.3.3 How does an equity lens influence the structural process of decision making?

5.3.4 How does the institutional environment influence the use of an equity lens? ......................................................... 130

5.4 Summary

Chapter 6. Discussion of Findings and Future Research 139

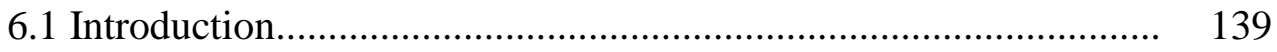

6.2 Discussion of Findings............................................................... 139

6.2.1 Equity Lens in Practice...................................................... 140

6.2.2 Decision Making Structures and Processes........................ 144

6.2.3 Selection of Groups for Special Representation................. 150

6.2.4 Institutional Environment.................................................. 153

6.3 Summary of Equity Lens Considerations for Future Practice........ 156

6.4 Future Research.................................................................... 161

6.5 Conclusion................................................................................... 163

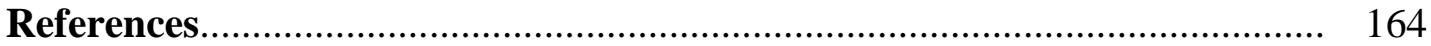

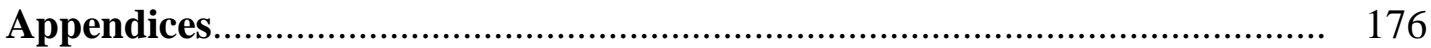

Appendix A: Positionality Statement.......................................................... 176

Appendix B: Consent Form.................................................................. 181

Appendix C: Recruitment Materials............................................................ 184

Appendix D: Data Collection Instruments..................................................... 185 


\section{List of Tables}

Table 1. Key Concepts of Young's Propositions of Justice.............................. 67

Table 2. Document Types.......................................................................... 72

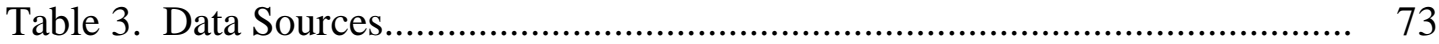

Table 4. Semi-Structured Interviews................................................................ 75

Table 5. Braun and Clarke's (2006) Six Phases of Thematic Analysis................ 78

Table 6. Sample Data Extract........................................................................ 79

Table 7. Theme Names and Definitions..................................................... 82

Table 8. Braun and Clarke (2018) Guidance for Thematic Analysis................... 83

Table 9. 2030 Regional Waste Plan Equity Work Group Members.................... 98

Table 10. Regional Waste Plan Roles................................................................. 99

Table 11. Definition of an Equity Lens........................................................ 104

Table 12. Limits of Appointed Representation................................................. 112

Table 13. Restructuring the Decision Making Process....................................... 119

Table 14. 2030 Regional Waste Plan Principles.................................................... 126

Table 15. Supports and Constraints of an Equity Lens Within the Institutional 131

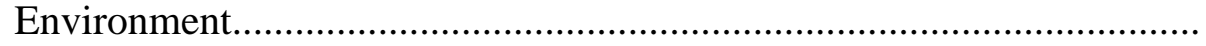

Table 16. Components of an Equity Lens in Practice......................................... 141 


\section{List of Figures}

Figure 1. 1937 City of Oakland Red Zone Map.............................................. 3

Figure 2. Rational Planning Model............................................................ 15

Figure 3. Advocacy and Equity Planning Models....................................... 18

Figure 4. Deliberative Planning Model......................................................... 20

Figure 5. Arnstein's Ladder: Degrees of Citizen Participation......................... 22

Figure 6. Fung's (2006) Democracy Cube................................................... 24

Figure 7. Participant Selection Methods..................................................... 25

Figure 8. IAP2 Spectrum of Public Participation.......................................... 27

Figure 9. Types of Racial Inequities........................................................ 35

Figure 10. Multnomah County Equity and Empowerment Lens....................... 41

Figure 11. Jurisdictions Connected to the Government Alliance on Racial Equity............................................................................. 46

Figure 12. Relationship of Theoretical Framework to Purpose of Study............ 54

Figure 13. Key Concepts Drawn from Young's Propositions of Justice............. 61

Figure 14. Map of Metro Jurisdictional Boundary.......................................... 89

Figure 15. 2030 Regional Waste Plan Policy Components.......,,,,,,,,,,,,,,,,,,,,,,,,,.. 92

Figure 16. 2030 Regional Waste Plan Phases of Development ........................ 96

Figure 17. Regional Waste Plan Decision Making Structure ............................. 100

Figure 18. Stakeholder Power Analysis Tool.................................................. 109

Figure 19. Composition of Equity Work Group by Gender, Race and Age........ 115

Figure 20. Equity Work Group Initial Mapping of Interests .......................... 115

Figure 21. Map of Decision Making......................................................... 122

Figure 22. Communication and Decision Making......................................... 125

Figure 23. Planning Model with an Equity Lens ........................................... 143

Figure 24. Participant Selection...................................................................... 146

Figure 25. Augmented Democracy Cube Adapted from Fung (2006)........... 149

Figure 26. Selection Criteria for Special Representation.................................. 151

Figure 27. Conceptual Model of Institutional and Individual Dynamics ............ 155

Figure 28. Embedded Values of Decision Making......................................... 158

Figure 29. Equity Considerations in Brief ............................................... 160 


\section{Chapter 1. Study Overview}

"Race is central in how we organize our structures and for whom we grant or limit opportunity. The increasing racial and economic segregation in housing, schools, and cities attest to a profoundly racialized set of institutions and policies." -john powell, 2017

\subsection{A Legacy of Discrimination}

In the twenty first century, race remains a defining feature in society across all indicators for success including employment, education, housing, public infrastructure and health (GARE, 2015). Despite policies aimed to eliminate racial bias and discrimination, economic and racial segregation continue to increase in the United States. According to data from the National Bureau of Economic Research, over the past 40 years economic inequality in the United States has returned to levels last seen in the 1920s (Saez and Zucman, 2014). This is illustrated in distribution of wealth among lower- and middle-income households with white families having four times as much wealth as black families and three times as much as Hispanic families (Pew Research Center, 2017). In housing, the percentage of families living in predominately high or low income neighborhoods as opposed to middle income neighborhoods has more than doubled since 1970 (2016, Reardon, S.F., \& Bischoff K). Even with the 50 $0^{\text {th }}$ anniversary of the Fair Housing Act, black individuals and families are more likely to live in concentrated poverty with less access to jobs, services and poorer educational resources and make up more than 40 percent of the homeless population (Annual Homeless Assessment Report, 2017; National Alliance to End Homelessness, 2018). Increasing racial divides are further highlighted in social movements such as "Black Lives Matter" 
responding to racialized police violence in segregated neighborhoods and the aftermath of hurricane Katrina that disproportionately affected people of color.

Government's role in these longstanding racial disparities can be traced to federal, state and local policies, crossing multiple institutions, creating and reinforcing practices that produce racialized outcomes. In the field of planning, a frequently cited example is the practice of "redlining," which began in the 1930s through Federal Housing Authority policies that labeled some, typically black neighborhoods, as undesirable for further development or investment (powell and Heller, 2011). The policy states:

If a neighborhood is to retain stability, it is necessary that properties shall continue to be occupied by the same social and racial classes. A change in social or racial occupancy generally contributes to instability and a decline in values (Federal Housing Administration, 1947).

As a result, financial institutions would not make loans for homes or businesses in these neighborhoods. This left many potential homebuyers unable to access home loans or loans to make improvements to their home. powell and Heller (2011) contend that these policies were mutually reinforcing and produced racialized outcomes with some groups not being able to invest in their neighborhoods or own their homes and caused people with more wealth or resources to leave the neighborhood and invest in other areas.

The lasting effects of these policies can be still found today with the same areas that were redlined in the 1930s remaining the areas of lowest opportunity. powell and Heller (2011) contend that leading up to the Foreclosure Crisis previously redlined neighborhoods were viewed as market opportunities for banks for sub-prime mortgages. These types of mortgages are loans with higher interest rates for individuals with lower 
credit ratings. In the wake of the Foreclosure Crisis, neighborhoods in these areas were unable to access loan modifications and experienced higher foreclosure rates (powell, Heller, 2011). In the City of Oakland (CA), there were 22 foreclosures for every loan modification made each month compared to the U.S. average of only seven foreclosures for every loan modification (California Reinvestment Coalition, 2010). The map below shows the Home Owners' Loan Corporation (HOLC), a federal agency, ratings for neighborhoods to guide investment. Red was considered "hazardous" and highest risk, yellow as "definitely declining," blue was "still desirable" and green was "best."

Figure 1. 1937 City of Oakland Red Zone Map

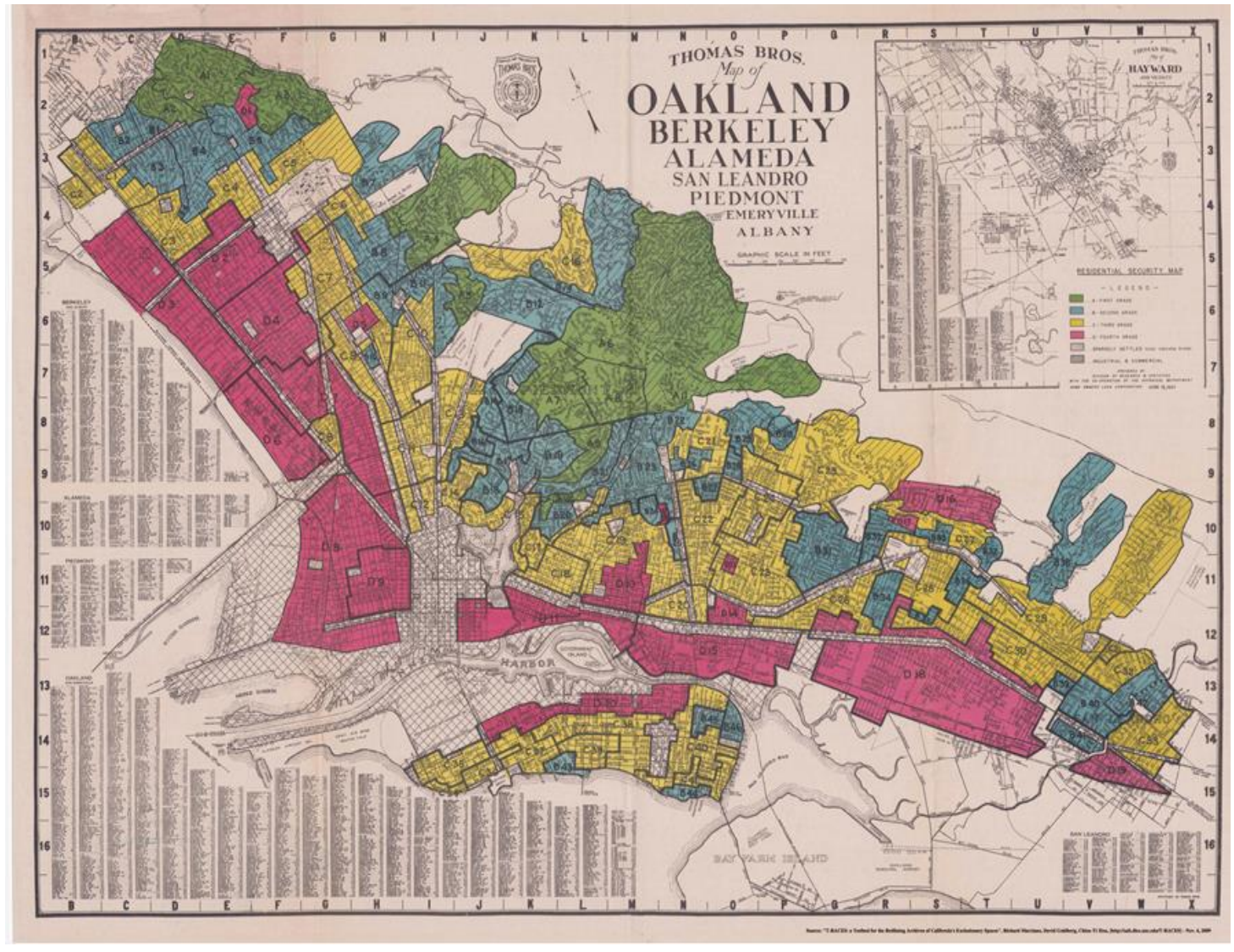

Source: Marciano, R., Goldberg, D., and Hou, C-Y. 
Another example of a federal policy that contributed to racialized outcomes is the Federal Aid Highway Act of 1956. This policy displaced residents using practices like eminent domain and condemnation laws that disproportionately affected black and Latino communities. The construction of new highways became a tool to redeem urban areas and remove blighted neighborhoods by displacing residents to make room for new roadways (Weingroff, 2017; Bayor, 1988; Mohl; 1993). Jane Jacobs (1969) in her well known book, "The Death and Life of Great American Cities," noted that these practices "At best, merely shifts slums from here to there, adding its own tincture of extra hardship and disruption. At worst, it destroys neighborhoods where constructive and improving communities exist and where the situation calls for encouragement rather than destruction” (p. 270). The impacts of housing and transportation has had long lasting effects on individual and group access to education and wealth producing opportunities.

These discriminatory practices are not only rooted in federal housing and transportation policies, but also reinforced by local city planning policies and practices. In 1997, June Manning Thomas wrote "Race, Racism, and Race Relations: Linkage with Urban and Regional Planning Literature" in response to a request to the White House for information on racial segregation in urban planning. Her report provides a comprehensive review of literature linking race and urban and regional planning policies and practices that perpetuate discrimination. In this review, she finds that poor race relations have heavily influenced local development and planning policy. Research on land use and zoning practices reveal that decision-making in cities, towns and particularly suburban areas excluded people based on socio-economic status or race (Huls, 1985; Yale, 1989: Ritzdorf; 1997). She notes that while in past decades race was formally 
excluded through policies, more modern and subtle practices exclude groups through informal means. In particular, land use control, such as zoning ordinances, can be used to exclude low-income or multi-family housing from well-off suburbs. Originally, zoning was developed as a tool for city planners to separate types of incompatible land uses. Exclusionary zoning became a common practice in the 1960s and 1970s, preventing groups deemed by some as undesirable from entering higher income neighborhoods, resulting in a disproportionate impact on racial minorities. Despite state court cases that challenged these practices and abolished certain aspects of exclusionary zoning, other types of practices such as conditional use permits, inappropriate variances, spot zoning allow for unwanted uses like landfills and transfer stations to be placed in in low income minority neighborhoods (Thomas, 1997). Impacts to these neighborhoods are highlighted in literature that draws the connection between the disproportionally negative impact of environmental pollutants on racial minorities and linkage to land use planning. Key studies include "Siting of Hazardous Waste Landfills and Their Correlation with Racial and Economic Status of Surrounding Communities" (1983) commissioned by the U.S. General Accounting Office and a study organized by Ben Chavis, "Toxic Wastes and Race in the United States: A National Report on the Racial and Socioeconomic Characteristics of Communities with Hazardous Waste Sites" (1987). Both studies provide evidence of these practices and the disproportionate environmental impact on low income minority communities resulting in health inequities.

The history of the discriminatory policies provides important context for the issue of social justice in planning and how decisions made by planners and local government officials impact the conditions where people live and access to basic resources and 
services. This draws attention to decision making processes that are used for planning and policy formulation. Differing theoretical approaches to planning have developed over time including rational planning, advocacy and equity planning and deliberative planning that are further outlined in Chapter 2. Each approach to planning adopts differing values, decision making processes and mechanisms of participation. Historically, urban planning's theoretical perspective focused on an approach to city planning limited to technical considerations rather than social factors (Ross and Leigh, 2000). In a rational model of planning, decision making was most often limited to a small group of experts. Advocacy and equity planning responded to increasing inequities in policy decisions arising in the 1960s and those left out of the planning process. Distinct from the rational approach, the equity planning model focuses attention on representation of politically marginalized groups in planning processes and with alternative plans and policy proposals (Bates and Zapata, 2015). Deliberative and communicative models focus on transparency, open communication and inclusion. These models call for greater participation of community in each stage of the planning process with an emphasis on a two-way dialogue rather than consultation. New mechanisms of participation emerged beyond public hearings such as citizen juries where a representative sample of citizens (usually selected in a random or stratified manner) who are briefed in detail on the background and current thinking relating to a particular issue or project are asked to make a recommendation for the community. These models bring to light important considerations of justice related to inequality of participation and influence and impact of policy decisions. The differing approaches require a closer evaluation of how models of planning may perpetuate inequities by considering who is included and in the position to 
influence decisions, the distribution of benefits and burdens as a result of policy decisions and the institutional context in which decision making processes take place.

In response to increasing pressures on government agencies as institutions that create and maintain inequities, agencies have identified racial equity as both a vision and a strategic objective. Racial equity is defined as the condition by which race can no longer be used to predict life outcomes and outcomes for all groups are improved (GARE, 2015). This new vision for government agencies has significant implications for planning models and the processes that guide the growth of cities and the design of urban systems. Momentum for these efforts can be seen in the formation of the Government Alliance on Race and Equity (GARE) that serves as a national network of government agencies working to achieve racial equity. In 2019, more than 170 cities and counties across the U.S. have joined GARE. The alliance includes cities and counties such as Baltimore (MD), Seattle (WA), Portland (OR), Dallas (TX), Alameda County (CA), Ann Arbor (MI) and others that are working to adopt racial equity strategic plans and new methods to advance racial equity as a part of the policy process and the delivery of public programs and services. This field of practice is growing rapidly with an increasing number of government agencies working to transform systems and processes to close the racial gaps. Emerging from this field are new models and methods for planning that are developing and are in need of investigation to determine their efficacy.

Distinct from past planning models, these new efforts adopt a structural approach to incorporate actions within public agency's systems and processes to address inequalities. This approach draws directly from structural justice theories by seeking to reform the structures and processes that sustain impartial policy development (Young, 
1990, 2000, 2001; powell, 2013). This includes processes within decision making that advantage some groups and disadvantage others and forms of racism that can occur at the individual, institutional and structural levels. Methods for advancing racial equity being used by cities and counties call for disciplined attention to race and class when making policy decisions particularly at the institutional level where policies, practices and procedures may unintentionally work to advantage white people over people of color (GARE, 2015). Many governmental agencies are now using what is called an "equity lens" to review existing policies and develop new ones (Clark, 2018). An equity lens can often include a set of questions or processes intended to counteract policies and practices that maintain inequities (Metro, 2018; GARE, 2015). The process for applying an equity lens can include appointed representation for communities who have been historically marginalized from the decision making process. The development of an equity lens responds to calls from scholars to establish mechanisms that acknowledge social difference and utilize appointed representation for oppressed or disadvantaged groups in the political decision making process (Young 1989, 1990, 1991). It also responds to theories that highlight historical and existing social structures and policies that perpetuate inequities (Gewith, 1996; powell, 2007; Young, 1991, 2001). Select studies from cities and counties involved in GARE are highlighted in Chapter 2 including Seattle (WA), Portland (OR), Multnomah County (OR) and Montgomery County (MD), which provide some documentation on how to apply an equity lens. However, the documentation does not provide rich descriptions on the real-life environment and complexities that may have been encountered as a part of the lens use. Further, the existing cases do not account for views from all the participants in the process and lack specific details on how decision 
making was structured to address inequalities. Questions about how an equity lens is defined and the extent to which the lens addresses structural inequalities identified in theory remains largely open for further investigation.

\subsection{Significance}

An equity lens seeks to reform social structures and processes and increase representation of marginalized groups in the policy process to advance justice. Therefore, there are implicit assumptions that the use of an equity lens in policy formulation will provide more just processes. However, public agencies are interpreting and using an equity lens in different ways across a variety of contexts. This leaves questions about how the equity lens is defined and used in particular settings and how it may reform existing structures and processes to address inequalities. The existing documentation on local governments that have utilized an equity lens in policy and planning lack in-depth descriptions of how the use of an equity lens increases representation of politically marginalized groups and reforms decision making processes to address inequalities. To advance justice in the larger institutional context, it is essential to build a more in-depth understanding of how these theoretical propositions that have shaped an equity lens actually perform in practice.

Local governments have been early adopters of the use of an equity lens and provide critical locations for inquiry. Further, local governments include a large scope of responsibility for planning and managing public infrastructure including land use, housing, and transportation that play a significant role in both employment and delivery of services. The promise of an equity lens lies in its potential to address exclusionary practices by including social groups that have been historically marginalized from the 
policy process and taking into consideration racial and economic differences. Yet, it remains unclear how an equity lens addresses structural inequalities within the planning process.

\subsection{Study Purpose}

The purpose of this study is to describe and analyze the current practice of an equity lens to gain a better understanding of how an equity lens may change the institutional planning process. This research focuses on an in-depth case study of a planning process that incorporated an equity lens for the development of a large scale urban system plan adopted by a regional government in Portland (OR). A case study approach presents the opportunity for an in-depth analysis of this new phenomenon. This moves significantly beyond documentation that has been provided to date by utilizing a variety of different sources and multiple views to understand the use of an equity lens in a specific context. Given the abstract nature of an equity lens, this type of study is necessary to increase understanding of an equity lens in a planning process and inform future study and practice.

Using Iris Marion Young's propositions for justice, this study examines how the equity lens changes decision making processes that advantage some groups and disadvantage others within policy formulation. Given the complex nature of justice and the many different meanings justice can take on in different contexts, Young's theoretical propositions offer a clearly defined framework for evaluating an equity lens with respect to the value of justice. Her worldview brings to light the concepts of structure, power and social identity as important forces that should inform our understanding of the nature and behavior of social life. Her concepts of institutionalized oppression, social groups, and 
social structures and processes guide the study and provide a logical structure to connect concepts and show how ideas in the study relate to one another based on her propositions.

Through this study, I aim to build upon structural theories of justice and provide new insights into further bridging theory and practice as it pertains to an equity lens. As both a practitioner and academic, my ultimate goal is to provide insights and considerations for practitioners to improve and evolve today's planning models.

\subsection{Research Questions}

Drawing from the literature and my own personal experience in the field of planning and public policy, the overall research question for this study is:

How does an equity lens change the institutional planning process?

Sub-questions to address more specific aspects of the research included:

- How is an equity lens defined by planners, policy makers and participants in the planning process?

- How are social groups identified and selected for special representation as a part of the equity lens in the planning process?

- How does an equity lens influence the structural processes of decision making?

- How does the institutional environment influence the use of the equity lens?

\subsection{Structure of this Dissertation}

This dissertation is structured across six chapters. Chapter 1 provides an introduction to the research topic, the study's purpose, the significance of the research, and offers a preview of the chapters within the dissertation. Chapter 2 provides a review of the relevant literature informing the research inquiry including past and present planning models, theories of justice and the most current documentation on the use of an equity lens as a method and practice within local governments. Chapter 3 presents the 
theoretical framework that serves as the foundation for the research inquiry. Chapter 4 outlines the research approach including the research design, case selection, data collection process and analysis, validation of findings, potential limitations and ethical considerations. Chapter 5 presents an in-depth case study analysis of the planning process for the 2030 Regional Waste Plan that utilized an equity lens for a large scale urban system plan in greater Portland (OR) and presents the findings in response to the research questions. Chapter 6 discusses the research findings and how they relate back to the existing literature as well as considerations for future research. 


\section{Chapter 2. Literature Review}

\subsection{Introduction}

A wide body of literature considers the relationship between social, economic and environmental inequities and the practices and processes within structures and institutions. The literature crosses disciplines from philosophy, public administration, sociology, environmental policy and urban planning. There are three main bodies of literature that are important for understanding the research goals of this study. One main body provides the backdrop for the approaches used by government for the design and management of urban systems that include the planning models, processes used for decision making and forms of participation. A second body of literature considers planning processes using theories of justice as a normative framework to consider how structures and processes may serve to reproduce inequities. Finally, the most current scholarship documents the emergence and use of an equity lens as a method and practice within local governments. This chapter presents each of these areas and concludes with a summary of the key gaps in literature. The intent of this section is not to present a comprehensive review of the literature, but to highlight relevant developments in the literature and the research gaps that remain.

\subsection{Planning Theory}

As a field of study, planning theory may be described as having two distinct perspectives. First, it may be defined by the objective of study such as land use, transportation or the natural environment. Second, it may be defined by the methods and processes that are used for decision making (Campbell and Fainstein, 1996). Therefore, 
planning contains both substantive and procedural elements. Central to this study are the planning methods, processes and underlying values that are used for decision making. The procedural approach to planning has evolved significantly over time influenced by political, economic and cultural forces. The approaches for planning range from small specialized teams of planning professionals to highly participative processes that involve the whole community. This section highlights differing approaches to planning that provide important context for this study.

\section{Rational Planning Model}

The emergence of planning can be traced to the nineteenth-century with the goal of improving public health evolving into movements from the garden city ideal of Ebenezer Howard to Baron Haussman's urban renewal conceptions and the ideas of the urban progressives in the United States and Europe (Fainstein, 2010). Each movement contained differing approaches, orientations toward democracy and desired outcomes, but all aimed to protect the common good (Scott, 1998 as cited by Fainstein, 2010). Critical considerations of planning are the policy outcomes that direct the spatial distribution of costs, risks and amenities within a community. Traditional approaches to planning and policy development have been modeled to follow rational, analytical and scientific methods (Stone, 2012). The rational process follows a systematic forward progression of goal setting to implementation including goals formulation, design alternatives, selection of preferred approach, implementation and monitoring (Kaiser et al, 1995). This approach to planning centered on the ideal of comprehensiveness, proactive planning and control for shaping the community when considering the design of a system such as a region, city or neighborhood that enabled the coordinated development of land use, 
transportation and facilities. Policy choices in planning could be measured utilizing statistical and economic analysis to weigh different actions to identify the best approach to achieve the stated goals with planners serving as neutral analysts. Cost-benefit analysis became a common tool to evaluate policy options. This greatly influenced the development of planning as a specialized profession with significant influence provided to planners who implemented the planning process and presented the policy options. As such, the planning process concentrated power in the planners or experts that conducted the analysis and minimalized the role of citizen participation (Kweit and Kweit, 1987). This served as the dominant framework for many decades influenced by a positivist epistemology drawing from theorists such as Karl Popper, Herbert Simon and decision theorists (Innes, 2013). Inherent in this approach was the ideal that good planning and public administration of government was equally good for everyone (Frederickson, 1997). Key concepts of the rational model highlighted in Figure 2.

Figure 2. Rational Planning Model

- Good planning is equally good for everyone

- Planners as value-neutral analyst/expert

- Limited public participation/feedback

- Systematic and comprehensive approach supported by cost-benefit analysis

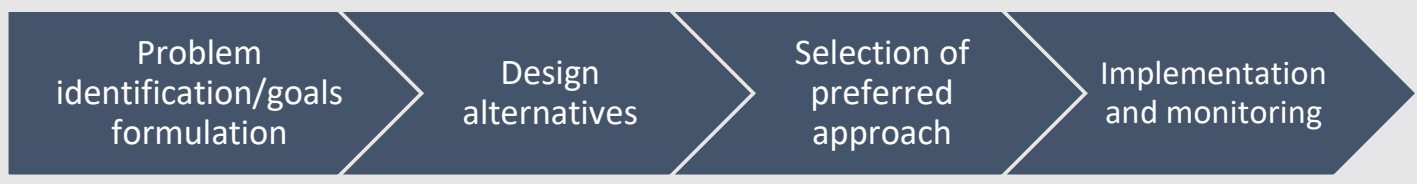

Note: Concepts drawn from Kaiser et al, 1995; Fainstein, 2010; Stone, 2012. 
This universal and rational model to planning has suffered much criticism. During the 1960s and 1970s, scholarship challenged the rationality and comprehensiveness of planning as a mask for the power of property developers and upper class groups (Fainstein, 2010; Harvey, 1978). It became increasingly apparent that the results of planning and implementation of policies resulted in much better outcomes for some as compared to others providing evidence of racial and class inequities (Frederickson, 1996). Shortcomings of public participation were brought to light through the wellknown and frequently citied article by Sherry Arnstein (1969) that provides an in-depth look at the spectrum of participation methods and the relationship with community power in describing participation as a "ladder." She draws attention to the importance of the relationship between the form of public participation and power community members have in the decision making process. Her article reflected the growing distrust and dissatisfaction of government during the 1960s particularly related to the exclusion of social groups in decision making and started an important dialogue in literature on public participation in the planning policy process. Perceptions of government during that time saw planners making decisions that affected urban residents without their knowledge or representation of interests (Lipsky, 1980). Reforms in federal policy and the adoption President Lyndon Johnson's Great Society programs institutionalized citizen participation in policy decisions (Cogan and Sharpe, 1986). Subsequent changes in planning process were made to increase the role of public input through the adoption of citizen advisory boards and public opinion polls. As a result, participation soon became a routine and expected feature of public policy making, but these changes in the decision making 
process did not address groups that continued to be marginalized from the decision making process such as low income minority communities.

\section{Advocacy and Equity Planning Models}

Growing disparities and increasing public pressures in the 1960s served as a catalyst for new forms of planning. New approaches to planning emerged that called planners to serve as advocates by working to the benefit of disadvantaged groups rather than impartial technicians (Davidoff, 1965). The advocacy planning model called greater attention to the different needs of groups that would require different plans. Rather than just relying on the professional planner to produce alternatives, options should also be developed by interest groups that will be affected by the plans (Davidoff, 1965). This grew the field of planning with planners taking positions outside of government in advocacy and non-profit organizations to represent community interests. Subsequently, emphasis on operating from within governmental organizations to advance policy choices for the least well off emerged out of efforts in Cleveland (OH) (Krumholz, 1982). This approach called practitioners to serve as advocates rather than technocrats in considering who is benefiting from resources and services. Krumholz (1982) argued that cities engaged in "equity planning" must strive to take into account the interests of those who have the fewest choices. Specifically, Krumholz's approach directed focus on representing marginalized groups within the planning process and the development of alternative policies as a means of addressing poverty and racial segregation. As such, equity planning is considered distinct from traditional planning in that the planning outcomes need not be justified as being in the general public interest and planning itself is considered to be more political rather than a scientific endeavor (Fainstein and 
Fainstein, 1996). Instead of focusing on the cost benefit of policy alternatives in aggregate as with the rational model, planners examine the distribution of costs and benefits within specific communities and account for disproportionate impacts in their analysis. Equity planning moved beyond advocacy planning in efforts to address imbalance of resources, opportunities and power that contribute to social inequities (Ross and Leigh, 2000). During this same time period, the field of public administration also adopted the concept of social equity. In 1968, at the Minnowbrook Conference, which convened scholars within public administration to discuss how to address the sociopolitical conditions of the time and growing inequalities, resulted in the beginning of the 'New Public Administration' that adopted social equity as a primary value (Denhardt and Denhardt, 2015).

Figure 3. Advocacy and Equity Planning Models

- Planning for those with the fewest choices

- Planners as advocates with focus on distribution of costs and benefits to specific communities

- Planning process guided by multiple views

- Options should also be developed by interest groups that will be affected by the plans

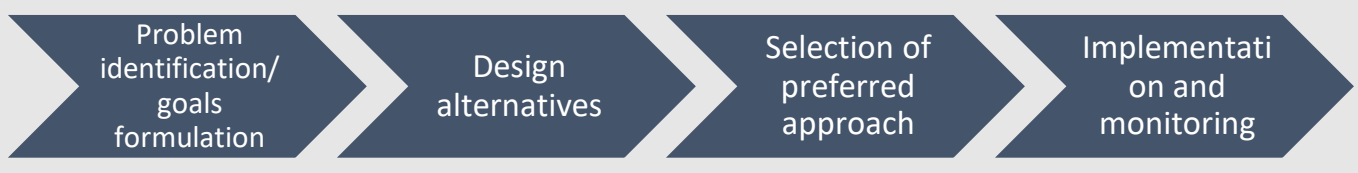

Note: Concepts drawn from Davidoff, 1965; Krumholz, 1982; Fainstein and Fainstein, 1996.

Momentum from both the advocacy and equity planning movement influenced practices over many decades in a variety of fields, urban scales and institutional contexts 
placing urban planning in a social justice framework. Zapata and Bates (2015) highlight the current state of equity planning by reviewing existing scholarship on equity planning. They draw attention to the variety of methods and modes of practice being used to advance equity planning including working with a community to define a shared vision for equity, institutionalizing policies to serve as frameworks for advancing equity, and utilizing "principled conflict" to advance agreement (Brand, 215; Corburn, Curl, Arrendondo, et al, 215, Benner and Pastor, 2015; as cited by Bates and Zapata, 2015). Differing from the rational planning model, the equity planning model represents an orientation toward social justice goals by representing politically marginalized groups in planning processes and with alternative plans and policy proposals (Bates and Zapata, 2015). Their review highlights successes in advancing equity, but also ongoing challenges including defining the meaning of equity in differing contexts from differing points of view, balancing community participation with the limits of participation, and the tension between advocacy and collaborative approaches. The work of advancing the equity planning model is ongoing with methods and practices continuing to evolve and further define this model.

\section{Deliberative Planning Model}

Another mode of planning focuses on a communicative or deliberative approach to planning. The general premise of this approach is focused on community deliberation that includes a broad range of voices at each stage of the planning process. This approach is intended to replace traditional notions of participation focused on community consultation that is limited to getting public feedback on policy. Instead, the emphasis is on a two way dialogue between government and community that provides for idea 
exchange and collaboration. The planner is viewed as facilitator and convener focused on discourse and public participation that provides for open discussion of problems, challenges and interests. Forestor (1999) advocates for deliberative practices that can facilitate practical and timely participatory planning practices. This model provides for collective decision making where ideas are challenged and the exchange of ideas serve as a key component in the development of proposed solutions. Planners are tasked to develop a way for citizens, politicians, and administrators to engage in a full discussion on issues facing the polity in a way that is inclusive of the citizenry and incorporates technical information and political preferences that take into account all viewpoints in a constructive and informed discourse (Denhardt and Denhardt, 2015). Therefore, the role of planners becomes one of engaging in the politics of listening, learning and shaping attention in the participatory planning process (Forestor, 1999).

Figure 4. Deliberative Planning Model

- Collective decision making

- Planners as conveners and facilitators

- Interaction of stakeholders throughout the planning process

- Co-creation of goals and deliberation of alternatives among those affected by the outcome

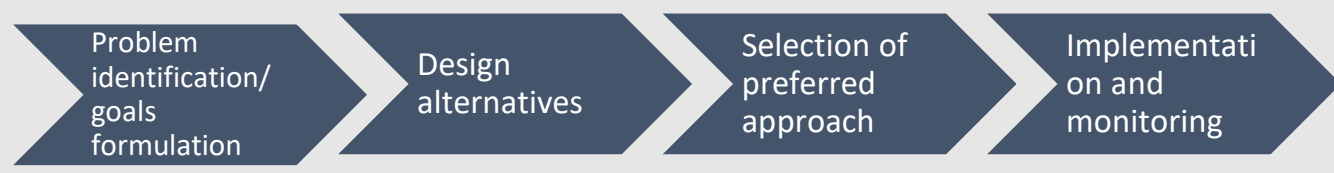

Note: Concepts drawn from Box, 1998; Innes, 2013; Forestor, 1999.

This model promotes new forms of engagement that focus on deliberation and active participation in partnership with government. There are a variety of methods used 
for participation including public conversations, participatory budgeting, citizen juries, study circles, collaborative policy making and deliberative polling (Fishkin, 2009, Gastil and Levine, 2005 as cited by Bingham, 2011). This approach denotes a shift in epistemology to a more critical perspective drawing from theorists including Habermas and Young that considers "facts" themselves as socially constructed and draws greater attention to dialogue, inclusion and the generation of mutual understanding (Innes, 2013). As such, community participation is foundational to this approach and planners serve as facilitators for leading the process. In contrast to the rational planning model where goals and alternatives are primarily framed by policymakers and planners, this model focuses on co-creation of goals and deliberation of alternatives among those most affected by the outcome of the process (Innes, 2013). Fisher, et, al, (1991) suggest that meaningful processes can be designed with a focus on interests rather than positions to bring about mutual gains.

\section{Planning Models and Typologies of Participation}

Today, the approach to planning employed by government organizations varies both according to policy area and by level of government. Rational, advocacy and deliberative planning models appear to be present in many forms and combinations. One of the key factors that distinguishes the different types of planning models is the design of decision making processes, who participates and mechanisms for participation. Public participation involves the direct or indirect involvement of individual or groups within decision making on policies, plans or programs that they may have an interest in (Bryson and Quick, 2016). Through participation, individuals or groups interact with government agencies to develop or implement public policies and plans. Three main typologies can be 
drawn from this literature that provide important context for the study by highlighting the mechanisms for participation and structural considerations in the design of planning processes.

\section{$\underline{\text { Ladder of Participation }}$}

As discussed earlier in this chapter, Sherry Arnstein's typology emerged in the late 1960s in response to increasing evidence of social disparities as a result of public policy and program decisions. In her typology, she presents a "ladder of participation" that includes eight rungs each representing a type of participation in association with who has power in decision making as shown in Figure 5. She contends that participation is valued to the extent that it "redistributes power and enables the have not citizens...to be deliberately included in the future" (Arnstein, 1969, p.216).

Figure 5. Arnstein's Ladder: Degrees of Citizen Participation

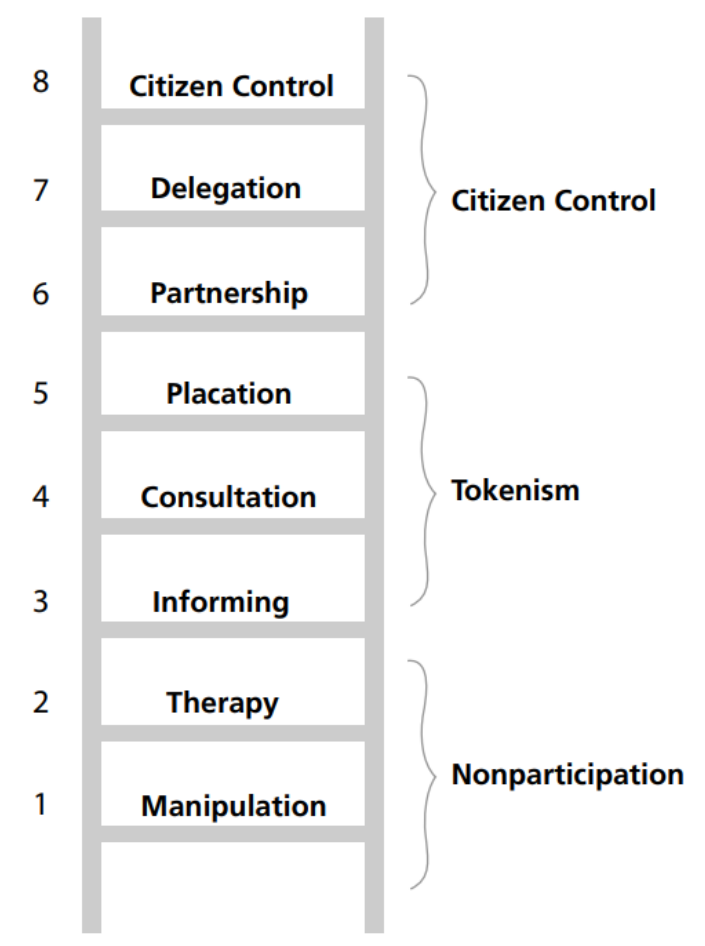

Source: Arnstein, 1969 
The first two rungs of the ladder, labeled manipulation and therapy, represent nonparticipative mechanisms for citizen participation that focus on education to achieve public support. The next two rungs, informing and consulting, make steps to legitimate participation through mechanisms such as surveys and neighborhood meetings, but often focus on one way flow of information. The next rung, placation, allows citizens to participate through forms like committees, but public agencies retain power over decisions. The final three rungs, partnership, delegation and citizen control, redistribute power to citizens in decision making with the final rung distributing decision making authority directly to citizens. Since Arnstein's ladder was published, a whole body of literature emerged focused on the role of citizen participation in the democratic process and different mechanisms for achieving varying policy objectives.

Relevant to this study is the connection that Arnstein draws between mechanisms of participation and influence and power in decision making. Her conception of citizen participation marked a significant shift in the view of decision making processes within policy formulation and planning. She drew attention to the gradations of citizen participation and provided a framework for examining how individuals are included in decision making. Her view of authority and influence in decision making contrasts citizens without power to those in power. However, she does not further distinguish differences within these groups and assumes greater citizen involvement is better.

\section{$\underline{\text { Democracy Cube }}$}

Another view on participation is presented in Archon Fung's (2006) democracy cube that considers the possibilities of participation by which public policy may be achieved to best serve the public. Using three dimensions, he outlines how differing 
participatory methods may advance differing democratic values including legitimacy, justice and effective governance shown in the figure below. The dimensions comprise a democracy cube that includes: who participates; how these participants exchange information and make decisions; and how their input influences policy outcomes. Figure 6. Fung's (2006) Democracy Cube

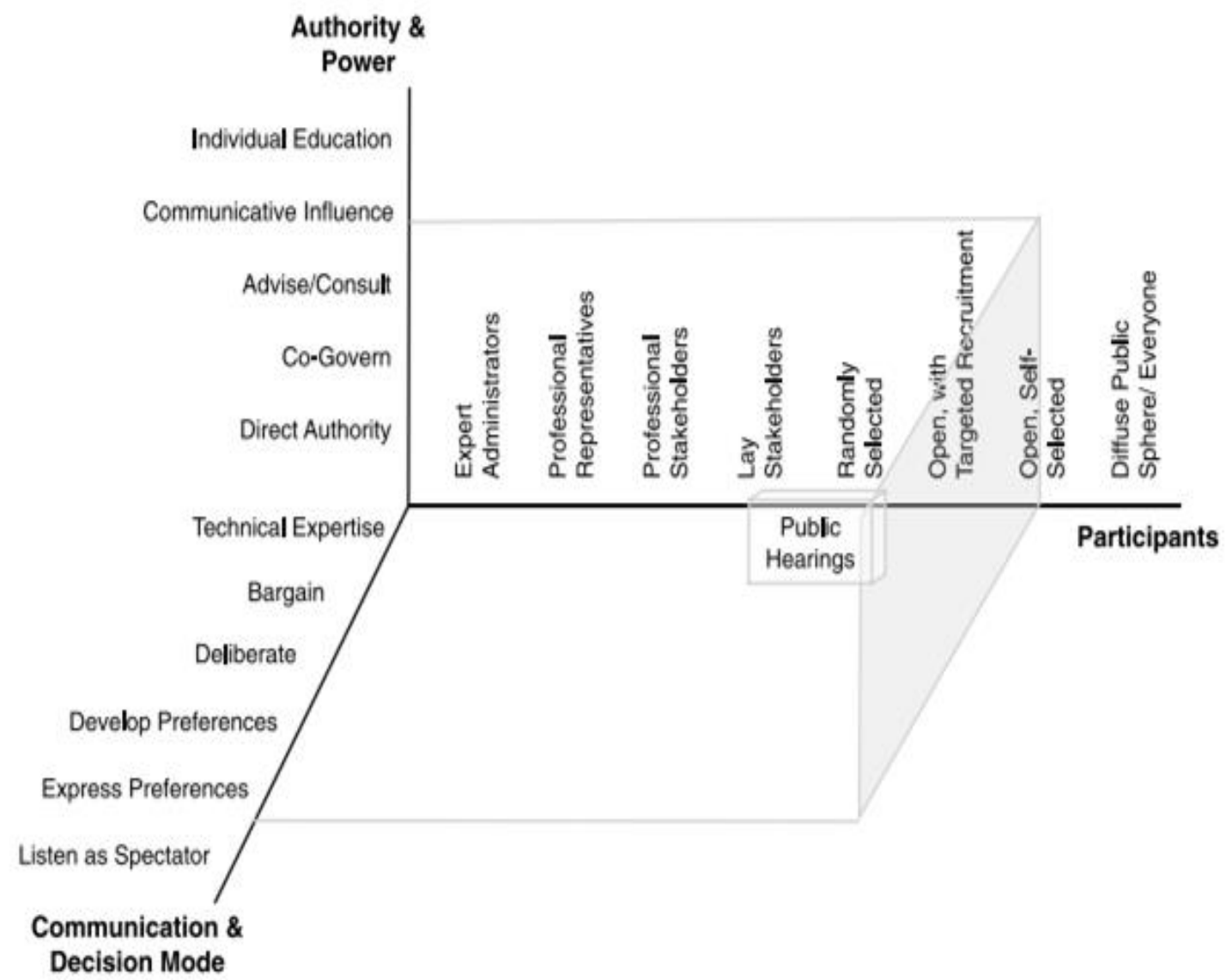

Source: Fung, 2006.

The authority and power dimension focuses on the impact of participation moving from individual education to communicative influence to consultation to direct authority. The communication and decision mode specifies how participants engage with the public issue or decision. The last dimension on who participates presents the least to most 
intense forms of participation, ranging from a spectator to direct expertise. Underlying this dimension on who participates is the concept of "mini publics" that intentionally bring together citizens in discrete bodies to discuss a matter of public concern (Fung, 2003). This contrasts with the large public that represents the diffuse sphere of informal venues of discussion and state that represents the expert administrators.

Figure 7. Participant Selection Methods

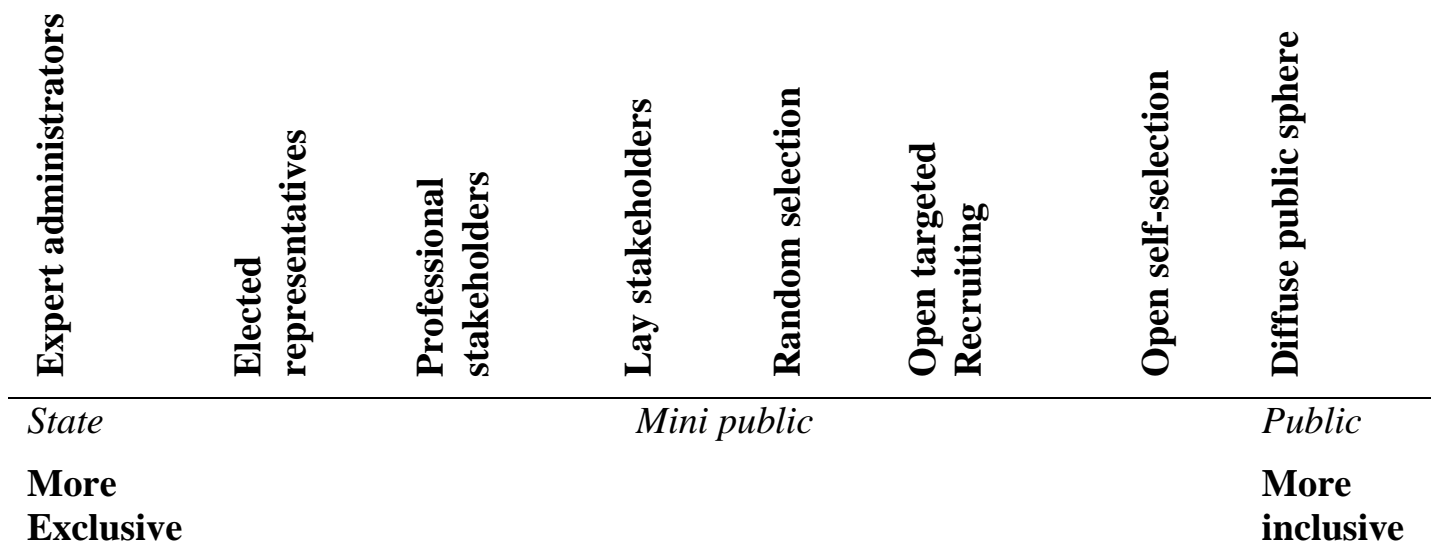

Source: Fung, 2006

Fung (2015) contends the institutional design for processes to advance legitimacy must consider the extent to which individuals are empowered and considerations on who decides whether their recommendations become law or policy. Therefore, some political processes may lead to unjust outcomes when certain groups, such as those advantaged by political, economic, or social circumstance can exercise undue influence to secure policies and public actions that reinforce their economic or political positions (Fung, 2015). As such, participation methods can advance justice by increasing access for disadvantaged or marginalized groups in the decision making process (Fung, 2015). He contends Arnstein's (1969) ladder is outdated and flawed in two main ways. First, the ladder assumes that more citizen involvement is always better. Fung argues that this is 
not always the case as there are instances in which full citizen control may not be ideal, such as decisions that require specific expertise of individuals whose training and professional specialization suits them to solving particular problems. Second, theory and practice has evolved significantly since the development of Arnstein's framework. Therefore, her approach does not take into account new mechanisms of participation such as targeted recruitment for participation.

Key to this study is Fung's view that more citizen involvement is not always better. His thinking supports more recent practices by local governments in using appointed representation in decision making for politically marginalized groups. Fung provides a useful framework for the structural considerations of the design of planning processes. He also brings to light the important considerations of legitimacy and justice in decision making. However, like Arnstein, underlying his conception of participation in advancing these values is a commitment to the homogenous "public sphere." $\underline{\text { Spectrum of Participation }}$

Another more recent typology for participation has emerged from the International Association for Public Participation (IAP2) called the "Spectrum of Public Participation." This typology, which is informed by both by scholarship and practitioners, presents a range of participation mechanisms in the context of specific objectives. The spectrum includes five types of participation moving from least to greatest citizen influence. Each type of participation is associated with a goal and specific participatory techniques. 
Figure 8. IAP2 Spectrum of Public Participation

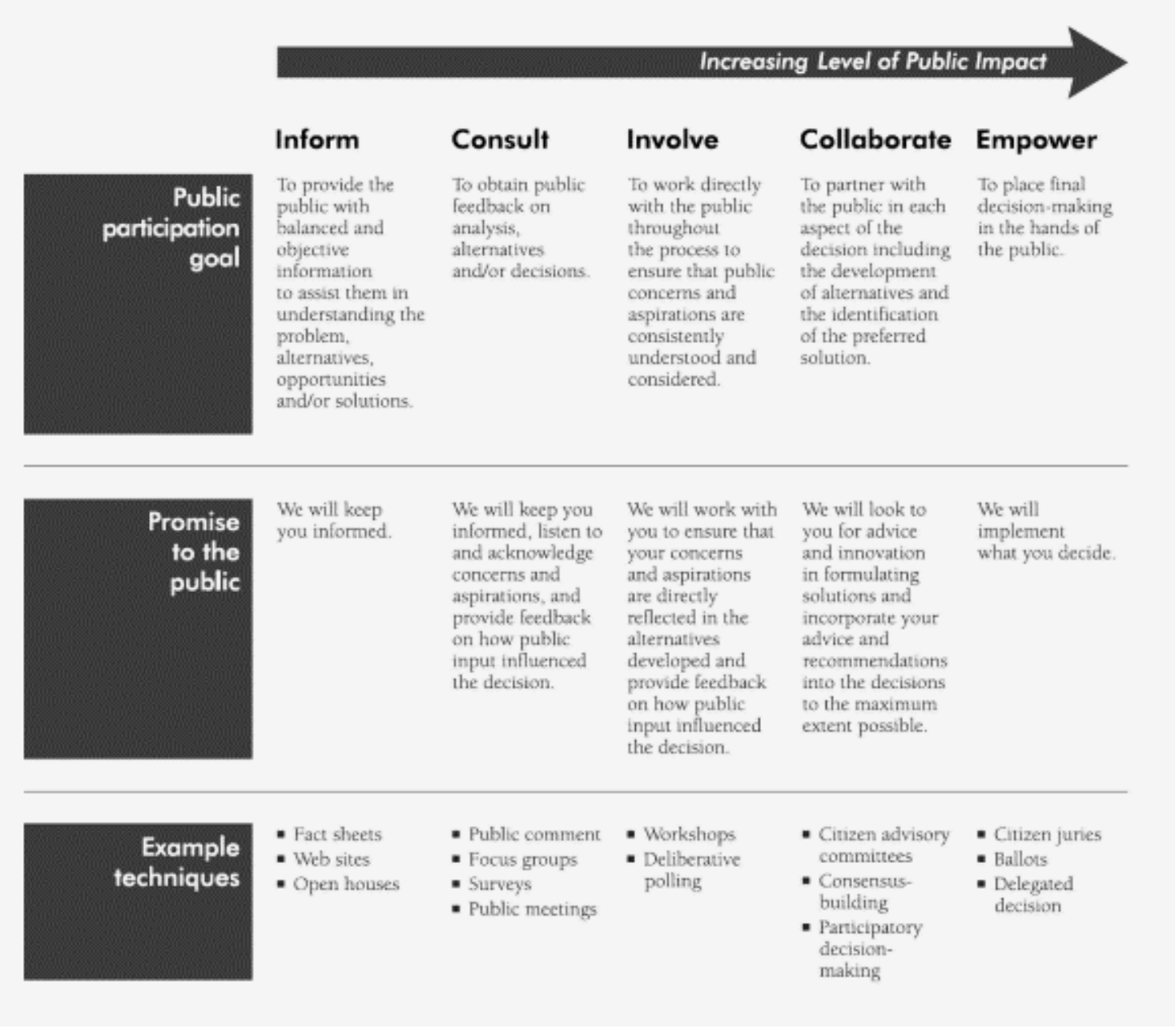

Source: IAP2, 2007

This typology presents a view of participation through a practitioner's lens that provides useful context for the study. The intent of the spectrum is to provide practitioners guidance on specific options for public participation related to goals and commitments to the public that may be used to inform policy and program decisions. The spectrum draws much inspiration from Arnstein's (1969) ladder of participation and shares some similarities with Fung's modes of communication and decisions. As with both of the prior typologies, this framework does not differentiate between groups within the diffuse 
public sphere. Like Arnstein's approach, this also views more citizen authority over decision making as the greatest level of impact.

\section{$\underline{\text { Significance of Typologies }}$}

Decision making processes have evolved over time within approaches to planning and policy formulation. In traditional models of planning, participation in decision making was limited to small groups of experts. As issues and problems being addressed became more political, who was involved became increasingly important (Insua and French, 2010). Each of the typologies represent a different view of participation within the institutional planning process and posit on mechanisms of participation and influence within the decision making. These typologies illustrate the ongoing discussion within scholarship and reflects the varying methods being used in practice on how to best include individuals in the policy formulation.

Most often the mechanisms of participation in the planning process are dependent on the governmental organization responsible for designing the process to involve individuals and groups in decision making. Increasing commitments to racial equity in some localities present a new view of the public and mechanisms for participation. These approaches prioritize historically marginalized communities in planning processes and bring to light new considerations in the design of decision making processes and frameworks for viewing participation. The use of appointed representation for marginalized social groups is not explicitly illustrated in existing typologies. However, this mechanism of participation is associated with the practice of an equity lens. This presents an important area of study as a new method for engaging those most directly 
affected in the decision making process and presents implications for existing typologies of participation.

\subsection{Theories of Justice}

The topic of justice is addressed in a wide body of literature across a variety of disciplines. Political philosophers have long paid particular attention to the concept of justice within the structure of institutions, decision making processes and the political community. Most relevant to this study are theories that address questions of fairness as it relates to the decision making processes, mechanisms of participation and institutional conditions within the planning models described in this chapter.

\section{Justice as Fairness}

One of the most prominent theories of justice was put forward by John Rawls (1971) who argues that in a society, all members should have the same basic rights of liberty and thus resources should be distributed to provide the greatest benefit to the least advantaged. His theory of justice may be applied as a normative guide for evaluating and reforming the basic structure of institutions. He claims that the basic structure of society is the fundamental consideration of justice because these institutional arrangements influence the rights and advantages of an individual's life opportunities. In other words, each individual is born with inequitable natural capacities and endowments and born into a specific social status, and the institutions of society favor certain starting places over others that affect an individual's life prospects from birth to death (Rawls, 1971). His conception of justice supports the definition of social equity as policies that distribute resources in a manner that provides for equality of opportunity. That is, each person being guaranteed the same basic rights in society, receiving the resources and support 
necessary to provide the same opportunity to participate in the public life, and the ability to provide for their basic needs. Under such a definition, outcomes may be unequal, but everyone will have the opportunity to have their basic human needs and rights met at a minimum. In this sense, justice in planning is concerned with the distribution of burden and benefits of policy decisions to be structured to not harm the least well off.

\section{Propositions of Justice as Elimination of Oppression and Domination}

In contrast, Iris Marion Young's (1990) conception of justice moves beyond distribution of resources and opportunities and focuses on the institutional conditions necessary for the development and exercise of individual capacities and collective communication and operation. She contends that discussions of social justice are primarily concerned with the allocation of material goods, income and position that obscure the broader social context and institutional conditions in which distribution takes place. She favors a wider, process-oriented view of society that focuses on power and decision making processes (Young, 1990). In her view, social justice is the elimination of institutionalized domination and oppression. This requires an examination of institutional behavior that perpetuates inequities and addressing social structural and systemic factors to advance justice. Young identifies relations of power and oppression that occur by virtue of the social division of labor and institutional relations that delimit peoples' material lives as sources of injustice (Young, 1990). She argues oppression is structural and its causes are embedded in norms, habits and assumptions that underlie institutional rules and decision making procedures and the collection of outcomes following those rules (Young, 1990). 
Central to her approach is the concept of social group that focuses on personal identity rather than economic interest and the conditions of oppression that occur to a part or all of a group including exploitation, marginalization, powerlessness, cultural imperialism and random violence and harassment (Young, 1990). She argues these positional differences in society must be accounted for in discussions of justice. Her thinking is supported by other theorists including Fraser (2000), Honneth $(1995,2001)$ and Taylor (1994) all of whom contend that recognition of oppressed groups must be a central concern of justice. Gewirth (1996) and Hampton (1997) call attention to structural inequality to distinguish the individual level actions and choices from the institutional conditions under which these occur and may limit individual opportunity or action. Hampton (1997) theorizes "the harm of oppression comes from the systemic effects of certain kinds of social institutions in which individuals find themselves and operate within. These social forms are such that individuals, despite any good intentions they might have, are forced to act and react in ways that result in considerable damage to some people" (p. 189). She argues that structural social relations tend to privilege some more than others and inhibit the capacity of some people. Therefore, developing just norms and social conditions requires the restructuring of decision making processes that are blind to difference and promote universal policies.

Young (1989) further explores institutional forms of oppression through her critique of the ideal of universal citizenship. Under the meaning of universal citizenship with "equality conceived as sameness," laws and rules are blind to difference and all laws and rules are applied the same to all persons (Young, 1989, p.250). This approach for equality as same treatment grew from demands for equal rights that are blind to group 
difference as a means to combat exclusion and degradation. However, this approach relies on a unified and universal point of view that is rooted in the ideal of impartiality. Young states, "Reducing difference to unity means bringing them under a universal category, which requires expelling those aspects of different things that do not fit in the category" (p.102). Under this logic, difference creates a hierarchical opposition by placing more value on what is accepted as the universal norm and what is expelled out of the universal category because it does not fit. In decision making, a universal perspective requires all situations to be treated according to the same rules and moral judgment must be "detached, dispassionate and universal" (Young, 2001, p. 102). Young (1989) argues the universal approach perpetuates rather than undermines oppression as the law may be blind to group difference but society is not. She points to the everyday interactions and processes where embedded values perpetuate exclusion and judgment of some social groups. This is evident in the histories, traditions and cultures among groups that influence how individuals or groups may associate with or perceive one another. In decision making, an impartial point of view assumes one can abstract themselves from their "partiality of affiliation, of social group perspective" (p. 99). She contends this approach creates a dichotomy between reason and feeling, an impossibility, as human beings are not capable of disassociating these elements and separating themselves from their life experience that constitute their identify (Young, 2001). Young states "It is impossible to adopt an unsituated moral point of view, and if a point of view is situated, then it cannot be universal, it cannot stand apart from and understand all points of view" (2001, p.104). Therefore, in order to reason on moral issues, individuals must draw on personal experience and knowledge of social and historical context. In the context of 
public institutions, the belief that bureaucrats and public officials can exercise their decision making power in an impartial manner legitimates authoritarian hierarchy. For example, decision makers in political institutions are most often from privileged groups and they perpetuate norms that support their positions of privilege. Young (1989) contends within decision making we must address the dilemma of social power that makes some individuals more equal than others. Part of this solution is providing the means within institutional practices to recognize and ensure representation of politically marginalized groups. This requires the provision of "mechanisms for the effective representation and recognition of the distinct voices and perspectives of those of its constituent groups that are oppressed or disadvantaged within it" (Young, 1989, p.261). Since privileged groups already have representation, special representation is only necessary for oppressed groups. Young argues that group representation is the best means to promote just outcomes in the political decision making process.

\section{Theories of Structural Racism}

Other theorists have also approached justice through the examination of structures and institutions with particular attention to race. The concepts of "structural racism" and "institutional racism" gained traction in national discourse in the 1990s. Bonilla-Silva (1994) put forward a structural theory of racism that centers on the concept of "racialized social systems.” These systems emphasize how political, economic, and social arrangements are structured by racial hierarchy and supported by colorblind ideology within social structures and institutions. Colorblind ideology does not acknowledge that policies and practices have the effect of disadvantaging certain racial or ethnic groups over others. Echoing this approach Calmore (1995) calls attention to the existence of 
racism both in individuals, but also in "[in] our societal organization and cultural understandings" (p. 143). Racism is most often associated with personal beliefs and belief systems and behaviors. However, institutional racism accounts for discriminatory behavior that is prescribed by formal rules and dependent upon organizational cultures to tolerate such behaviors (Grant-Thomas and powell, 2006). john powell (2007) advocates for a systems approach to identify the way in which institutional behavior and practices produce unintended consequences. powell (2008) defines institutional racism as the macro level systems, social forces, institutions, ideologies, and processes that interact with one another to generate and reinforce inequities among racial/ethnic groups. He contends an institutional racism framework provides a broader view of the forms of racialized power that is distributed and entrenched within social behavior and structures. This is consistent with institutional theory proposed by Scott (1995) that contends institutions carry symbolic and relational systems and operate at different levels from the world system to localized interpersonal relationships. He defines institutions as social structures composed of "cultural-cognitive, normative, and regulative elements that, together with associated activities and resources, provide stability and meaning to social life” (p. 235). This supports Young's (1990, 2001) approach to look within social structures at the practices and processes that oppress certain social groups. powell (2007) argues a structural analysis provides a framework to identify the ways racism exists at individual, institutional and inter-institutional levels. This departs from traditional thinking of racism that focuses on individual instances of bias that may be either conscious or unconscious. Structural racism or structural racialization acknowledges that racism may be produced through practices and cultural patterns that can perpetuate racial 
inequity without reliance on racist actors (powell, 2007). Figure 9 outlines types of racial inequities drawing from structural theories of racism.

Figure 9. Types or Racial Inequities

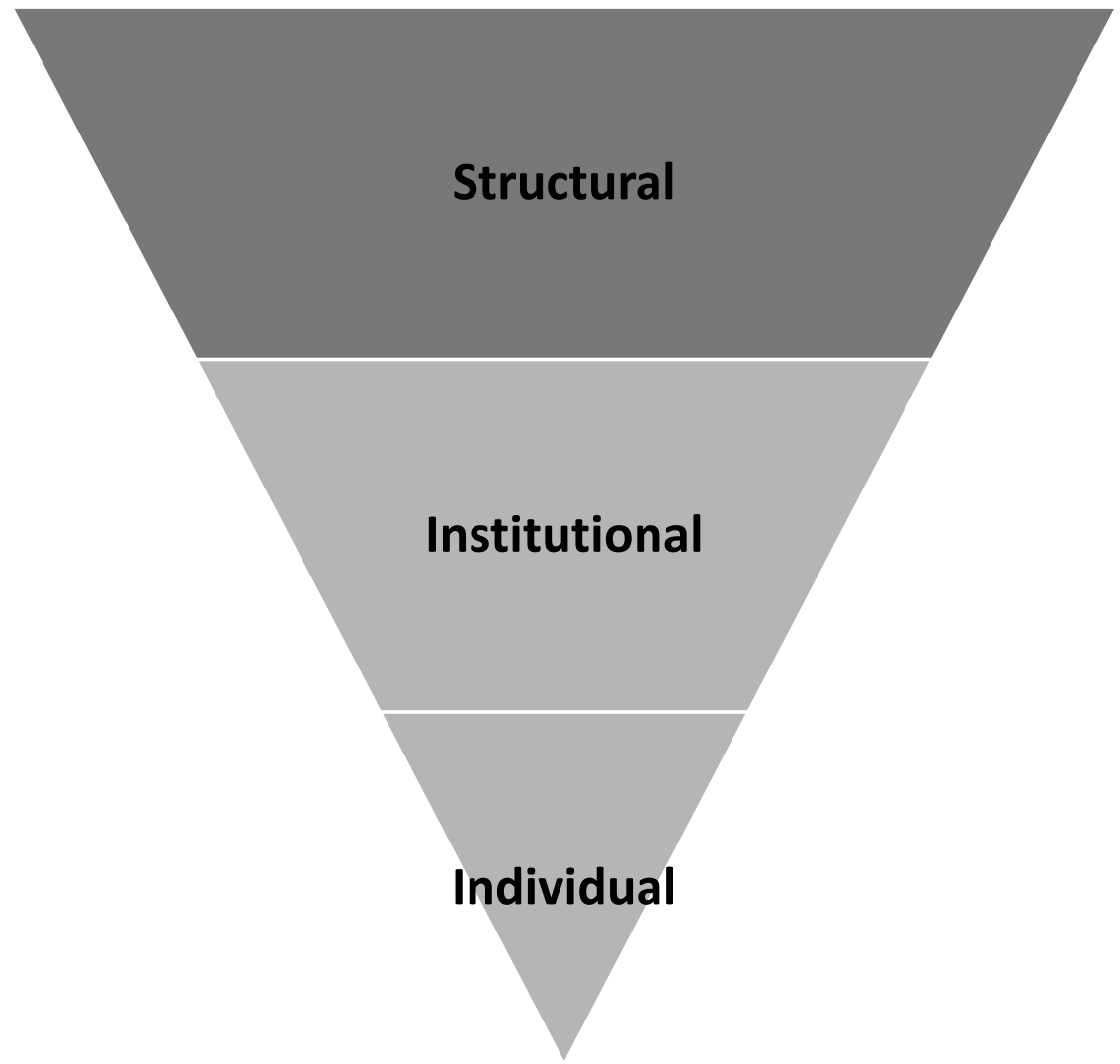

Structural - The interplay of policies, practices and programs of differing institutions which leads to adverse outcomes and conditions for communities of color compared to white communities that occurs within the context of racialized historical and cultural conditions.

Institutional - Policies, practice, and procedures that work to the benefit of white people and the detriment of people of color, usually unintentionally or inadvertently.

Individual/Interpersonal - Pre-judgment, bias, stereotypes or generalizations about an individual or group based on race. The impacts of racism on individuals - white people and people of color (internalized privilege and oppression). Individual racism can result in illegal discrimination.

Source: Nelson and Brooks, 2016. 
A structural lens provides an important diagnostic tool for identifying actions, thoughts and practices that distribute meaning and can perpetuate inequalities. Viewing governmental organizations through this framework brings to light existing models of planning and decision-making that strongly favor those with higher income, and who are well educated and those that belong to dominant racial and ethnic groups to the potential exclusion of less organized or underrepresented groups. Drawing from Young, scholars such Fainstein (2009) propose equity as criterion for policy evaluation that does not require each person to be treated the same but rather that treatment be appropriate and that distribution of material and nonmaterial benefits does not favor those already well off. Further, justice may also be used as a criterion for guiding the design of public engagement processes. Young's theory highlights the inadequacy of decision making processes that do not account for barriers to participation for social groups that are oppressed or disadvantaged. Mechanisms for participation do not always account for barriers to participate such has language, jobs or needs for childcare. Therefore, who does and does not participate is significant for constituting which people and interests are considered as a part of the public domain (Young, 2000; Disch, 2012 as cited by Bryson and Quick. 2016). New initiatives within public organizations have begun to shift engagement practices to focus on elevating the voices of those who have been historically marginalized from policy making and incorporating the use of group representation in planning processes (Metro, 2017). These new methods are testing the propositions put forward by Young, powell and others in an attempt to address structural inequalities to advance justice in the planning process. 


\subsection{Equity Lens}

Historically, the concept of social equity emerged in the field of urban planning and public administration in response to growing disparities in the 1960s and 1970s and recognition of the role of government institutions in sustaining inequities. Although equity has been acknowledged as a value in both planning and public administration, advancing the concept in practice has not been realized (Besser, 2014). In the last two decades, increasing social disparities and awareness of racialized life outcomes has linked social equity with justice and generated new initiatives focused on racial equity. Racial equity is defined as the condition by which race can no longer be used to predict life outcomes and outcomes for all groups are improved (GARE, 2015). Commitments to racial equity agendas are demonstrated by memberships of local governments to the Government Alliance on Race and Equity that is focused on advancing racial equity (GARE, 2016). Advancement of racial equity calls for the development of new methods and tools to reform policies and practices. Cities and counties name an equity lens as a new practice or tool to help address racial disparities in the delivery of public policy and services. Despite the increasing use of the term 'equity lens', the concept carries broad values, definitions and associated practices that may be interpreted and prioritized in different ways (Besser, 2014). Definitions range from the use of a questionnaire to inclusion of appointed representation in the decision making process for politically marginalized groups. This section reviews the most current scholarship that documents the emergence and use of an equity lens within local governments that provide important considerations for this study on how an equity lens is being defined and used in the public sector. 


\section{City of Seattle}

Seattle was one of the first cities to attempt an antiracism strategy at a citywide scale (Brostein, 2014). As part of City of Seattle's Race and Social Justice Initiative, the city adopted the use of a racial equity lens to guide program planning and decision making. Launched in 2004, efforts were structured to focus internally on applying an equity lens to structures and processes within the agency before expanding the focus externally. Select departments including contracting and outreach and engagement served to pilot the equity lens approach that primarily focused on analyzing existing procedures that account for potential barriers for particular social groups in accessing city services and resources. Trainings and toolkits were provided for city departments to use to examine internal practices. The toolkits outlined a process and a set of questions to guide the development, implementation and evaluation of policies, initiatives, programs and budget issues to address the impacts on racial equity. First, the toolkit provides guidance that the use of the tool should be completed by people with different racial backgrounds. The analysis then includes six steps:

1) Set outcomes- Leadership communicates key community outcomes for racial equity to guide analysis.

2) Involve stakeholders and analyze data- Gather information from community and staff on how the issue benefits or burdens the community in terms of racial equity.

3) Determine benefit and/or burden- Develop strategies to create greater racial equity or minimize unintended consequences.

4) Advance opportunity and minimize harm- Develop strategies to create greater racial equity or minimize unintended consequences. 
5) Evaluate, raise racial awareness and be accountable- Track impact on communities of color over time. Continue to communicate with and involve stakeholders. Document unresolved issues.

6) Report back- Share information learned from analysis and unresolved issues with department leadership and change team.

The initial projects revealed discriminatory practices that led to new practices. For example, as a result of the application of the tool, the city was able to double the percentage of contracting for non-construction goods and services for women and minority owned businesses. The city also created a new outreach and public engagement policy focused on inclusion. However, documentation on these results lacked information on how the tool changed existing practices and decision making processes. Based on initial results, the city moved forward with continued use of the equity lens and applying it to additional programs. The Seattle City Council passed an ordinance in 2009 that directed all the departments to use the tool including all budget proposals made to the city's budget office. By the next year, all departments began to use this tool to analyze race and social justice implications of a wide variety of budget proposals, programs and policies. This directive was reaffirmed by an executive order of Mayor Ed Murray in 2014. Lessons learned from this initiative included the importance of maintaining a shared vision of success, focusing on balancing both relationships and deliverables so they are not working in conflict with one another, and working within the existing power structure to facilitate change (Bronstein, et al, 2014). Although the case study provides general information on the use of the equity lens, outcomes and lessons learned, it lacks specific details on how the tool was used and viewed by participants within the 
organization. For example: What mechanisms were used to ensure the tool was used by individuals with differing racial backgrounds? How were stakeholders involved in the decision making process? What was the process and/or criteria for selecting who was involved? How did the tool change decision making processes to address inequalities? Answers to these questions are needed to further build understanding of how an equity lens is applied in a specific context.

\section{Multnomah County}

Following Seattle's racial justice initiative, Multnomah County (OR) adopted an equity lens with a racial justice focus in 2012 to guide their organization's programs, policies, investments and decision making processes. The lens was developed as a part of the county's Health Equity Initiative that was launched in 2008 in response to a report on racial and ethnic health disparities in the country. The lens is described as:

a transformative quality improvement tool used to improve planning, decisionmaking, and resource allocation leading to more racially equitable policies and programs. At its core, it is a set of principles, reflective questions, and processes that focuses at the individual, institutional, and systemic levels by:

- deconstructing what is not working around racial equity;

- reconstructing and supporting what is working;

- shifting the way we make decisions and think about this work; and

- healing and transforming our structures, our environments, and ourselves.

(Multnomah County, 2012).

The primary focus of the lens is to identify and eliminate the root causes of racial and ethnic inequities. To accomplish this, the lens leads staff through nine questions that "seek to uncover patterns of inequities, separate symptoms from the actual causes of 
inequities, and maintain the visibility of impacts on communities of color, immigrants and refugees" (Multnomah County, 2012). Highlights of the questions are illustrated in the following figure.

Figure 10. Multnomah County Equity and Empowerment Lens

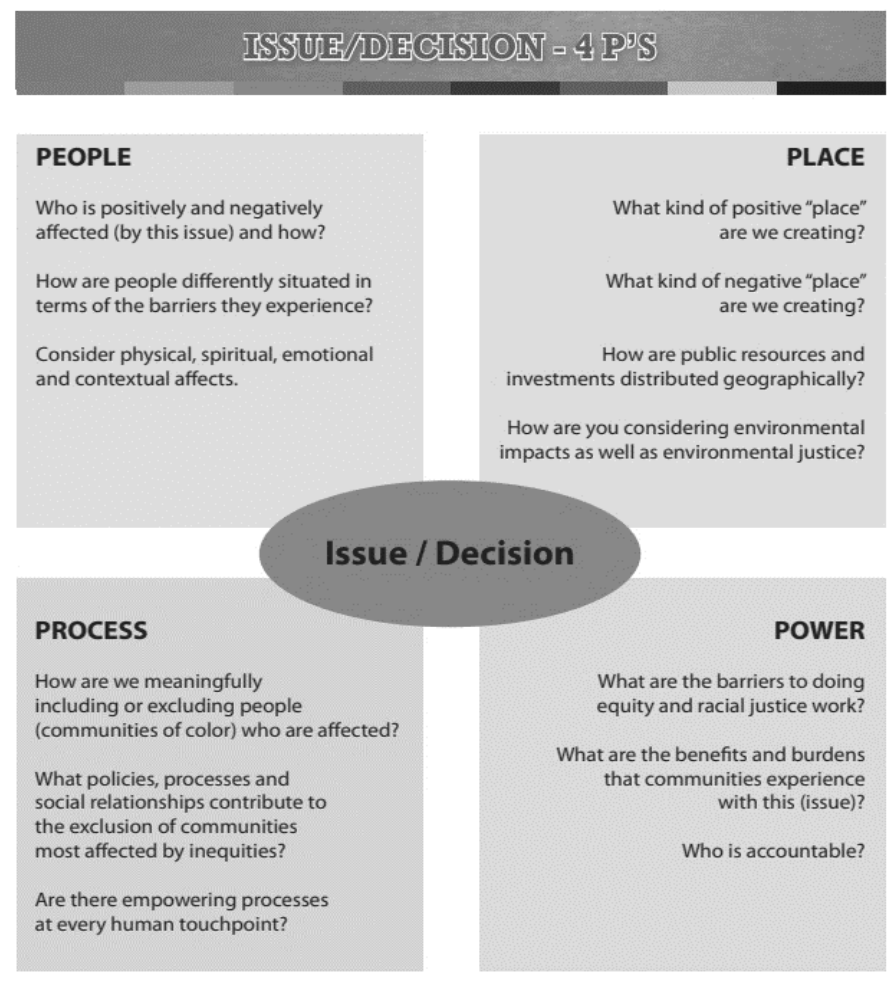

Source: Multnomah County, 2012.

Drawing inspiration from the City of Seattle, the county piloted their equity lens on the opening of a new clinic and budget development for critical services. Staff utilized the questionnaire to consider who is affected by a policy decision or may experience disproportionate impacts. This helped draw attention to the social and institutional policies, procedures and practices that perpetuate differential outcomes for populations. Following the pilot, the county began disseminating the lens toolkit countywide. Some of the major challenges noted by the county include balancing the depth of content with the 
analysis of ease of use of the lens and allocating sufficient staff time and resources.

Lessons learned from this process include the importance of acknowledging power dynamics between community members and government employees, the importance of patience to allow the process to take the time it needs, as well as the effectiveness of creating metrics to measure impact and progress. Consistent with Seattle's case study, Multnomah County's lens focused on a questionnaire to be used by staff to guide policy and program decisions. However, the case study lacks specific details on how staff in different areas of work used the lens, who was involved and specific details on how the lens changed decision making processes to include marginalized groups in policy formulation.

\section{Montgomery County}

Montgomery County Department of Health and Human Services in Maryland began a concerted effort to advance equity within their organization in 2008 that included the development of an equity lens. As part of the equity lens, the department convened an "Equity Work Group" comprised of 15 staff to steward the initiative process. The work group included membership from across the department including community affairs, human resources, child welfare, health initiatives, and several others. The county defined an equity lens as:

- Recognizing the equity impact of decisions - i.e., that decisions are not "equity neutral," but do have some impact, positive or negative, on equity.

- Considering who bears the burdens and who receives the benefits of decisions.

- Making resource cuts and investments to spread the burdens and benefits.

- Embedding this orientation in policies and practices in order to move from individual perspective transformation to institutional perspective 
transformation (Gulati-Partee, 2013).

The county stated that applying the equity lens to the department's work resulted in changes to processes and practices within the agency. This included a shared definition of equity in the context of the department's mission and program developed by the Equity Work Group that stated, "Equity refers to fair policies, decisions and actions by MCDHHS when impacting the lives of people" (Gulati-Partee, 2013, p.5). The work group also developed a guide with specific questions to assist with decision making on programs, budgets and tracking of new data that included questions like:

- Will the decision help eliminate disparities?

- Does the decision promote or improve access to services?

- Have you considered who will be the most and least advantaged by your decision?

- Are the voices of all groups affected by the decision at the table? (Gulati-Partee, 2013)

These questions were applied to an assessment of the minority health programs and used in customer service training as a first step. However, like other documentation on equity lenses used by local governments, the case study lacked detail on how the equity lens changed decision making processes and how individuals were selected and prioritized for inclusion in decision making.

\section{City of Portland}

The City of Portland adopted an equity lens that prioritized the needs of lowincome communities and communities of color as a part of their planning process for developing their 2015 Climate Action Plan. Their approach included the creation of an Equity Working Group made up of representatives from six community-based organizations representing the interests of low-income populations and communities of 
color. Organizations included Groundwork Portland, Upstream Public Health, the Coalition of Communities of Color, OPAL Environmental Justice Oregon, Wisdom Council of the Elders and the Asian Pacific American Network of Oregon (APANO). Each organization was responsible to identify a representative that would meet specific qualifications. Representatives varied across the participating organizations and included a board member, an intern, program staff and an executive director. Compensation was provided to the organization not the individuals using grant funds awarded to this city to assist with plan development. Representatives serving on the Equity Working Group worked in coordination with technical staff over the course of two years to evaluate the opportunities and challenges of specific actions for consideration in the Climate Action Plan (Williams-Rajee, et al, 2016). During the process, the work group members provided feedback on how to implement the actions. The case study stated:

The process proved invaluable for City and County staff involved. Many staff members noted that attending Equity Working Group meetings and hearing community concerns enabled them to see their work differently and better understand its equity implications. This resulted in rethinking actions and modifying them accordingly. The process highlighted that while City and County staff have expertise, there is also tremendous knowledge and expertise at the community level. This model of engagement can be replicated to foster mutual learning. - City of Portland, 2016

In addition, the group developed an implementation guide as a companion to the Climate Action Plan to ensure continued consideration of equity throughout the life of the plan. Specifically, the work group was tasked with reviewing proposed climate actions to identify potential impacts (positive and negative) for communities of color, low-income populations and other marginalized groups. Decision making was structured to allow staff 
to introduce topics and ask group members to share their relevant experiences on the topic. Then, staff was tasked with determining how to incorporate the group's feedback into the plan's actions and reviewed changes with the Equity Working Group. Two new objectives and ten actions were identified with specific emphasis on equity as a result of their work. Objectives focused on engaging with underrepresented and underserved populations and focused on equitable distribution of services and investments. In addition, the work group developed an Equity Implementation Guide as a companion document to support equity considerations as a part of plan implementation. Lessons learned from the process included meeting the need of participants and providing flexibility in agendas, content and logistics of engagement, facilitating awareness of power and privilege to create space for mutual learning and building capacity and relationship by informing new relationships with staff and community (City of Portland, 2016). Their approach was most closely aligned with an equity planning model with an orientation towards social justice. The case study indicates the equity lens increased representation of marginalized groups in the development of the plan that resulted in policy actions that reflected the views and interests of the work group. However, the case study lacked detail on how the specific organizations were prioritized for representation on the work group and how the institutional environment may have influenced how the lens was used and defined.

\section{Government Alliance on Race and Equity}

The Government Alliance on Race and Equity (GARE) provides literature and toolkits for racial analysis and connects practitioners and academics to advance racial equity within local and regional governments. The alliance is a joint project between 
Race Forward and the Haas Institute for a Fair and Inclusive Society. Race Forward includes the Center for Social Inclusion that are both nonprofit organizations focused on advancing racial justice through research, practice and supporting communities and government in dismantling structural racism. The Hass Institute within the University of Berkley is focused on research, analysis, policy and strategic narrative to eliminate barriers to advance justice and inclusion. These organizations developed the Government Alliance on Race abd Equity as a joint project. The union of these two organizations is representative of the collaborative efforts by academic and practitioner communities to advance the idea and methods associated with the racial equity analysis and the equity lens (GARE, 2015). The organization has worked with more than 170 local and regional governments across the country. The figure below highlights the jurisdictions connected to GARE and where these jurisdictions conducting some level of work on racial equity.

Figure 11. Jurisdictions Connected to the Government Alliance on Race and Equity

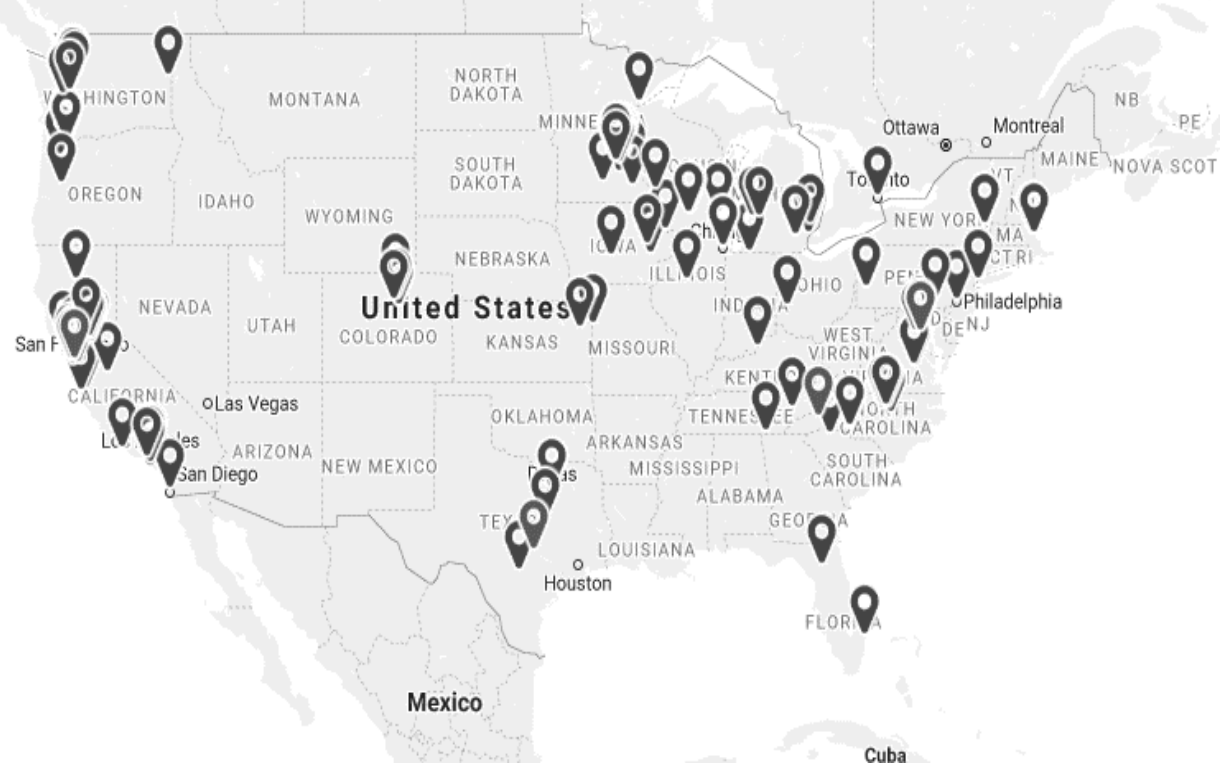

Source: Government Alliance on Racial Equity, 2020. 
In 2015, the Government Alliance on Race and Equity released a new "Racial Equity Toolkit: An Opportunity to Operationalize Equity.” Drawing from cities and counties across the country, the toolkit aims to capture the commonalities across tools being used in these jurisdictions. The racial equity tool is intended to provide a structure for institutionalizing racial equity. The racial equity tool:

- proactively seeks to eliminate racial inequities and advance equity;

- identifies clear goals, objectives and measurable outcomes;

- engages community in decision-making processes;

- identifies who will benefit or be burdened by a given decision, examines potential unintended consequences of a decision, and develops strategies to advance racial equity and mitigate unintended negative consequences; and,

- develops mechanisms for successful implementation and evaluation of impact.

(Nelson and Brooks, 2016).

This is accomplished by asking a set of questions including:

1. Proposal: What is the policy, program, practice or budget decision under consideration? What are the desired results and outcomes?

2. Data: What's the data? What does the data tell us?

3. Community engagement: How have communities been engaged? Are there opportunities to expand engagement?

4. Analysis and strategies: Who will benefit from or be burdened by your proposal? What are your strategies for advancing racial equity or mitigating unintended consequences? Implementation: What is your plan for implementation?

5. Accountability and communication: How will you ensure accountability, communicate, and evaluate results?

(Nelson and Brooks, 2016). 
The questions are intended to be used in all phases of a project from development to implementation to evaluation and should be used by government staff, elected officials and community based organizations. The tool carries many similarities of the equity lenses adopted by Seattle, Multnomah County and Portland that reflect the collaboration between these local governments and the Government Alliance on Race and Equity.

\section{Summary}

The equity lens conceptualization is rooted in academic origins of structural theories of justice. From this view, the practice of an equity lens is a means to reform structures, policies and processes that perpetuate inequities. The practice of equity lenses is growing rapidly particularly within local governmental institutions. These instances present evidence of the adoption of an equity lens within government organizations. Each case provides a definition of an equity lens and general discussion of how the lens was applied in a particular context. The documentation also reveals continued efforts to evolve and improve racial equity analysis tools. In each of the cases, the scale and scope of equity lens application varied and was used in different ways including a questionnaire, a process, appointed representation of marginalized groups in decision making, and a set of guiding principles. City of Portland was the only case in which appointed representation for specific groups was included as a component of an equity lens within a planning process. The case study indicated that the lens provided increased representation of marginalized groups within the decision making process. However, the case study lacks description of how these groups were prioritized for inclusion and the influence of the larger institutional environment. These instances indicate that an equity lens is being used and interpreted in a variety of ways that creates challenges in 
determining the extent to which the lens addresses structural inequalities. The cases provide limited details on who was responsible for defining and using the lens, the specific stages of decision making and the influence of institutional environment. Therefore, the question of how an equity lens may change the institutional planning process requires further inquiry.

\subsection{Summary and Review of Key Gaps in the Literature}

The brief review of the relevant literature draws attention to the processes and methods used for decision making in the planning and policy process for designing urban systems. Attention to justice in planning leads to considerations of fairness and transparency by which decisions are made, the structure of decision making processes, and the institutional context in which decision making processes take place.

Scholarship calls attention to past models of planning that excluded certain groups from decision making and new communicative models that involve others more directly in the planning process. Theories of justice contend that fairness does not mean that each person must be treated the same. Rather, that the treatment be appropriate and distribution of material or nonmaterial benefits should not further harm the least well off. Young's work is critically important in this context as she draws attention to the role of social group and identity in political life. Her discussion moves beyond the traditional notion of "public sphere" to provide a framework for defining "difference" and outlining the components of oppression that are historically situated to identify groups that require special treatment in the political decision making process. She places her work in direct contrast to Rawls' with a conception of justice that favors doing instead of having and oppression rather than distribution (Haggard, 1994). Therefore, accounting for social 
group differences within the planning process requires identification of oppressed social groups and providing different treatment of these groups in the design of decision making processes. Fung's (2006) typology on mechanisms for participation brings to light dimensions for structural considerations in the design of planning processes. A key concern of this study is how the equity lens addresses the structural inequalities within the institutional planning process for the development of urban system plans.

Preliminary findings on the use of an equity lens in the planning field indicate the practice may be helpful to some extent in addressing institutional conditions that have operated to perpetuate inequities and exclude certain groups. However, there is a clear need for more in-depth research that considers how an equity lens is being applied during the planning process, by whom, how the individual actors in that area influence the use of the lens and what methods are being adopted as a part of the lens. Existing case studies do not account for multiple perspectives on the definition and use of an equity lens and how the lenses may increase representation of politically marginalized groups in decision making. In addition, research is needed to develop a better understanding of how institutional conditions shape the use of the equity lens within the planning process. Therefore, research on the implementation of an equity lens, needs to also explore the larger institutional context within which the individuals, groups and processes are being studied. Key gaps in the existing literature that are explored in this study are outlined below.

\section{$\underline{\text { Lack of data on equity lens use }}$}

The equity lens represents a new method intended to address structural inequalities within internal and external practices of public organizations. The concept of 
the equity lens includes abstract and complex concepts and most guidance provided on equity lenses is general and not specific for a particular context. How do policy makers, planners and community conceptualize an equity lens? What methods and practices comprise an equity lens? Only limited documentation has been provided on the experiences of government agencies using an equity lens and how it may address structural inequalities in decision making. A more in-depth analysis that accounts for multiple views of participants is required to understand how an equity lens may change the structures and processes within a government organization's planning process for a large scale urban system plan. Further, given the emerging use of an equity lens within urban planning, there are limited studies that provide knowledge on the use of an equity lens in practice

\section{$\underline{\text { Use of criteria for selecting groups for representation }}$}

Categorization of social groups based on personal identity is an important shift in American political thought that looks beyond the broader view of the "public" or "public sphere" (Haggard,1994). There is evidence of local governments making special efforts to include social groups that have not been historically part of the political decision making process. However, how groups are defined and prioritized for representation remains unclear. Local governments have adopted broad definitions for historically marginalized groups and communities of color, but there is lack of research on how groups are more narrowly selected and prioritized for special representation for a planning process and how these groups may be historically situated in the particular context. Asking how and why questions about group selection provides a richer description of methods and criteria being used in practice and how they relate to 
propositions of justice for inclusion of oppressed groups in decision making.

\section{Decision making structures}

Much of the discourse focused on developing just decision-making processes view institutions through a structural lens (powell, 2007, Young, 2011). This perspective draws attention to the structure of decision making processes with respect to the planning process, mechanisms for participation and the structure of decision making. In what ways does an equity lens address structural inequalities in the planning process? Multiple viewpoints are needed to provide a fuller and more in-depth description of the existing decision making structures within a public organization. More research is needed on the ways and to what extent an equity lens may restructure these processes and augment existing scholarship on mechanisms of participation and structural theories of justice.

\section{$\underline{\text { Institutional environment }}$}

Viewing institutions through a structural lens brings to light both policies and practices within institutions that may perpetuate inequities. Structural theories of justice posit that racial inequities must be addressed at the systemic, institutional and individual level. What institutional conditions affect how an equity lens is defined and used in the planning process? What factors support or challenge the use of an equity lens in the planning process? More research is needed to evaluate the institutional conditions that guide the planning process and establish the organizational structures. This provides important context by outlining the institutional environment in which the equity lens was implemented and to what extent these conditions may have influenced the application of the equity lens. Answers to these questions can elaborate on current scholarship and 
inform future practices. This research aims to address these gaps by investigating how an equity lens changes the institutional planning process. 


\section{Chapter 3. Theoretical Framework}

"Social change arises from politics, not philosophy. Ideals are a crucial step in emancipatory politics, however, because they dislodge our assumption that what is given is necessary. They offer standpoints from which to criticize the given, and inspiration for imagining alternatives.” -Iris Marion Young, 2011

\subsection{Introduction}

A critical aspect of the study is the theoretical orientation that serves as the foundation for the research inquiry. The theoretical framework provides "a structure that guides research by relying on a formal theory... constructed by using an established, coherent explanation of certain phenomena and relationships" (Eisenhart, 1991, p. 205). Therefore, the theoretical framework includes a selected theory that underpins the study and research approach as well as the concepts and definitions from that theory that are relevant to the study. As Merriam (2009) suggests, the theoretical framework in relationship to the research problem and purpose of the study can be viewed as a set of interlocking frames as illustrated in the figure below.

Figure 12. Relationship of Theoretical Framework to Purpose of Study

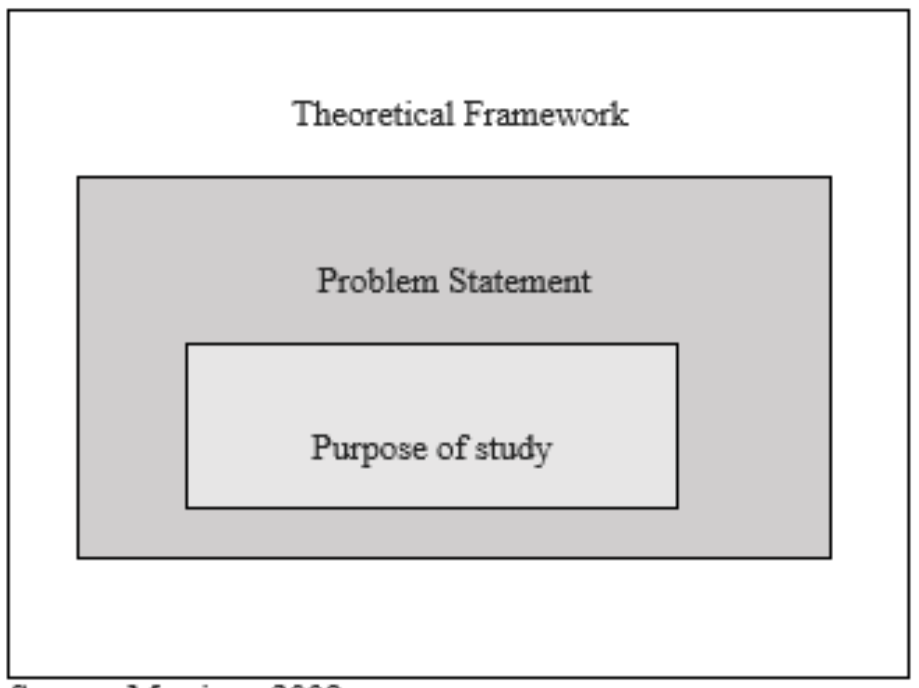

Source: Merriam, 2009 
This chapter provides a description of the theoretical framework used to view both the design of the study and its results.

\subsection{Theoretical Basis and Key Concepts}

Iris Marion Young's theoretical propositions for addressing social justice served as the framework for the study. Young's collection of works including "Polity and Group Difference: A Critique of the Ideal of Universal Citizenship," "Equality of Whom? Social Groups and Judgments of Injustice," "Justice and the Politics of Difference," and "Inclusion and Democracy" provide a powerful reconceptualization of the role of groups and social identity in the policy process and place structural processes as the subject of justice. The choice of Young's framework is based on her in-depth and thorough analysis of the various dimensions of inequality and justice and the philosophical position she presents for evaluating the institutional conditions that perpetuate inequities. Specifically, she calls attention democratic decision making processes as an important condition of justice and how the denial of social group difference contributes to social group oppression. Important aspects of her framework pertinent to this study include her definition of social justice, criteria for identifying oppressed and exploited groups that require special representation in the political process, and the aspects of social organization and practice that are subject to domination and oppression. Each of these aspects require attention.

First, Young's conception of justice. Drawing from multiple frames of reference including critical theory, feminist theory and moral and political philosophy, Young puts forward her own definition of social justice that critiques and examines the power dynamics and structures that may serve to oppress or exclude certain groups. According 
to Young (1990), critical theory is "a normative reflection that is historically and socially contextualized" that "rejects as illusory the effort to construct a universal normative system insulated from a particular society" (p.5). As such, normative reflection is derived from a particular social context with social and political explanation. This worldview is important for this area of study to consider what occurs in society and who benefits and who is harmed (Young, 1990). Young distinguishes herself from traditional critical theory in her resistance to generalizing categories of the "public sphere" or totalizing ideals of the "public good." She argues modern political theory contends that all citizens have the same status as others in the public sphere and every citizen is treated the same regardless of their wealth, status or power. This notion, "citizenship for everyone and everyone the same qua citizen," transcends particularity and difference (Young, 1990, p.250). Young argues, if equality is conceived as sameness, then the ideal carries two additional meanings. First, universality as a generality defined in terms of what citizens have in common. Second, universality as equal treatment in terms of laws and rules that are blind to individual and group difference. However, Young claims this conception has failed. Even with groups attaining full citizenship status of equal political and civil rights, some groups continue to be marginalized, which begs the question why has full citizenship has not led to social justice and equality. Young argues the reason is within the implicit meanings of citizenship. The universality of citizenship that desires the inclusion and participation of everyone stands in direct tension with the other two meanings of universality as a generality and universality as equal treatment (Young, 1990). She supports her arguments by pointing to social movements that have developed political practices that reflect a heterogeneous public. These movements have formed 
political organizations to represent voices that may otherwise be silenced such as women, Latinos, gays and lesbians. Young contends we must solve the "paradox of democracy by which social power makes some citizens more equal than others and equality of citizenship make some people more powerful citizens" (1989, p. 259). Therefore, Young (1990) defines social justice as the elimination of institutionalized domination and oppression. Any aspect of social organization and practice subject to domination and oppression falls within her conception of justice. This includes decision making procedures, division of labor and culture. She draws specific attention to the embedded norms, values and assumptions that underlie institutional rules and decision making procedures that may assist or hinder a given social group's exercise of capacities and serve to produce and reproduce racialized outcomes (Young, 1990). Young argues that group representation is the best means to promote just outcomes in the political decision making process.

Another component of her work that informed this study is her work on defining social groups and conditions of oppression as it relates to the selection of groups for special representation as a part of an equity lens. Her approach provides a more comprehensive view on what groups may or may not have been left out. Distinct from other theorists such as Karl Marx, Young's approach considers oppression as a structural concept that does not always include the intentional suppression of one group by another. She draws on Foucault's (1977) view that looks beyond models of power that are dyadic relations of ruler and subject, but instead looks at power in the context of every day actions of many individuals that contribute to maintaining and reproducing oppression, but these individuals are usually living their lives and doing their jobs without 
understanding themselves as agents of oppression (Young, 2011). In this way, power is exercised at many levels within individuals, in relations to others and through institutions.

Young (1990) defines oppression as conditions experienced by individuals or groups in the form of exploitation, marginalization, powerlessness, cultural dominance and/or violence. She describes exploitation as "the steady process of the transfer of the results of the labor of one social group to benefit another group" (Young, 2011, p. 49). This condition enacts a structural relation between groups with "relations that are produced and reproduced through a systematic process in which the energies of the havenots are continuously expended to maintain and augment the power, status and the wealth of the haves" (Young, 2011, p.50). Marginalization is when a whole group of individuals are excluded from "useful participation in social life and thus potentially subjected to severe material deprivation and even extermination" (Young, 2011, p. 53). In the United States, this can be seen in older individuals who get laid off from jobs and cannot find new work or people of color who cannot find first or second jobs (Young, 2011). The condition of powerlessness is when members live and work under the authority of others with little autonomy (Young, 2011). This occurs when an individual or group lacks the "authority, status, and sense of self that professionals tend to have. The status privilege of professionals has three aspects, [college education, relative day-to-day work autonomy and social status associated with cultural preference of the professional class, or 'respectability'] the lack of which produces oppression for nonprofessionals" (Young, 2011, p. 57). Cultural imperialism is the "universalization of a dominant group's experience and culture and its establishment as the norm" (Young, 2011, p. 59). With this condition of oppression individuals and groups are "both marked out by stereotypes 
and at the same time retendered invisible.... and find themselves defined from the outside [by] those with whom they do not identify and who do not identify with them" (Young, 2011, p. 59). Lastly, random violence and harassment is considered when group members experience random violence or harassment motivated by group hatred or fear. This condition is "is less the particular acts [of violence] themselves . . than the social context surrounding them, which makes them possible and even acceptable. What makes violence a phenomenon of social injustice, and not merely an individual moral wrong, is its systemic character, its existence as a social practice. Violence is systemic because it is directed at members of a group simply because they are members of that group" (Young, 2011, p. 61).

These conditions serve as criteria for determining whether individuals or groups may be oppressed. They may be operationalized and applied through an assessment of observable behavior, status, relationships, distributions, texts and other cultural artifacts. She distinguishes between three types of groups that may experience oppression. First, a social group that involves individuals and affinity with other persons by which they identify with one another. Second, an aggregate group that is any classification of persons according to some attribute. Third, an association group that is a collective of persons who come together voluntarily. Her approach will serve as a framework for the study to identify and classify social groups from oppressed populations that would require appointed representation within the planning process.

Lastly, her attention to structural inequality, including the structures and processes within decision making that advantage some groups and disadvantage others, informed this study by considering what groups are included in decision making and how 
advantages and disadvantages are accounted for in the design of the decision making process. She provides four conditions to illustrate the general meaning of "social structure" or "structural process" including: 1) as objective constraint, 2) as considering position, 3) as something produced in action, and 4) as unintended consequences (Young, 2011). Constraints may be considered past actions that affect the present by allowing some actions and blocking others. This may include social policies, investment decisions, cultural preferences, and racial hegemonies of the mid-twentieth century. Under this premise, social structure or processes refer to the position or initial standing of a given social group or individual in given context that would later on determine the range and possibilities of its action and interaction with the other social groups or individuals. Third, social structure or structural process may be something that is produced in action. Here, Young draws from Anthony Giddens' (1938) theory of structuration and Bourdieu's concept of "habitus." Young states, "when individuals act, they are doing two things at once: (1) They are trying to bring about a state of affairs that they intend, and (2) they are reproducing the structural properties, the positional relations of rules and resources, on which they draw for these actions" (Young, 2011, p.60). Lastly, social structure or process as an unintended consequence is drawn from Sartre's notion of "counter-finality," the situation in which people are scampering to pursue their various ends that adds into a cumulative situation that works against their desired ends (Young, 2011, p.63). She explains, "Social structure refers to the accumulated outcomes of the actions of the masses of individuals enacting their own projects, often uncoordinated with many others. The combination of actions affects the conditions of the actions of others, often producing outcomes not intended by any of the participating agents" (Young, 2011, 60 
p.64). Young's lens offers a structural view to examine the way in which individuals interact within an institutional planning process. These concepts illustrated in the following figure including social structure and processes, conditions of oppression and social identity underpin the study and guided the selection of the research design, methods and analysis to answer the research questions.

Figure 13. Key Concepts Drawn from Young's Propositions of Justice

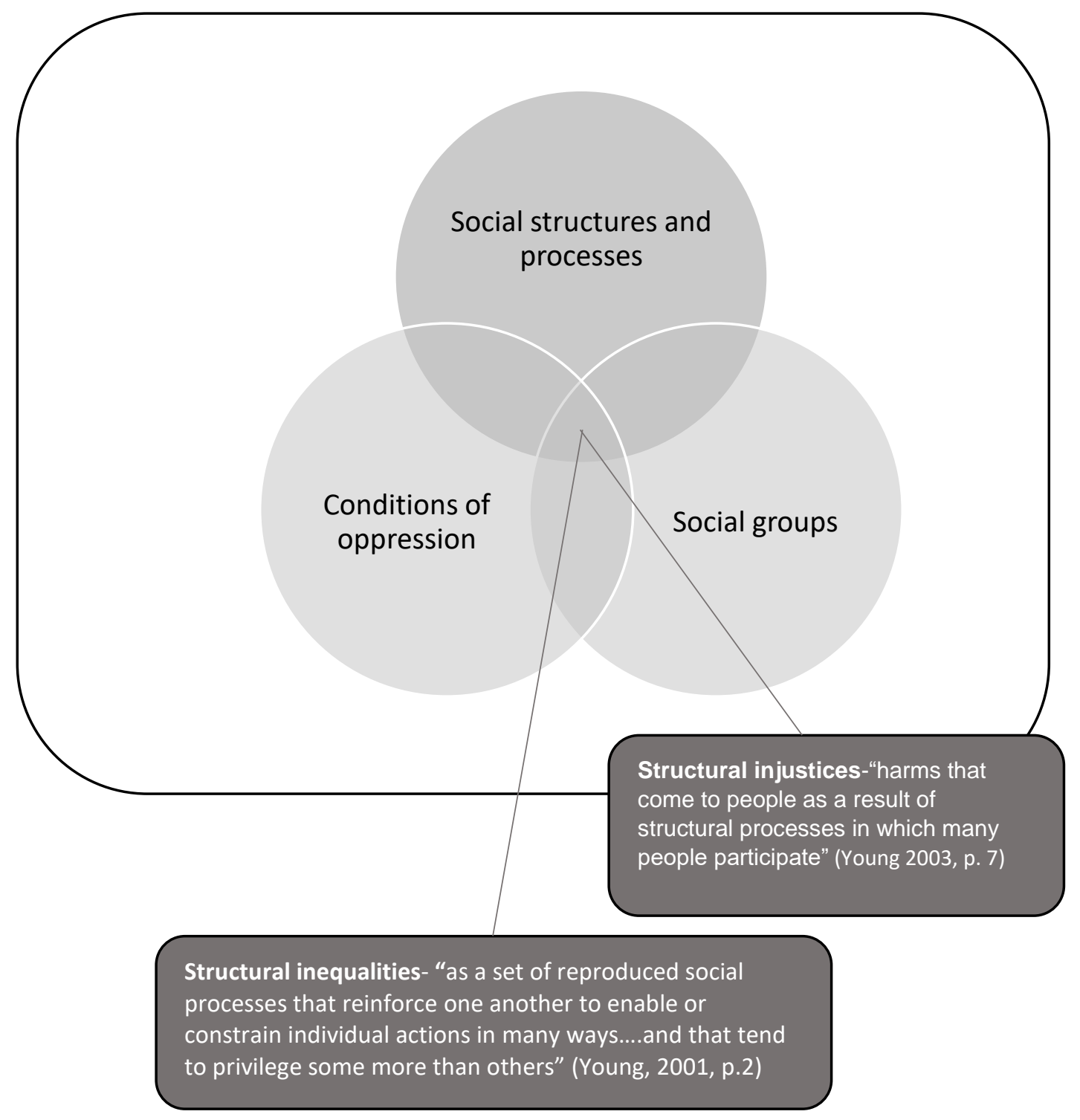

Source: Young, 2001, 2003, 1989, 1990, 2011. 
The practice of equity lenses is growing rapidly in the public sector as a means to reform institutional processes that perpetuate inequities. However, scholarly research on the use of an equity lenses in the institutional context and how the lens is being defined and used by practitioners remains largely unexplored. Young's propositions and concepts of social structure and processes, conditions of oppression and social identity provide a defined framework for examining the use of an equity lens within the institutional environment with respect to the value of justice. From this view, the intent of an equity lens is to revise social structures and processes to increase representation of oppressed groups within the political process to advance justice. This requires accounting for differing social power in the decision making with the design of the planning process and creating distinct mechanisms for participation for oppressed groups to influence policy outcomes. 


\section{Chapter 4. Research Approach}

\subsection{Introduction}

In this section, I outline the research approach and design for the study guided by the theoretical framework. First, I review my research questions. Second, I provide a general overview of my selected approach and rationale for why the single case study approach was the appropriate design to address the research questions. Next, I present the criteria I used for selection of my case study and a description of the case. Then, I provide a detailed description of my phases of data collection, data analysis process, validation and reliability of findings, and ethical considerations accounted for in the study. I conclude with an explanation of the limitations of the study.

\subsection{Research Questions}

The overall research question for this study was: How does an equity lens change the institutional planning process? Sub-questions to address more specific aspects of the research included:

- How is an equity lens defined by planners, policy makers and participants in the planning process?

- How are social groups identified and selected for special representation as a part of the equity lens in the planning process?

- How does an equity lens influence the structural processes of decision making?

- How does the institutional environment influence the use of the equity lens?

\subsection{Research Design}

To answer the research questions, the study adopts a qualitative case study research approach. Qualitative studies focus on meaning, understanding and process 
drawing from data collected from multiple sources that typically include interviews, observations and documents to formulate findings that are richly descriptive and presented in themes and categories (Merriam, 2009). A case study design aims to provide "an intensive, holistic description and analysis of a bounded phenomenon such as a program, an institution, a person, a process, or a social unit" that provides particularistic, descriptive and heuristic understanding to the object of study (Merriam, 2009, p. xiii). In this section, I will review this approach, rationale for the research design for this study and reference the theoretical framework presented in Chapter 3 that underpins the study.

A case study approach was most appropriate to answer the research questions for multiple reasons. First, a case study design offers a means to investigate social processes with multiple variables of potential importance in understanding a phenomenon. In this study, the research questions required an investigation that would provide a rich and holistic account of an equity lens being used within a planning process in a real-life situation. Second, the case study approach draws particular importance to the context in which it is studied to provide understanding of the case and consideration of variables including political, economic, social, cultural, historical and/or organizational factors. This design was critical to move beyond some of the limitations of quantitative methods by providing holistic and in-depth descriptions of the social and behavioral conditions through the actor's perspective. This provided the ability to formulate context dependent knowledge to explore multiple contextual variables that was required to answer the research questions. Third, case study research offers advantages over other approaches in its use of multiple sources of data including documents, interviews and observations to 
provide multiple views of a phenomenon (Merriam, 2009; Stake, 1995; Yin, 2002). This was critical in order to address limitations of prior research done on the use of an equity lens by answering the research questions from multiple participants engaged in the use of the equity lens. This provided the ability to develop detailed qualitative accounts to explore and describe the real-life environment and complexities of the use of an equity lens in a real life situation that may not have been revealed through experimental or research data. Further, being able to draw from a wide variety of sources allowed me to explore research questions in more depth. Such as, document review helped answer questions pertaining to 'what' and 'who' questions, while interviews from participants offered an in-depth look from each individual's perspectives to answer 'how' and 'why' questions. The combinations of these sources provided a complex view of the structures and processes at play. The case study approach also provided a level of flexibility not offered by other qualitative approaches. For example, the case study research design does not claim any particular methods for data collection or analysis. Methods may be selected to align with the researchers' philosophical position and best suited to the research question. The study drew from Merriam's (2009) approach to case study design where the researcher has a personal interaction with the case and assumes that reality is constructed inter-subjectively through meanings and understandings developed socially and experientially. This was important to the study given the constructionist position of the researcher and informed the selection of methods. Lastly, case studies provide context dependent knowledge and do not attempt to formulate universals in the study of human affairs (Flyvberg, 2006 as cited by Merriam, 2009). This approach enabled me to explore multiple contextual variables to answer the research questions. These features of the case 
study approach highlight the ability of this research design to provide opportunity for insight, discovery and interpretation to build context specific knowledge.

For the study, a single case study design was selected to answer the research questions. Although the value of single cases is often contested, scholarship such as Flyvberg (2006) and Merriam (2009) argue the force of single example is underestimated and formal generalization offered by other approaches is overvalued as a source of scientific development. Selecting a single case study $(n=1)$ was done purposefully in order to pursue an information rich case that required in-depth study to illuminate the understanding for the particular phenomenon of the equity lens and provide a "thick" description of the phenomenon to answer the research questions (Patton, 1990). Eisner (1991) contends the detail provided by case studies can provide "a vivid portrait" that can become a prototype that can be used to inform future practices (p.199). This is important in the study of equity lenses given that existing documentation lacks in-depth descriptions of the use in practice from multiple views of participants.

Also important to the case study research design is the selection of the theoretical framework that is used to help mold the research questions and points of emphasis (Merriam, 2009). As outlined in Chapter 3, Young's theoretical propositions offer a clearly defined framework for evaluating an equity lens within an institutional context with respect to the value of justice. Her propositions draw attention to the concepts of social structures, processes and social identity. For this study, her central concepts and definitions presented in Chapter 3 and summarized in Table 1 on the following page were used as a framework to connect themes within the research findings and show how ideas in the study related to one another. 
Table 1. Key Concepts of Young's Propositions of Justice

\begin{tabular}{ll}
\hline Concept & Definition \\
\hline Social justice & $\begin{array}{l}\text { Social justice means the elimination of institutionalized domination } \\
\text { and oppression. }\end{array}$
\end{tabular}

Oppression as a

structural concept
The conscious actions of many individuals that contribute daily to maintaining and reproducing oppression. This takes the form of institutional constraints on self-development, and domination, the institutional constraint on self-determination.
Social structures and
social processes
Oppression and domination are social processes that exist within social structures. "Structures refer to the relation of basic social positions that fundamentally condition the opportunities and life prospects of persons located in these positions," through "mutually reinforcing processes" of effecting individuals and effecting rules and institutions. This includes:

1) as objective constraint- allowing some actions or blocking others (policies, investment decisions, cultural preferences)

2) as considering position- initial standing of a given social group or individuals in a given context that would later determine the range of possibilities of its action or interaction with another group

3) as something produced in action- when individuals take action they both act and reproduce structural properties that they draw on for action

4) as unintended consequences- combination of actions that reproduce outcomes that may not be intended

Structural injustice

Structural injustices are harms that come to people as a result of social processes in which many people participate.

Structural inequality

Reproduced social processes that reinforce one another to enable or constrain individual actions and tend to privilege some more than others. This includes structure and processes within decision making that advantage some groups and disadvantage others.

Social groups

A social group is a collective of persons differentiated from at least one group by cultural forms, practices or way of life 
Oppressed groups deserving representation
When one or more of the following conditions occurs to a part or all of a group:

- exploitation is when members benefits of labors go to others disproportionately;

- marginalization is when members are excluded from participation in major social activities, esp. workplace;

- powerlessness is when members live and work under the authority of others with little autonomy;

- cultural imperialism is when as a group they are stereotyped at the same time that their experience and situation is invisible in the society in general; and

- random violence and harassment is considered when group members experience random violence or harassment motivated by group hatred or fear

Source: Young 1990, 1989, 2001, 2003, 2011.

\subsection{Case Selection}

The case selected for study is the planning process for developing the 2030 Regional Waste Plan, a 12 year urban system plan, adopted by Metro, the regional government for greater Portland (OR). The 2030 Regional Waste Plan is a policy document with formal authorities that requires public participation, includes decisions on the allocation of programs, resources and location of facilities and sets policy direction across 12 year planning horizon for the Portland metropolitan area. The 2030 Regional Waste Plan was the first large scale urban system plan adopted by Metro to apply an equity lens as a part of a planning process. The equity lens included the appointment of a seven-member "Equity Work Group" to guide the development and application of the equity lens as a part of the planning process. This section will cover the criteria and conditions that informed the selection of the case. 
Merriam (2009) provides specific criteria for selecting the object of study. First, the case must be a single instance of a bounded phenomenon such as a program, an institution, a person, a process, or a social unit (Merriam, 2009). The selection of a bounded system is critical to focusing the scope of the study, data collection and analysis. This involves identifying specific parameters of the case including participants, location, and process to be explored and establishing the timeframe for investigating the case (Merriam, 2009; Stake, 2006; Yin, 2002). For this study, the planning process that occurred between spring 2017 and 2018 and the participants within the planning process that were involved with the design and use of the equity lens including the Equity Work Group members, project planning staff and the elected council members that approved the plan served as the bounded system. Next, Merriam (2009) states the remaining criteria for selection of the case should be informed by the purpose and conditions of the study. For this study, the case meets the purpose of the study by providing a planning process that formally adopted an equity lens with a starting and end point. Second, the planning process included formal decision making processes that required public participation. Lastly, the planning process was overseen and directed by a local government organization who was responsible for formally approving the plan.

The last major factor in the case study selection process was a practical one for the researcher. Specifically, I considered studying a planning process where I had established contacts, access to information and relevant individuals and support and interest from the organization to conduct the research. In addition, for more than 20 years I have been working in planning and public policy in the areas of resource conservation and sustainability at Metro. I also served two terms as an appointed member and chair of 
the City of Wilsonville Planning Commission. My work experience with Metro, plus my work as a city commissioner, give me deep practical knowledge of the development, implementation, and evaluation of public policy and provide intimate knowledge and insights into the decision making processes, communication structure and history of past planning processes. This experience both generated my interest in investigating the complex and process oriented path of inquiry, but also influenced my decisions on the research design and data collection and analysis. Further, my access to information and knowledge of the subject, provided the opportunity to purposefully select an information rich case that would provide a great deal of information and greatly illuminate the questions under study.

\subsection{Data Collection}

To answer the research questions, the study included in-depth data collection involving multiple sources of information. Data was drawn from a wide variety of documentary materials and interviews. The data was systematically recorded and managed through a database (Yin, 2009). A research journal was utilized to keep track of observations and speculations. In addition, analytical memos were produced at each phase of the data collection and analysis process. This section presents the phases and sources of data collection.

\section{Phase 1: Document Review}

The purpose of this phase was to understand the background of the case, timeline, the incorporation of the equity lens and to develop an initial map of participants and the decision making process and the extent to which interests of the equity work group surfaced in the final plan. This phase of research focused on review of documents drawn 
from public records to help "uncover meaning, develop understanding and discover insights related to the research problem" (Merriam, 2009, p.163).

I began this data collection with 20 years of experience working in the planning field and for Metro. Given this experience, I have in-depth knowledge of Metro, guiding plans and policies and the decision making processes. Despite my knowledge and involvement in the Regional Waste Plan, I conducted a complete review and search for documents relative to the case under study. Although document review can provide important insights for the context of the case, I kept in mind that mining data from documents has some inherent limitations including that the documentary data was not developed for research purposes and did not provide accounts for how different individuals or communities may have viewed the planning process (Merriam, 2019). I recognized that all the documents reflect the perspective and inherent bias of the author and should be treated with caution as a part of my case study research (Yin, 2009). I viewed my insights and knowledge of Metro and the Regional Waste Plan as strength to this study, but practiced reflexivity as I moved through each document. I used a research journal to keep track of my observations and assumptions.

Following my internal review board certification and advancement to candidacy, I began data collection at the end of January 2019. Data was gathered from public documents associated with the development of the Regional Waste Plan including meeting minutes, progress reports, agendas, work plans, media reports and planning documents. Prior plans were also reviewed to understand how the planning processes were structured in the prior version of the plan. The data items were systematically 
collected and provided an ID code. The documents fell into three main categories listed in Table 2.

Table 2: Document Types

\begin{tabular}{|c|c|c|}
\hline Document Type & & Examples of Documents \\
\hline $\begin{array}{l}\text { Agenda and } \\
\text { meeting minutes }\end{array}$ & $\begin{array}{l}\text { These included documents } \\
\text { from the Equity Work } \\
\text { Group, Metro advisory } \\
\text { committee meetings and } \\
\text { Metro Council work } \\
\text { sessions and public hearings } \\
\text { from March } 2017 \text { through } \\
\text { February } 2019 .\end{array}$ & $\begin{array}{l}\text { Metro. (2017) Equity Work Group meeting } \\
\text { Agenda May 31, 2017. Portland, OR } \\
\text { Metro. (2018). Solid Waste Alternatives } \\
\text { Advisory Committee December 12, } 2018 \\
\text { Meeting Minutes. Portland, OR. }\end{array}$ \\
\hline $\begin{array}{l}\text { Administrative } \\
\text { documents }\end{array}$ & $\begin{array}{l}\text { These included work plans, } \\
\text { progress reports, and other } \\
\text { planning or policy } \\
\text { documents related to the } \\
\text { Regional Waste Plan from } \\
1989 \text { to } 2019 .\end{array}$ & $\begin{array}{l}\text { Metro. (2016). Strategic Plan for } \\
\text { Advancing Racial Diversity. Portland, OR. } \\
\text { Retrieved from: } \\
\text { www.oregonmetro.gov/sites/default/files/2 } \\
\text { 016/11/15/Strategic-plan-advance-racial- } \\
\text { equity-diversity-inclusion-exec-summary- } \\
\text { 17063-20160613.pdf } \\
\text { Metro. (2017). 2030 Regional Waste Plan } \\
\text { Development Project Work Plan. Portland, } \\
\text { OR }\end{array}$ \\
\hline $\begin{array}{l}\text { News stories or } \\
\text { articles }\end{array}$ & $\begin{array}{l}\text { These included new articles } \\
\text { or stories related to the } \\
\text { Regional Waste Plan from } \\
\text { September } 2017 \text { to March } \\
2019 .\end{array}$ & $\begin{array}{l}\text { Metro (2017. Metro's Diversity, Equity and } \\
\text { Inclusion program has a new director } \\
\text { Retrieved from: Portland, OR } \\
\text { https://www.oregonmetro.gov/news/metro- } \\
\text { council-adopts-2030-regional-waste-plan }\end{array}$ \\
\hline
\end{tabular}

The documents were retrieved from Metro's website or directly from Metro's server with permission from Metro. The documents were read and reread and then uploaded to Nivo for coding. Using Nivo software, I captured notes, ideas, tentative themes and questions to pursue in future phases of data collection based on this first set of data. Following a complete coding process, I began with my first data item and systemically worked through the whole item to find chunks of data that potentially address my research 
questions (Braun and Clark, 2006). Data that did not contain anything relevant was not coded. As the coding progressed, I modified existing codes to incorporate new material. I aimed to develop an initial list of codes that differentiated between different concepts, issues and ideas in the data, which has been applied consistently to the dataset. I errored on the side of more inclusive with my coding in items that may address the research questions. The data sources reviewed are listed in Table 3.

Table 3: Data Sources

\begin{tabular}{|lll|}
\hline Types of Data & & \\
\hline Documents & Agenda and meeting minutes & 26 \\
& Administrative documents & 12 \\
& News stories and media & 4 \\
\hline
\end{tabular}

Considerations for investigation in the document review related to the research questions included:

- Past planning process structure and participants

- Institutional rules or policies that direct the planning process

- Equity lens definition

- Process for identifying and selecting equity work group members in the planning process

- Types of social groups represented in the process and on the equity work group

- Process for decision making

- Communication between planning process participants

- Representation of equity work group interests in final policy actions

The document review was helpful to provide insights into the context in which the 2030 Regional Waste Plan planning process took place and to identify the participants in the planning process. To document my initial observations and thinking, I produced an 
analytical memo that included additional consideration and questions to investigate in the following phase of semi-structured interviews.

\section{Phase 2: Semi-Structured Interviews}

The purpose of the second phase was to interview those directly involved in the application of the equity lens and the Metro Council members that served as the final authority on the plan adoption. An interview may be defined as "a process in which the researcher and participant engage in conversation focused on questions related to a research study" (Demarrais, 2004, p. 55). Participants interviewed included Equity Work Group members that were individuals from the community that served on the work group; Metro Councilors that were elected officials that served as the final decision making authority on plan adoption; and Metro staff that served on the project team that included planners and department and division directors in management.

Following the initial document review, I began interview scheduling in May 2019. Interviewees were contacted by email to request an interview. Upon scheduling the interview, I sent a follow-up confirmation email including a consent form. Interviews were digitally recorded with consent and fully transcribed. A summary document with transcripts was produced for each interview. The interview instrument included both open and close ended questions to collect information. Open ended interview questions were informed by the results of the first phase of data collection and analysis. Questions included identification of participant interests related to the plan and understanding of decision making and communication structure. Close ended questions were used to categorize self-identification of race and ethnicity of each individual, occupation and role on the project. All interviews were conducted in one-on-one settings. Interviews lasted 
thirty minutes to an hour and half. Twenty-one interviews were completed based on purposive sampling of the equity work group members, seven Metro councilors, department leadership and staff directly involved in equity lens application including interacting with the Equity Work Group members in the process for developing the 2030 Regional Waste Plan. The interview participants are summarized in the following table.

Table 4: Semi-Structured Interviews

\begin{tabular}{lcc}
\hline & Population & Sample \\
\hline Equity Work Group members & 7 & 6 \\
Metro Council & 7 & 5 \\
Metro department leadership and planning staff & 11 & 10 \\
involved in equity lens application & & 21 \\
Total interviews & 25 &
\end{tabular}

Considerations for investigation in the interviews related to the research questions included:

- Equity lens definition

- Timing of equity lens application

- Equity work group structure and format

- Self-identification of equity group members

- Expressed interests of equity work group members

- Decision making and communication structure

- Equity interests considered within the decision making process

- Process for defining policy issues and solutions

As I moved into the semi-structured interviews, I acknowledged the importance of my role as the interviewer and the assumptions and values that may subconsciously inform the interview. The interview questions were open ended and follow up questions 
were focused on "tell me more" and focused on probing deeper into the view of the interviewee. I made the conscious effort to focus on "how" questions. As an employee of Metro, I have in-depth knowledge of the organization, institutional environment and individuals that provides me unique perspective into the social and political conditions of the case under study. Further, as a participant in the development of the Regional Waste Plan, I have an insider's view of how the planning process was conducted, who was involved, and developed relationships with a number of participants in the study. I believe my connection to this study served as an opportunity to provide insights that others may not have been able to contribute. I also recognized that I had an existing relationship with many of the interviewees. I believe this allowed me to enter the interview with an already established level of trust. At the same time, I recognized that this relationship may also influence individual's response as well as my assumptions for the study. To address some of these concerns, I provided participants the option of skipping any questions that they did not want to answer. I viewed my insights and knowledge of Metro and the Regional Waste Plan as strength to this study, but also recognized the continued importance of reflexivity as I entered this phase. I used a research journal to document my thinking and observations, and to consider how my experiences may influence how I viewed the data results. I continually reminded myself that the analysis process is not linear, and provided the space for a more recursive process and not rushing to conclusions.

\subsection{Data Analysis Process}

The data analysis served as the process to answer the key research questions and included data presentation, discussion and interpretation. As Merriam (2009) states, data 
analysis is "the process of making sense of the data that involves consolidating, reducing and interpreting what people have said and what the researcher has seen and read - it is the process of making meaning" (Merriam, 2009, p. 178). To complete the analysis, the study utilized Braun and Clark's (2006) six-phase process for identifying, analyzing, and reporting qualitative data using thematic analysis. This section reviews the data analysis approach and process of interpretation to arrive at the study's findings.

Thematic analysis is a process of identifying patterns or themes within qualitative data. Thematic analysis is not wed to any pre-exiting theoretical framework and may serve as a realist method or a constructionist method (Braun and Clark, 2006). Important to applying thematic analysis as a method in qualitative analysis is making the researcher's epistemological orientation explicit in approaching the data and the theoretical framework and methods align with what the researcher wants to know (Braun and Clark, 2006). In this study, thematic analysis is used as a constructionist method to examine "the ways in which events, realities, meanings, and experiences and so on are the effects of a range of discourses operating within society" (Braun and Clark, 2006). This worldview aligns both with my epistemological orientation and theoretical framework. Thus, the analysis is conducted within a constructionist framework that seeks to theorize the socio-cultural contexts and structural conditions within which individual accounts are provided (Braun and Clarke, 2006). The overall process of thematic analysis involves searching across a data set to find repeated patterns of meaning. This may include both latent and semantic themes. Braun and Clarke (2006) outline a process comprised of six phases outlined in the table on the following page. 
Table 5. Braun and Clarke's (2006) Six Phases of Thematic Analysis

\begin{tabular}{|c|c|c|}
\hline Phase & & Description of Process \\
\hline & $\begin{array}{l}\text { Familiarizing yourself with } \\
\text { the data and identifying } \\
\text { items of potential interest }\end{array}$ & $\begin{array}{l}\text { Transcribing data (if necessary), reading and } \\
\text { rereading the data, noting down initial ideas. }\end{array}$ \\
\hline 2. & Generating codes & $\begin{array}{l}\text { Coding interesting features of the data in a systematic } \\
\text { fashion across the entire data set, collating data } \\
\text { relevant to each code }\end{array}$ \\
\hline 3. & Generating initial themes & $\begin{array}{l}\text { Collating codes into potential themes, gathering all } \\
\text { data relevant to each potential theme. }\end{array}$ \\
\hline 4. & Reviewing initial themes & $\begin{array}{l}\text { Checking in the themes work in relation to the coded } \\
\text { extracts (Level 1) and the entire data set (Level 2), } \\
\text { generating a thematic map of the analysis. }\end{array}$ \\
\hline & $\begin{array}{l}\text { Defining and naming } \\
\text { themes }\end{array}$ & $\begin{array}{l}\text { Ongoing analysis to refine the specifics of each } \\
\text { theme, and the overall story the analysis tells; } \\
\text { generating clear definitions and names for each theme. }\end{array}$ \\
\hline & Producing the report & $\begin{array}{l}\text { The final opportunity for analysis. Selection of vivid, } \\
\text { compelling extract examples, final analysis of selected } \\
\text { extracts, relating back of the analysis to the research } \\
\text { question and literature, producing a scholarly report of } \\
\text { the analysis. }\end{array}$ \\
\hline
\end{tabular}

The initial phase of thematic analysis includes becoming familiar with the data to identify segments of data that are responsive to the research questions and developing an initial list of codes. This phase of data analysis served as means to identify important words or groups of words in the data and label them accordingly. As a first step, to familiarize myself with the data, I read through each data item individually and noted items of interest being as inclusive as possible. Then, I read and reread through the transcripts, conducting multiple sweeps to start generating codes. A code is a pithy label that captures what is interesting about the data. I aimed to be inclusive, comprehensive and approached the coding systematically. This allowed me to generate initial themes, review the initial 
themes and define and name the themes. These steps were recursive and not completely linear. Coding labels evolved as I moved through the data. According to Braun and Clark (2018), the coding labels one starts with may not be the labels one ends with. I used both semantic and latent codes. Semantic codes capture surface meanings of the data. Latent codes capture assumptions underpinning the surface meanings, or use pre-existing theories and concepts to interpret the data. Young's concepts as outlined in Table 1 in this chapter that focused on social groups, oppression and structural processes informed the analysis and provided a logical structure to connect concepts and show how ideas in the study relate to one another based on her propositions. I conducted several thorough coding sweeps of the data. An example coding extract is provided below.

Table 6: Sample Data Extract

Data Extract
An equity lens tends to be perceived as a product right, as
some sort of check the box rather than what it truly is which
is it's just the ensuring of a process that those individuals
who have historically been left out of the conversations or
historically not had any decision making influence or power
over a decision that impacts them is actually part of those
decisions. And so, the process truly is to identify those
communities and bring them into a process where they now
have influence in decision making power that is in
accordance to how they're going to be impacted in real life
to those decisions so that their perspectives are taken into
account so that there are no unintended consequences that
come from the decision at hand. And so, that's what that
equity lens is trying to get to is it is to create a process that
allows for that to happen."

\section{Data Extract}

An equity lens tends to be perceived as a product right, as some sort of check the box rather than what it truly is which is it's just the ensuring of a process that those individuals who have historically been left out of the conversations or historically not had any decision making influence or power over a decision that impacts them is actually part of those decisions. And so, the process truly is to identify those communities and bring them into a process where they now have influence in decision making power that is in accordance to how they're going to be impacted in real life to those decisions so that their perspectives are taken into account so that there are no unintended consequences that come from the decision at hand. And so, that's what that allows for that to happen."

\section{Coded for}

Equity lens is a process for inclusion not a product

Equity lens ensures communities that have been historically left out are included in decision making

Historically marginalized as groups impacted with little influence

Equity lens as shift of who has power in decision making

Intention of inclusion

Including views of lived experiences to account for unintended consequences Putting communities impacted at the front of decision making 
In the process, I both clustered codes together to collate and build them, and broke other larger codes down into more labels. Then, I searched further to define and name themes. This process was done through several coding sweeps and did not follow a linear approach, but followed a more recursive process moving between data items and searching across the data set to find repeated patterns of meaning (Braun and Clarke, 2006). I ended this phase with a list of codes and all the data relevant to each code collated. Following this, I moved into the third phase that focuses the analysis on broader level themes rather than codes and sorting codes into potential themes. In this step, I collated all the relevant coded data extracts within the identified themes. This process involved considering how different codes may combine to form an overarching theme. As I considered codes to generate themes, I used Braun and Clarke's (2018) guiding questions including:

- Is this a theme (or just a code)?

- If it is a theme, what is the quality of this theme (does it tell me something useful about the data set and my research question)?

- What are the boundaries of this them (what does it include or exclude)?

- Is there enough (meaningful) data to support this theme (is the theme thin or thick)?

- Is the data too diverse and wide ranging (does the theme lack coherence)? I also used visual representation to help sort different codes into themes including tables and mind maps. I concluded this phase with a collection of candidate themes, sub themes, and all the extracts of data that have been coded in relations to them. Individual themes with significance began to emerge and were considered candidate themes. 
As a part of the next phase, I worked to further review and refine the themes. This involved reading all the collated extracts for each theme, and considering whether they appeared to form a coherent pattern. Additional analysis was conducted to refine the candidate themes and develop a refined thematic map. The next step involved considering the validity of the individual themes in relation to the data set and determining if the candidate thematic map reflected the meanings evident in the data set as a whole.

The fifth phase of work began with a finalized thematic map of the data and table of themes. I continued my analysis to help define and further refine the themes. As a part of this, I went back through the collated data extracts for each theme, and organized them into a coherent and internally consistent account, with accompanying narrative with attention to what is interesting about them. I used a combination of conceptual mapping and tables to refine the themes. For each theme, I began to write a detailed analysis to outline how the data relates to the research question and subthemes within each them. Sub-themes served as essentially themes-within-a theme. As a part of the last step of this phase, I worked to clearly define what the themes included by giving them working titles and succinctly describing their content in a couple of sentences. Braun and Clarke (2006) recommend theme labels that are short, punchy, and immediately give the reader a sense of what the theme is about. Further themes should be distinct, but clearly linked back to the overall research question. I worked through theme labels to identify descriptions that were both concise and descriptive, but also reflected the ideas drawn from the data. This went through a process of iteration before landing on final theme names and concise descriptions. Table 7 illustrates the theme names and definitions. Within each of these 
main categories of themes, there were also subthemes that supported and connected to the overall theme that were called out separately within each larger theme.

Table 7: Theme Names and Definitions

Theme Name Theme Definition

Equity lens as a means of Overarching theme that explains perceptions of the equity lens inclusion

and practices as a means of inclusion for individuals and groups that been historically marginalized from policy decision making processes. Participants constructed an equity lens both as an intention and as a series of actions or steps taking when designing a process to identify who participates in the planning process and establishing appointed representation for groups.

Limits of appointed representation
Overarching theme that conveys perceptions of how equity group members were prioritized and selected for representation. The representation of select social groups was generated as theme associated to appointed representation within the planning process. Importance of group size was conceived as factor limiting the number of individuals that were selected to serve on the equity work group. In reviewing the outcomes of the selection process, importance of tending to difference within social groups was generated as a potential limitation in representation.

Restructuring of decision making processes

Overarching theme that explains views on how an equity lens influences the structural process of decision making. The theme initial standing of the equity work group explores the considering position of the equity work group within the planning process. The theme access to decision makers captures perceptions from participants as a factor that influenced decisions on policies within the plan. Time constraints emerged as a theme that placed limitations on decision making. Across both themes is the restructuring of the decision making process as a result of the equity lens.

Institutional environment

An overarching theme that explains factors that influence the use of an equity lens with an institutional environment. Participants constructed policy guidance in a positive sentiment for influencing agency norms and values leading to new practices. Executive level leadership support also emerges as a means for introducing new practices that is intertwined with shifting agency norms and values. 
Lastly, the themes were refined and finalized to report out the themes within the data with supporting evidence. Braun and Clarke (2018) provided guidance for good practices in reporting out thematic analysis in the following table.

Table 8. Braun and Clarke (2018) Guidance for Thematic Analysis

\section{Good Practices in Reporting Thematic Analysis}

- Good balance between analytical narrative and data extracts

- Analytical commentary provides original and novel insights into the meaning of the data

- There is a good fit between the data and analytical claims

- Each theme has a clear central organizing concept and is distinctive

- Each theme is discussed in sufficient depth and detail

- The analysis explains why the data is interesting and important in relation to the research question

Analytical memos and conceptual mapping of the process and participants were used to present the findings from each phase to illustrate the respective data themes and facilitate systematic analysis and reporting (Stake 1995 and Yin 2009). The analysis led to explanation and findings to answer to the study questions.

\subsection{Validity and Reliability}

As Merriam (2009) points out, "All research is concerned with producing valid and reliable knowledge in an ethical manner" (p.209). As such, this study must be able to demonstrate that the findings are credible including both validity and reliability given the data presented. Two main strategies were used to ensure validity of the study findings including respondent validation and researcher position. An audit trail was used as the primary method of reliability. These strategies are described in this section. 
The principal strategy used for validation was respondent validation that entails soliciting feedback on emerging findings from select interview participants. This strategy helped ensure that the meaning of what participants say is not misinterpreted by the researcher and helped identify any biases of the researcher (Merriam, 2009). In this process, I took preliminary analysis back to select participants to determine if they were able to recognize their experience in my interpretation. Another strategy that was used is explanation of the researcher's position. In this strategy, I explained my own biases, disposition and assumptions regarding the research to allow the reader to clearly understand my orientation to the study at hand. This process was completed both through the positionality statement provided in Appendix B and through reflexivity throughout the analysis process. Throughout the document and interview process, I paid particular attention to my own implicit views and perceptions. Further, with the audio recording of the interviews, I was able to review and consider my notes with the language used by participants.

The principal strategy for reliability was the use of an audit trail as suggested by Lincoln and Guba (1985). The audit trail was used to describe in detail how the data was collected, categorized and how decisions were made throughout the inquiry. To construct the audit trail, I kept a series of analytical memos to document the process of conducting the research and what was being done. The memos included the development of my analysis, reflections, questions and decisions made with regard to problems, issues or ideas encountered with collecting data. 


\subsection{Limitations}

There are three main limitations to the study's research design and approach. These limitations include:

- Sample size: The use of a single case study design does not provide the ability to generalize beyond this particular case. Flyvberg (2006) points out that one of the key "misunderstandings" to qualitative research is that general knowledge is more valuable than context specific knowledge. However, general knowledge does not provide context specific information that is often needed to understand a phenomenon under investigation. A single case study was selected for this research because of the nature of the research problem and the path of inquiry presented by the research questions. The purpose of the study was to apply Young's propositions for justice to a particular case to build understanding and augment existing theory. Using this approach, I was able to draw on a wide variety of sources to examine multiple variables and gather a rich holistic account of a particular phenomenon. As a result, others can draw insights from this study that is context specific and may be used to inform future studies.

- Personal bias: My experience as practitioner and as participant in the project may bias how I gathered and interpreted the data. My experience as both a practitioner and participant in the Regional Waste Plan helped inform and shape the research design. I selected this case to study based both on my own interests and access to information and contacts that other researchers may not have. I believe my connection to this study served as an opportunity to provide insights 
that others may not have to contribute. I also believe my relationship with participants in the planning process established trust and helped increase their willingness to talk openly about their experiences. At the same time, I recognized that this relationship may have also influenced individual's response as well as my assumptions for the study. The study included a range of individuals that elicited multiple perspectives to help answer the study questions. I was transparent about my past experience and role in the Regional Waste Plan project with all participants involved and continuously engaged in the process of reflexivity throughout the research process. Further, I used the process of respondent validation to help address research bias and allow participants to confirm my interpretation of their experience.

- Data collection method: Data from interviews relied on the retrospective recollections of participants to identify their role, contributions and interests to the development of the Regional Waste Plan. Relying on retrospective recollections may be an issue if interviews do not recall events clearly and may not be able to answer research questions or recall specific details. Longer recall periods may impose greater challenges for individuals to recall events with great detail. Timing and interview questions attempted to minimize these limitations as the interviews were conducted within a few months of the completion of the Regional Waste Plan planning process. Participants were offered the opportunity to skip questions they could not recall. In addition, participants were invited to review the transcripts following the interview to review their responses. Lastly, 
respondent validation was also used to ensure validity of the findings drawn from the interviewee and to provide interviewees a second opportunity to review their responses.

\subsection{Ethical Considerations}

Ethical considerations are a critical aspect in carrying out this study. To ensure the research process maintained ethical practice, the study included three key considerations. First, free and informed consent was obtained from all the participants in the research through a written consent form. Participants were advised that they may withdraw at any point and could get a copy of their transcript upon request. Second, confidentiality was maintained throughout the study by removing names and other references that could identify individuals. Each interviewee was given a code number to which their comments were assigned. I was the only individual with access to consent forms, the participant list and the assigned codes. Finally, I conducted this research according to Portland State University's Institutional Review Board human subject's research protocol. This adheres to a comprehensive approach designed to protect the rights, safety and welfare of human subjects. This required me complete required training in human subject research and prepare a research proposal for review and approval by Portland State University's Institutional Review Board. My approval was provided in January 2019. 


\section{Chapter 5. Equity Lens Case Study}

"My experience has been enlightening. I have been inspired by Metro's willingness to take risks and promote transformational change."

Juan Carlos Gonzalez, Equity Work Group member

\subsection{Introduction}

This chapter presents an in-depth case study examining the equity lens utilized within the 2030 Regional Waste Plan planning process to gain a better understanding of how an equity lens may change the institutional planning process. First, I provide background information on the governmental agency responsible for developing the 2030 Regional Waste Plan including the history and policy framework for the plan. Next, I provide a detailed account of the development of the plan and use of an equity lens. Lastly, I present the research findings and analysis using Young's theoretical propositions for justice.

\subsection{Background}

\subsubsection{Metro Regional Government}

Metro is the regional government for the Portland metropolitan area, serving more than 1.5 million people in Clackamas, Multnomah and Washington counties in Oregon. The agency's boundary encompasses City of Portland and 23 other cities. It is the only directly elected regional government and metropolitan planning organization in the United States. Metro is governed by a seven-member council that is elected according to geographic districts for four year terms. The Metro Council consists of a president, elected region wide, and six councilors who are elected by district in nonpartisan races. The Metro Auditor, elected region wide, is responsible for oversight of Metro's annual 
financial statements and for conducting performance audits. The council appoints a chief operating officer to carry out council policies and manage the agency budget.

Figure 14. Map of Metro Jurisdictional Boundary

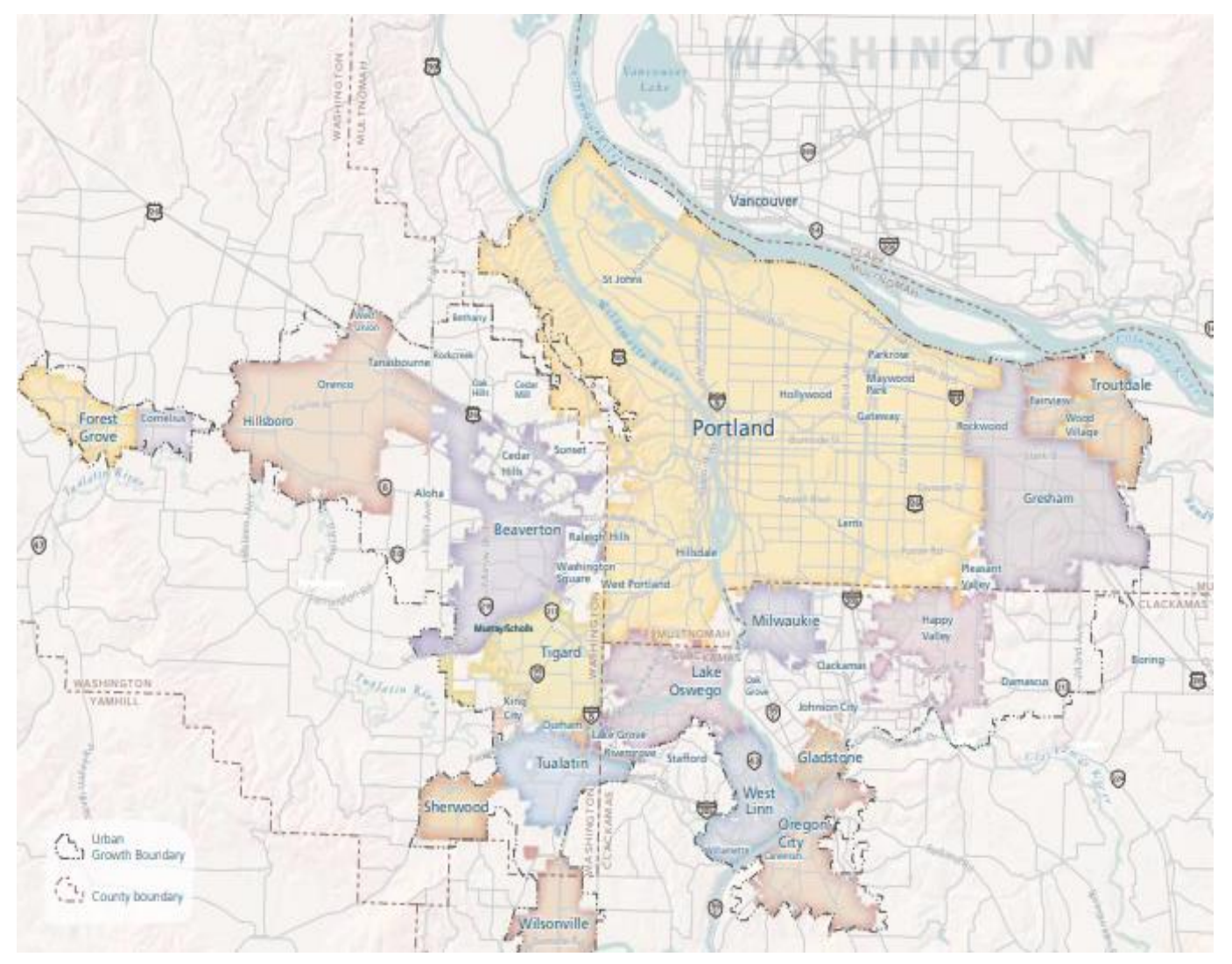

Source: Metro, 2019

Metro was formed in 1970 as metropolitan district designed to improve regional planning and service delivery within the Portland area and is currently the only regional government in the United States. The necessity for a regional government grew out of needs for coordinating transportation, housing and sanitation planning on regional basis to meet federal requirements to receive funding for infrastructure improvements. In 1992, the region's voters adopted the Metro Charter that gave Metro jurisdiction over matters of regional concern. Metro's responsibilities include managing the region's 
garbage and recycling system, coordinating land use and transportation planning for the cities in the region, and managing regional parks and natural areas. As a part of these responsibilities, Metro adopts "functional plans" that address matters of regional significance and require coordinated action by cities and counties. Metro has adopted three functional plans including the Urban Growth Management Functional Plan, Regional Transportation Functional Plan and the Regional Waste Plan that each address different large scale urban systems. These three plans set important direction for the long term development and planning for the urban systems within the region including investments and actions for local cities and counties. The plans are regularly updated at different intervals. In 2016, Metro adopted a Strategic Plan to Advance Racial Equity that endorses the use of equity lenses in planning processes and program development. The Regional Waste Plan was the first large scale functional plan within Metro to formally adopt an equity lens as a part of the planning process to update a functional plan.

\subsubsection{Regional Waste Plan Overview}

The Regional Waste Plan is the greater Portland area's long range plan that sets policy direction for managing and reducing the health and environmental impacts of goods consumed in the region, from production to disposal. This includes more than two million tons of garbage, recycling, and hazardous material. The plan also addresses how residents and businesses can reduce the environmental and human health impacts from the products they buy and use. The plan establishes long term direction for the system by establishing policies, goals and actions to accomplish the plan's vision. The plan includes directive actions to be implemented through Metro and local government code, 
administrative rule or other instruments, and actions that do not require such policymaking such as the program development and services.

Metro worked with local government partners, businesses and communities around greater Portland to develop the plan from spring 2017 to fall 2018. The plan was structured across multiple phases of work and used a variety of mechanisms of participation to engage community groups, local governments, industry and non-profit organizations and Metro as part of plan development. A key aspect of plan development that was different from past plan processes was the use of an equity lens as a part of the planning process. A primary element of the equity lens was the incorporation of an "Equity Work Group" as a part of the plan decision making process. The Equity Work Group was responsible for ensuring that the development of the Regional Waste Plan fully incorporated equity into the planning process and to identify opportunities to leverage Metro's role in managing the garbage and recycling system to support racial equity outcomes (Metro, 2017). Work group members were drawn from the public to represent communities of color and historically marginalized communities. Seven individuals were selected through an open recruitment process where they applied to serve on the work group and were compensated for their participation. Members served on the work group across the 18-month planning process that concluded in October 2018. The work group members participated in each phase of plan development attending 14 work group meetings. In addition, members participated in community engagements such as public meetings and forums throughout the planning process and presented to formal advisory committees that provided input on the plan development. The final plan was unanimously approved in March 2019 by the seven member Metro Council. The adopted 
plan includes policy direction components highlighted in Figure 15 including 19 goals and 105 actions that will guide investments, programs and services for the next 12 years. More than 40 actions were identified as focusing directly on advancing equity and reducing disparities.

Figure 15. 2030 Regional Waste Plan Policy Components

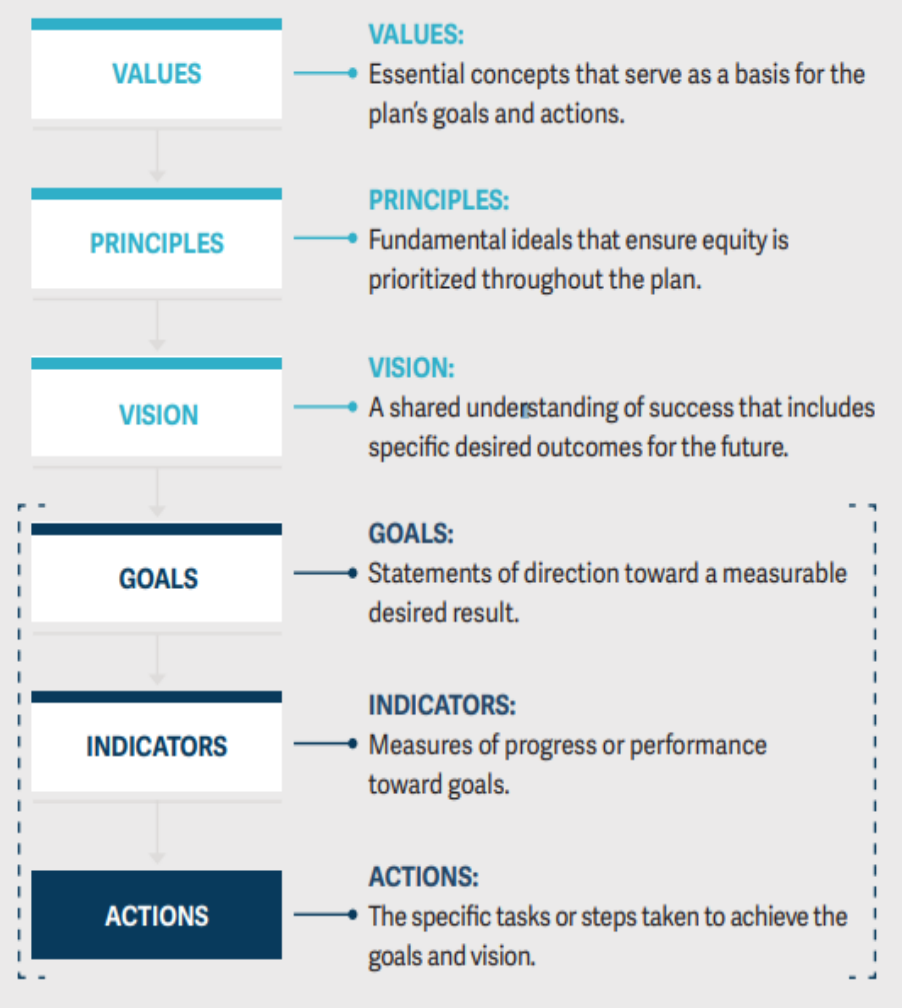

Source: Metro, 2030 Regional Waste Plan, 2019

\subsubsection{History and Legal Foundation of the Regional Waste Plan}

As the regional government, Metro has broad authority, from the Metro Charter, the Oregon Constitution, and Oregon statutes, for planning, managing and overseeing the regional garbage and recycling system (Metro, 2017). Oregon Revised Statutes 268.390 authorize Metro to prepare and adopt functional plans for activities identified by Metro 
Council as regionally significant within the metropolitan area. A functional plan is one that sets out detailed information, policies and standards for a specific function of government, such as transportation, water resources or land use. The plans are used as a vehicle for requiring changes in city and county comprehensive plans in order to achieve consistence and compliance in the designated areas and activities of metropolitan concern. This type of plan follows a general planning process, but has specific requirements for review and adoption. Metro's Regional Framework Plan directs the participation of the Metro Policy Advisory Committee (MPAC) in the preparation of any functional plan and requires MPAC to review and make a recommendation to Metro Council after preparation of the plan and broad public and local government participation. Once an area is designated a functional planning area, it remains through future plans or until the Metro Council changes the designation.

In 1987, the Metro Council designated solid waste as an area and activity appropriate for a functional plan (Metro Ordinance 87-740). The management of solid waste is considered part of a broader strategy of managing the environmental and human health impacts associated with the production, use and disposal of products and materials. Metro has adopted three solid waste system plans to date including 1988, 1995 and 2008. The plans are updated roughly every ten years to meet the needs of the changing region and align with state and federal guidance.

Since the adoption of the 2008 plan, Metro adopted a Strategic Plan to Advance Racial Equity, Diversity and Inclusion in June 2016 to inform the development of all Metro plans, programs and services. This plan sets five goals for advancing regional equity including: 
1. Metro convenes and supports regional partners to advance racial equity.

2. Metro meaningfully engages communities of color.

3. Metro hires, trains and promotes a racially diverse workforce.

4. Metro creates safe and welcoming services, programs and destinations.

5. Metro's resource allocation advances racial equity.

In addition, the plan provides direction for the use of an equity lens in the development of Metro's policies and programs. The definition of an equity lens provided in the Strategic Plan to Advance Racial Equity, Diversity and Inclusion includes:

"A racial equity analysis and decision-support tool that proactively filters out unconscious bias and institutional racism, and counteracts policies and practices that inadvertently maintain inequity” (Metro, 2016, Strategic Plan to Advance Racial Equity, Diversity and Inclusion, p. 58).

As a decision support tool, the equity lens may take the form of a questionnaire to guide the analysis of existing policies, procedures, programs and services to determine how well they advance or hinder the practice of racial equity at Metro. This includes a 13point questionnaire to guide analysis of existing programs and budgets. The questionnaire includes direction to engage the individuals, groups or communities that are most impacted by a policy/procedure/program/ and/or service/investment/decision to learn from their lived experience and enhance value and impact of the application of this tool. Education to raise awareness within the planning process on equity and the use of data to set and monitor goals to achieve equity, and promote accountability and transparency are also called out as components of the equity lens.

\subsubsection{Planning Process for the 2030 Regional Waste Plan}

The development of the plan spanned nearly three years from the pre-planning to plan adoption. The pre-planning phase created a formal project work plan to outline the 
project goal, engagement objectives and approach for developing the 2030 Regional Waste

Plan. The project work plan was endorsed by Metro Council in March 2017 and work on

the plan began shortly after. The project goal outlined in the project work plan included:

The goal of the project is to adopt a Regional Waste Plan that reflects community and regional values, sound technical analysis, input from partners and the public, and advances the region as a leader in conserving resources and protecting the environment. This will be accomplished through an inclusive engagement approach. Engagement efforts will focus on individuals and groups who Metro has not historically engaged in decision-making on garbage and recycling issues, but are significantly impacted by the outcomes of those decisions. Those audiences include communities of color, low-income communities, communities historically impacted by the placement of solid waste and recycling facilities, individuals and families living in multi-family housing, and communities with limited English proficiency. - Regional Waste Plan Work Plan, Metro, 2017

The project work plan outlined five phases of development:

\begin{tabular}{|c|c|}
\hline Getting started & Share work plan with local, regional, state and community partne \\
\hline Phase 1: Values & $\begin{array}{l}\text { Develop a shared understanding of existing policy guidance and } \\
\text { commitment to values that will guide the development of the plan. }\end{array}$ \\
\hline $\begin{array}{l}\text { Phase 2: System } \\
\text { Scenarios and } \\
\text { Vision }\end{array}$ & $\begin{array}{l}\text { Visualize alternative future scenarios to consider tradeoffs of di } \\
\text { paths forward and select a preferred scenario to serve as a visio } \\
\text { plan. }\end{array}$ \\
\hline $\begin{array}{l}\text { Phase 3: System } \\
\text { Analysis and } \\
\text { Goal Setting }\end{array}$ & $\begin{array}{l}\text { Analyze the system to identify priority areas and goals for achi } \\
\text { the region's vision and conduct a gap analysis between the curr } \\
\text { reality and the desired future. }\end{array}$ \\
\hline $\begin{array}{l}\text { Phase 4: Building } \\
\text { a Strategy }\end{array}$ & $\begin{array}{l}\text { Develop short, medium and long-term strategies, initiatives and } \\
\text { investments, prioritized into a single plan. }\end{array}$ \\
\hline $\begin{array}{l}\text { Thase 5: Plan } \\
\text { ddoption }\end{array}$ & $\begin{array}{l}\text { Engage stakeholders in review of the plan and bring to the Me } \\
\text { Council for adoption. }\end{array}$ \\
\hline
\end{tabular}


Each phase was structured to develop a component of the plan guidance. The plan development included community groups, local governments, industry, non-profit organizations and Metro. An equity lens was explicitly highlighted as a part of plan development, and was defined as "asking questions or prescribing a process in order to counteract policies and practices that maintain inequities" (Metro, 2019, p. 35). In the project work plan, and final adopted plan, the equity lens is shown to have been incorporated in each phase of plan development as illustrated in Figure 16.

According to project documentation, the planning process generally followed the approach outlined in the work plan with some adjustments. The first phase was revised to include principles, a new component of plan direction not originally envisioned as a part of the policy document, but produced by the Equity Work Group. The second phase took longer than anticipated and the schedule adjusted course by shifting some of the elements of phase 3 into phase 2 . The last phase was adjusted to provide more time for public comment which extended the schedule by two months. The final timing and phases of

\section{PHASES OF PLAN DEVELOPMENT}

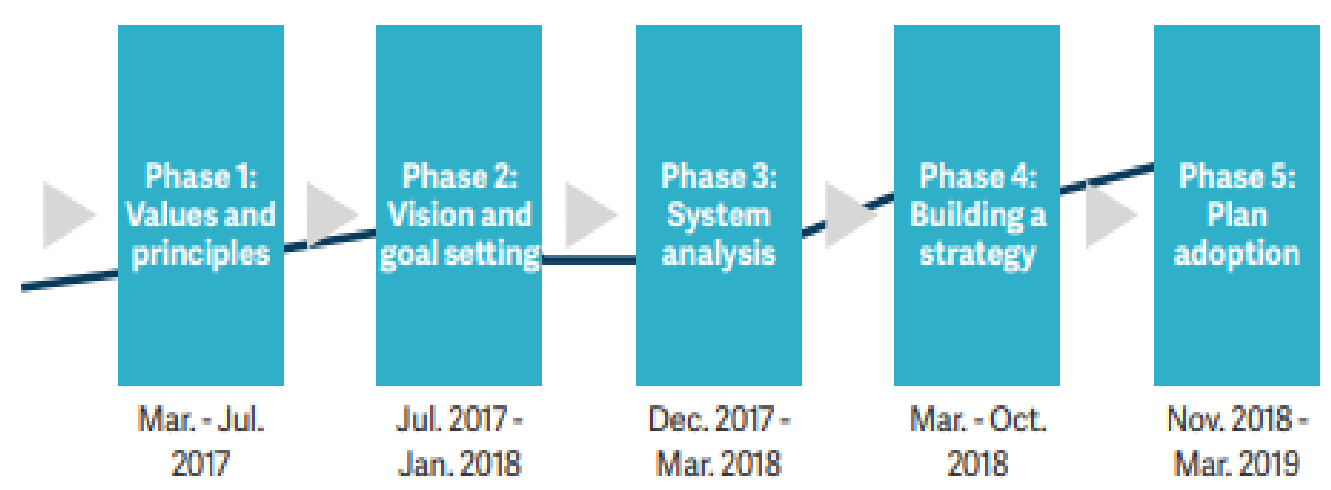

- Equity lens 
work for the plan development are illustrated in the Figure 16.

Figure 16. 2030 Regional Waste Plan Phases of Development

Source: Metro, 2019, 2030 Regional Waste Plan.

\subsubsection{Project Organization}

The development of the 2030 plan involved a wide range of individuals, formal bodies and informal groups. Metro was responsible for the overall development of the plan, engaging others and adoption of the final plan. The formal groups included two advisory committees, the Metro Policy Advisory Committee and Solid Waste Alternatives Advisory Committee. These advisory bodies are established in Metro code to provide recommendations and input to Metro Council on policy and legislative matters. In addition, Metro formed several work groups to provide guidance to the Metro Council and the advisory committees. First, to meet the guidance of Metro's Strategic Plan to Advance Racial Equity, Diversity and Inclusion and incorporate an equity lens in the process, Metro formed a work group, named the Equity Work Group, made up of individuals with expertise and experience working with communities of color and other historically marginalized communities. Metro conducted an open recruitment for selecting individuals to serve on the work group. Members were recruited for participation through interested parties e-mail lists and through referrals by affiliations and relationships with community based organizations. The recruitment documentation identifies the purpose of the work group was to ensure: 1) that development of the Regional Waste Plan fully incorporates equity into the planning process and outcomes and 2) the Regional Waste Plan advances Metro's progress towards the racial equity 
goals adopted by Metro Council. The work group participated in each phase of plan development, working alongside staff to develop the plan components. Individuals selected for the equity work group and affiliations are highlighted in the table below.

Table 9. 2030 Regional Waste Plan Equity Work Group Members

\begin{tabular}{ll}
\hline Name & Affiliation \\
\hline Rob Nathan & Individual; Referred by Coalition of Communities of Color \\
Emma Brennan & $\begin{array}{l}\text { Oregon Tradeswomen, Inc. } \\
\text { Individual; Referred by Asian Pacific American Network of } \\
\text { Oregon }\end{array}$ \\
Pa Vue & Individual; Referred by Oregon Health Equity Alliance \\
Juan Carlos Gonzalez & Individual; Referred by Centro Cultural \\
Andre Bealer & National Association of Minority Contractors of Oregon \\
Tommy Jay Larracas & Individual; Referred by OPAL Environmental Justice Oregon \\
\hline Source: Metro, 2017, Staff Report.
\end{tabular}

Second, Metro convened a set of technical work groups related to system priorities identified in phase 3 of the plan development. The work groups developed draft actions to meet the goals. Equity work group members also served on the technical work groups. In addition, Metro conducted a separate series of engagement with communities of color and other historically marginalized communities around greater Portland to help inform plan development.

At the staff level, Metro's Property and Environmental Services Department assembled a team to coordinate the plan development. The department director served as the project champion, representing the project on an executive level, linking the project to department efforts, and expediting issues of importance. The Resource Conservation and 
Recycling program director served as the project sponsor, assisting with project direction, reviewing deliverables and monitoring team performance. A team of planners in Metro's Property and Environmental Services Department coordinated the planning process and staff from the Office of Diversity, Equity and Inclusion served as the Equity Work Group facilitator and assisted with the design of the planning process. The participants and roles for the plan development are outlined below.

Table 10. Regional Waste Plan Roles

\begin{tabular}{|c|c|}
\hline Participants & Description \\
\hline Equity Work Group & $\begin{array}{l}\text { An informal body that was comprised of seven members } \\
\text { drawn from the community to represent communities of color } \\
\text { and historically marginalized communities. This body } \\
\text { participated in each phase of plan development. }\end{array}$ \\
\hline Technical Work Group & $\begin{array}{l}\text { A set of informal work groups including representatives from } \\
\text { Metro, local governments, businesses, community } \\
\text { organization, Equity Work Group and non-profits that helped } \\
\text { develop the plan actions. }\end{array}$ \\
\hline $\begin{array}{l}\text { Solid Waste Alternative } \\
\text { Advisory Committee }\end{array}$ & $\begin{array}{l}\text { A formal advisory committee to Metro Council that was } \\
\text { comprised of } 14 \text { members drawn from local governments, the } \\
\text { solid waste industry, Oregon Department of Environmental } \\
\text { Quality, a non-governmental organization with a } \\
\text { sustainability focus, and Metro. This body provided input on } \\
\text { each phase of plan development. }\end{array}$ \\
\hline $\begin{array}{l}\text { Metro Policy Advisory } \\
\text { Committee (MPAC) }\end{array}$ & $\begin{array}{l}\text { A formal advisory committee to Metro Council on policy } \\
\text { issues and includes members representing cities, counties, } \\
\text { special districts and the public. This body provided input on } \\
\text { each phase of plan development. }\end{array}$ \\
\hline Metro Council & $\begin{array}{l}\text { The elected body that governs over the tri-county area } \\
\text { including seven members elected by geographic district. The } \\
\text { council served as the final decision making authority of the } \\
\text { plan. }\end{array}$ \\
\hline Metro steering team & $\begin{array}{l}\text { An informal body comprised of Metro management and staff } \\
\text { that directed and managed the plan development. }\end{array}$ \\
\hline Metro project team & $\begin{array}{l}\text { An informal body comprised of planners that were } \\
\text { responsible for designing the process, managing the ongoing } \\
\text { work of the project, completing assignments and making } \\
\text { recommendations to the steering team. }\end{array}$ \\
\hline
\end{tabular}

Source: Metro, 2017, 2030 Regional Waste Plan Project Work Plan 


\subsubsection{Decision Making Structures}

The decision making structure for the planning process and plan adoption included both the formal and informal bodies. Metro Council served as final decision making authority of the plan. The Metro Policy Advisory Committee and Solid Waste Alternatives Advisory Committee provided input at key decision points. The project documentation indicates that the process for communication and reviewing draft plan components are to be taken first to the advisory committees and then to Metro Council. Input from the Equity Work Group and Technical Work Groups were summarized by staff in reports that went to both the advisory committees and Metro Council. Metro Council made final decisions on how to incorporate input into the final plan based on staff recommendations. The project work plan outlined a decision making structure highlighted in following figure.

Figure 17. Regional Waste Plan Decision Making Structure

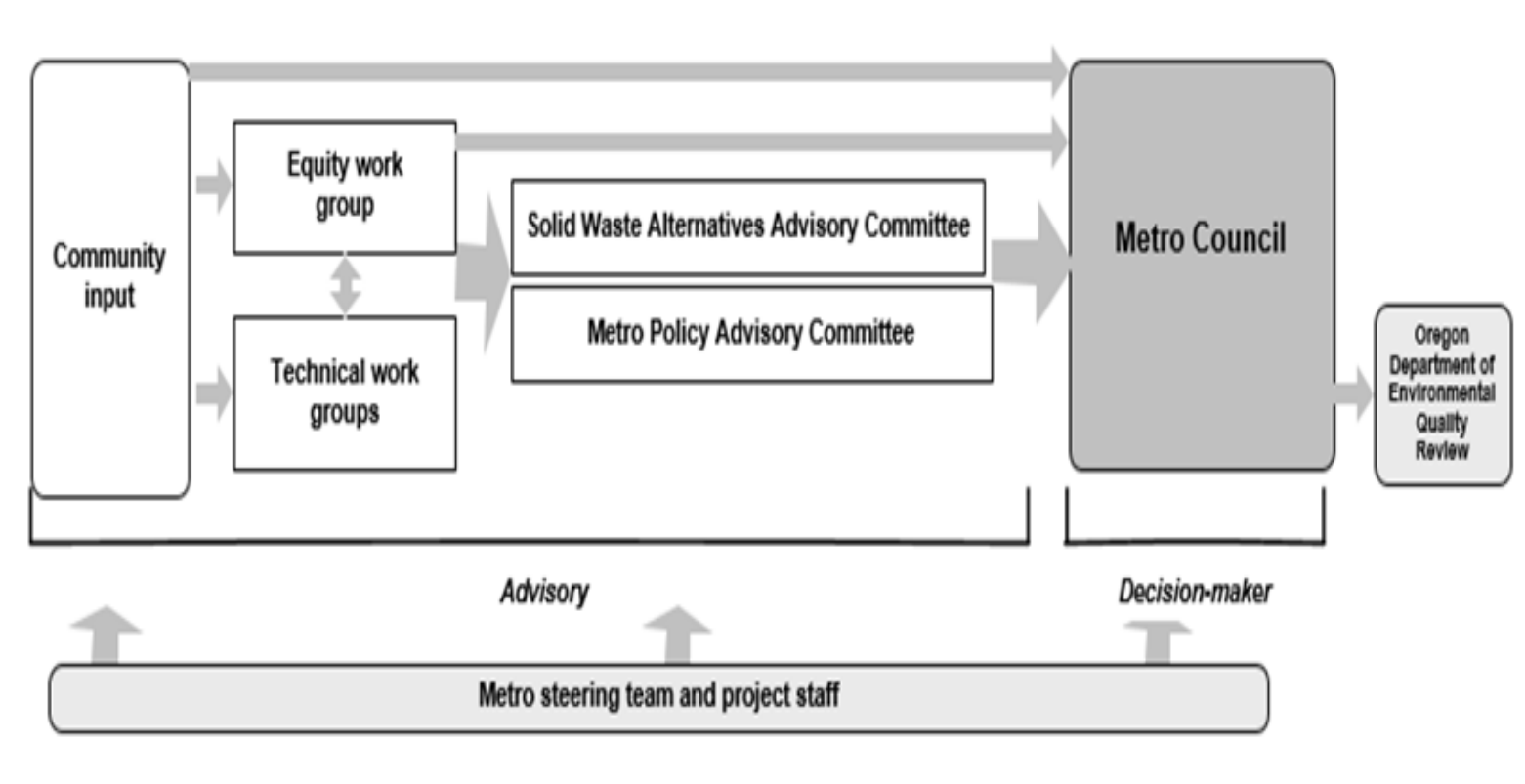

Source: Metro, 2017, 2030 Regional Waste Plan Project Work Plan 
According to the staff reports, the decision making structure was consistent throughout the planning process. Metro Council unanimously adopted the plan in March 2019.

\subsection{Research Findings}

This study seeks to describe and analyze the use of an equity lens in the planning process for the 2030 Regional Waste Plan. The equity lens conceptualization is rooted in academic origins of structural theories of justice. From this view, the practice of an equity lens is a means to reform structures, policies and processes that perpetuate inequities. The primary research question was: How does an equity lens change the institutional planning process? Supporting questions included:

- How is an equity lens defined by planners, policy makers and participants in the planning process?

- How are social groups identified and selected for special representation as part of the equity lens in the planning process?

- How does an equity lens influence the structural process of decision making?

- How does the institutional environment influence the use of the equity lens?

Answers to these questions help build understanding of how an equity lens is defined in practice, the features of an equity lens that incorporate special treatment for historically marginalized groups in the decision making process and how an equity lens may have restructured decision making within a planning process in this case. This section presents the findings from the data collection and analysis in response to the research questions. First, I review the data sources and analysis process discussed in Chapter 4. Then, I present key findings generated from the data.

To answer the research questions and expand my personal knowledge and experience of the case, data was drawn from a wide variety of documentary materials and interviews. 
This included extensive document research where data was gathered from public documents associated with the development of the Regional Waste Plan including meeting minutes, progress reports, agendas, work plans, media reports and planning documents. Prior plans were also reviewed to understand how the planning processes were structured in the prior version of the plan. In addition, semi-structured interviews were used to provide a more in-depth understanding from multiple views of participants. This included 21 semi-structured interviews with Metro Councilors that served as the final authority on the plan adoption, individuals directly involved in the application of the equity lens including project planning staff and Equity Work Group members and department leadership that oversaw implementation of the planning process. Each interview provided a specific perspective on the planning process and use of the equity lens.

The data collected from these sources was interpreted and analyzed in the context of Young's propositions of justice. Her concepts of social groups, oppression and structural processes and institutional conditions provided a logical structure to connect concepts and show how ideas in the study relate to one another based on her propositions. Results from the data analysis and interpretation are organized by research question and the associated themes that were generated from the data. Each theme contains a central organizing concept that captures a central point of coherent and meaningful pattern in the data that addresses the research question (Braun and Clarke, 2016). The themes are further broken out into sub-themes with a description of the meaning and what the theme is about with supporting information from the data collection. 


\subsubsection{How is an equity lens defined by planners, policy makers and participants in the planning process?}

One of the initial areas of investigation I considered was how an equity lens is defined in practice and constructed by participants in the 2030 planning process. Specifically, the study investigated how an equity lens was defined from multiple views of individuals participating in a planning process. This investigation revealed both the language and terms used to define an equity lens from the perspective of planners, elected officials and Equity Work Group members engaged in the planning process and provides insights into how the term equity lens is understood and used in practice. Young's concepts of conditions of oppressions, social groups, and social structures and processes were key to interpreting these views.

The interview data generated an overarching theme of equity lens as a means of inclusion for individuals and groups that have been marginalized from the policy process. Inclusion is defined using Young's concept of structural inequalities. She contends structural inequalities exist as processes within decision making that advantage some groups and disadvantage others. In this view, inclusion is associated with the capacity of oppressed groups to participate in the political process. Within the 2030 Regional Waste Plan planning process, participants' constructed an equity lens as form of inclusion in the following ways: as an intention to address social disparities in the planning process and as a series of actions or steps taking when designing a process to identify who should participate in the planning process and establishing appointed representation for historically marginalized groups. The major themes and sub themes generated in 
response to the research question are summarized in the table below. Each sub-theme is given special attention in the following sections.

Table 11. Definition of an Equity Lens

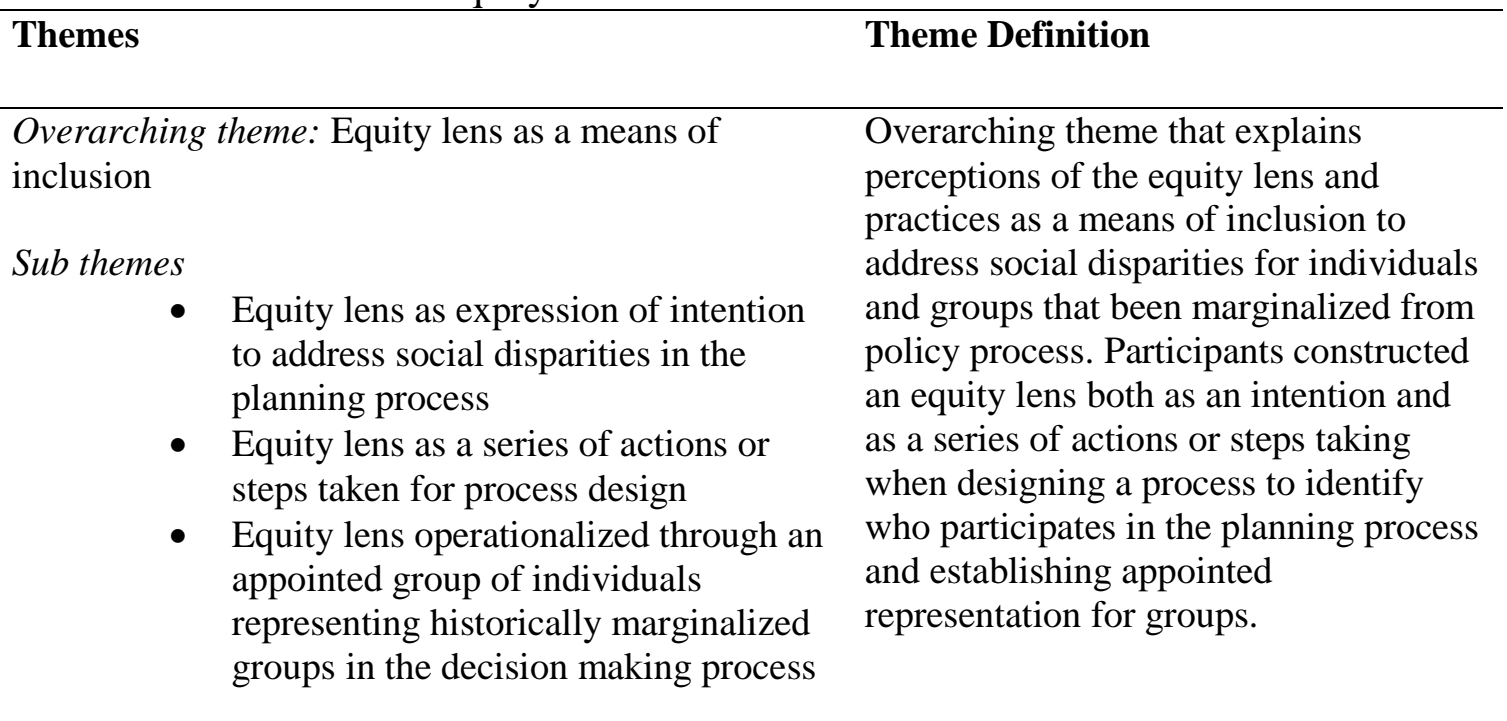

\section{Equity lens as expression of intention to address social disparities in the policy process}

At the elected official and leadership level, individuals defined an equity lens not as a tool but as an intention or way of thinking. The stated use of an equity lens in 2030 Regional Waste Plan was perceived by Metro Councilors as acknowledgement of inequities that have been experienced by specific social groups and an expression of intention to address these disparities as part of the development of the 2030 Regional Waste Plan. Individuals conveyed that identifying the use of an equity lens as a part of the planning process set expectations of how work would be done, expressing the intention to be more inclusive in decision making for marginalized communities and recognition of the level of impact and influence policies have on different social groups. Interviews often spoke about inclusion in relationship to historically marginalized communities and communities of color. Interviewees commented: 
Individual understanding of an equity lens is to center the folks who are most vulnerable or would be most impacted by changes or decisions in the system in the planning process.

The equity lens that was used was about being more inclusive, for people who are not often asked to be part of these conversations through Metro or part of these conversations about work that Metro is doing.

We can all agree that we came from this place of acknowledging that people have been excluded from decision making spaces institutionally and structurally and we wanted to actively include people.

I think that what we determined was the lens was a way of thinking.

In the context of Young's work, this represented a shift from a universal point of view to one that recognizes particularities of social identity. Young (1990) argues that policies that are universally formulated are blind to social group difference and assume norm capacities, values and behaviors of dominant groups. This approach can perpetuate rather than undermine oppressed groups by not acknowledging that some social groups such as communities of color have been historically disadvantaged, which impacts the group's capacity to engage in the political process. As described in the project documentation, the equity lens was defined as a tool or process to counteract inequities. The interviews expanded this understanding by revealing the views of the project staff and leaders, Metro Councilors and Equity Work Group members. The accounts conveyed in the interviews as well as policy documentation conveyed a new view that recognizes the particular aspects of social identity including race, class and gender and calls attention to these differences in the policy process and prioritizing these groups for inclusion. However, the methods and practice of what this intention meant within the 
design and decision making of the planning process and how it was achieved was less clear to individuals at elected official and management level.

\section{Equity lens as a series of actions or steps taken for process design}

In contrast, staff on the project team who were responsible for defining and designing the equity lens provided a more specific view on the practice of an equity lens. A theme that was generated from staff interviews was an equity lens as actions or steps taken to design a process. In Young's view, these actions or steps lead to the design of decision making processes that may advantage some groups and disadvantage others. In this context, staff described the actions as identifying who is positively or negatively affected by the issue under consideration, taking into account historical and present context, considering level of influence of groups and individuals in decision making and prioritizing specific groups or individuals for participation in the planning process. Project staff involved in the development of the equity lens for the 2030 Regional Waste Plan stated:

An equity lens to me is not a tool, but a process. And, it starts with asking the questions about who to involve and then figuring out what to do about it.

An equity lens tends to be perceived as a product right, as some sort of check the box rather than what it truly is, which is ensuring a process for those individuals who have historically been left out of the conversations or historically not had any decision making influence or power over a decision that impacts them is actually part of those decisions. And so, the process truly is to identify those communities and bring them into a process where they now have influence in decision making power that is in accordance to how they're going to be impacted in real life to those decisions so that their perspectives are taken into account. And so, that's what that equity lens is trying to get to--it is to create a process that allows for that to happen. 
The questionnaires that can be used (as an equity lens) tend to be questionnaires that make sure you've created the process rather than ask questions about the decision itself.

We start out by answering how are we meaningfully involving people of color and others who have traditionally been underrepresented in these kind of processes in in this work by doing our stakeholder matrix and then thinking around then to make sure we knew who we were talking about and who we weren't. Then, we developed a concerted plan on how to do address what we found.

A project team member also commented on the lens as actions taken to design a process to shift power stating:

The lens is also about creating a new environment to shift power to those who have been historically marginalized, so a "lens" can be so many things. It just depends on the situation. This has become a source of confusion for many because many people who do not understand the intent of the equity lens, just assume that a lens is a plug and play tool rather than something that is built to fit the circumstance to get to the intention of shifting power.

The interviews revealed that questions for the design of the 2030 Regional Waste Plan process focused primarily on the "who" should be involved in decision making with the intention of shifting power. The focus of who should be included was centered on what the agency had identified as historically marginalized communities and communities of color within guiding policy documents. Metro’s 2016 Strategic Plan to Advance Racial Equity includes the following definitions:

Historically marginalized - A limited term that refers to groups who have been denied access and/or suffered past institutional discrimination in the United States and, according to the Census and other federal measuring tools, includes African Americans, Asian Americans, Hispanics or Chicanos/Latinos and Native Americans. This is revealed by an imbalance in the representation of different groups in common pursuits such as education, jobs, housing, etc., resulting in marginalization for some groups and individuals and not for others, relative to the number of individuals who are members of 
the population involved. (Metro Strategic Plan to Advance Racial Equity, Diversity and Inclusion, 2016) .Other groups in the United States have been marginalized and are currently underrepresented. These groups may include but are not limited to other ethnicities, adult learners, veterans, people with disabilities, lesbian, gay, bisexual and transgender individuals, different religious groups and different economic backgrounds. (University of California, Berkeley, 2015, Berkeley Diversity - Glossary of Terms.)

Communities of Color - For the purposes of this plan, Communities of Color are Native Americans, African Americans, Asian Americans and Pacific Islanders, Latinos or Hispanics, and immigrants and refugees who do not speak English well, including African immigrants, Slavic and Russian speaking communities, and people from the Middle East. (Metro Strategic Plan to Advance Racial Equity, Diversity and Inclusion, 2016)

Within these groups, staff pointed to a "stakeholder power analysis tool" that was used as a part of the process design to identify groups for inclusion and to prioritize how groups would be included in decision making. The definitions of historically marginalized communities and communities of color were the larger categories to identify specific social groups. Although stakeholder analysis, the process by which one identifies individuals that have a "stake" or interest in a policy issue, was not a new concept when designing planning approaches, the concept of "power" as a part of the analysis was distinct. Power in this context, was categorizing social groups based on the level of influence over the policy issue or access to decision makers and level of impact related to the policy issue at hand. This is consistent with Young's (1989) view of power that contends some citizens have more social power than others and this should be accounted for in the design of decision making processes. According to staff, those

${ }^{1}$ City of Portland, Stakeholder Analysis Tool. 
individuals or groups with the least influence and highest impact were the top priority of groups to determine how to best include in the planning process. Therefore, intent of the tool as expressed by staff is consistent with Young's understanding of social power. At the same time, this also brings to light the authority and influence distributed to staff in the decision making conducted with the use of the power analysis tool. Young (2003) contends that individuals are each situated in institutional or social positions in structures that produce unjust outcomes, which afford different opportunities and capacities for influencing those outcomes. This brings attention to the individuals that serve as the decision makers in conducting the analysis and designing the process that ultimately influence how the planning process is designed and how different social groups are included in decision making. Young argues that it is the responsibility of individuals that have the ability to influence processes to address structural injustice.

Figure 18. Stakeholder Power Analysis Tool

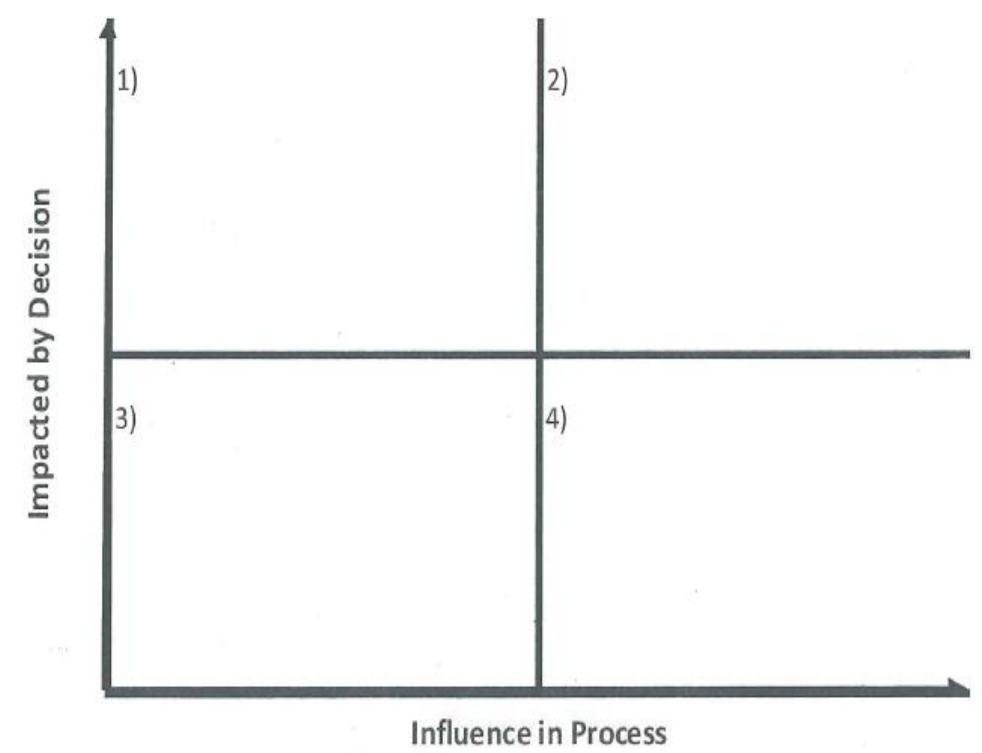

Source: City of Portland, 2016 


\section{Equity lens operationalized through an appointed group of individuals representing}

\section{historically marginalized groups in the decision making process}

A key aspect of the equity lens as defined by staff was appointing representatives from communities most affected to work directly with staff to inform decision making and ensure equity considerations were identified throughout the planning process. City of Portland had convened an Equity Work Group, comprised of representatives of community based organizations, to inform the development of the city's Climate Action Plan. Drawing inspiration from this example, Metro staff crafted a proposal for a work group focused on equity to participate in the planning process. Staff conveyed the work group was informed by the definition of equity lens in the Metro's Strategy to Advance Racial Equity that identifies both questions and communities most impacted answering the questions. Thus, the conception of the work group was to co-develop and answer questions drawn from the racial equity guidance questionnaire in Metro's Strategic Plan to Advance Racial Equity throughout plan development. However, staff pointed out that the role of the group evolved through the planning process. Staff commented:

I think that we did the best that we could and what we thought would be the most effective, which was to have a group of individuals that have specialty areas and areas of expertise within DEI (Diversity, Equity and Inclusion) to advise the plan from beginning to end.

The equity work group brought the strategic plan to advance racial equity to life in the context of this plan. They helped to take generalities and make them specific to the Regional Waste Plan.

The equity work group was bringing another planning team essentially to work in parallel with the main with Metro planning team. 
Many staff and Equity Work Group members perceived the group itself as becoming the equity lens. One project team member described the Equity Work Group as an embodiment of a lens that served as the "literal filter" for nearly all the planning work. Another staff commented:

We originally developed the work group to co-develop the lens, but they actually became the lens.

The newness of an equity lens and variety of ways it is defined and used in practice allowed for staff and members of the Equity Work Group to design and evolve the practices related to the equity lens. Although having an appointed of group of individuals representing marginalized groups in the planning process was a key component of the equity lens at the onset, the ongoing role of the group tending to equity considerations reinforced the notion that the equity lens was not a static in this context. In Young's framework, the equity lens served as the mechanism for addressing institutionalized oppression and domination by increasing representation of marginalized groups in the decision making process.

\subsubsection{How are social groups identified and selected for special representation as a part of the equity lens in the planning process?}

Another key area of inquiry was the incorporation of special representation for historically marginalized groups in the decision making processes for developing the plan. According to Young (1989), to develop just norms and social conditions requires the provision of "mechanisms for the effective representation and recognition of the distinct voices and perspectives of those of its constituent groups that are oppressed or disadvantaged within it" (p.261). Since privileged groups already have representation, 
special representation is only necessary for oppressed groups. Central to her approach is the concept of social group that focuses on personal identity rather than economic interest and the conditions of oppression that occur to a part or all of a group including exploitation, marginalization, powerlessness, cultural imperialism and random violence and harassment (Young, 1990). As discussed in the previous section, the Equity Work Group was established as a component of the equity lens to provide representation for perspectives that have previously been excluded from this type of planning process. The study investigated how social groups were selected and prioritized for representation in the planning process in the context of Young's definition of social groups.

The data generated an overarching theme of the limits of appointed representation that conveys perceptions of how equity group members were prioritized and selected for representation. The representation of select social groups was generated as a theme associated with the selection of the Equity Work Group members in the planning process. Importance of group size was conceived as factor limiting the number of individuals that were selected to serve on the equity work group. In reviewing the outcomes of the selection process, importance of tending to difference within social groups was generated as a potential limitation in representation. The major themes and sub themes generated in response to the research question are summarized in Table 12. Each sub-theme is given special attention in the following sections.

Table 12. Limits of Appointed Representation

\begin{tabular}{ll}
\hline Theme Name & Theme Definition \\
\hline $\begin{array}{l}\text { Overarching theme: Limits of appointed } \\
\text { representation }\end{array}$ & $\begin{array}{l}\text { Overarching theme that conveys perceptions of } \\
\text { how Equity Work Group members were } \\
\text { prioritized and selected for representation. The } \\
\text { representation of select social groups was } \\
\text { generated as theme associated with the selection }\end{array}$ \\
\hline Representation of select groups & 112
\end{tabular}


- Importance of group size

- Importance of tending to difference within social groups of the Equity Work Group members in the planning process. Importance of group size was conceived as factor limiting the number of individuals that were selected to serve on the equity work group. In reviewing the outcomes of the selection process, importance of tending to difference within social groups was generated as a potential limitation in representation.

\section{Representation of select groups}

Seven individuals were selected by Metro staff to serve on the Equity Work Group for developing the 2030 Regional Waste Plan. Prioritization for groups for special representation was initially based on direction from Metro's Strategic Plan to Advance Racial Equity that prioritizes historically marginalized communities and communities of color for inclusion in planning process. The recruitment for the Equity Work Group members sought individuals from communities of color and those historically marginalized from system planning and policy development, including but not limited to:

- Young adults ages $18-25$

- Immigrants and refugees

- Seniors and elders

- Oregon COBID-certified business owners in the garbage and recycling field

- Environmental justice practitioners

- Garbage and recycling system workers

The recruitment also sought individuals for skills and background:

- Background in social and racial equity at both institutional and systemic levels

- Willingness to adapt Metro's equity lens and apply it to the regional garbage and recycling system

- Critical thinking skills to identify ways that the current garbage and recycling system is inequitable 
- Ability to help articulate a vision for an equitable garbage and recycling system

- Familiarity with planning processes or a willingness to learn

- Ability to effectively collaborate with others

Within these groups, staff prioritized individuals with prior government or policy experience for participation in the planning process. Project staff stated:

Through the application process we focused recruitment on individuals that had a bit more experience with policy and working with government to ensure that they were set up to succeed to really advance racial equity within this kind of larger more government focused kind of process.

Information was posted on the organization's web site and letters and emails were sent to an interested parties list. Interested individuals submitted letters of interest and resumes to apply for the work group. As a part of the application process, individuals selfidentified with racial categories and some were affiliated with specific community organizations. Staff commented:

I think we went through a thoughtful process of trying to identify the members of that group to get representation that was reflective of the communities we wanted to reach, with attention to gender, geographic location in addition to work and lived life experience.

The final selection was completed by Metro staff serving on the project team and approved by the department director. There was not an explicit effort to ensure individuals with different racial background served on the selection committee. Metro received more than 20 letters of interest and applications from individuals interested in serving on the committee. In selection of the final membership, staff also tried to balance gender, geographic representation, and expertise in selection of the final membership. 
Seven individuals were selected to serve on the work group including six people of color, three women and four men. All members were under the age of 40 .

Figure 19. Composition of Equity Work Group by Gender, Race and Age

\begin{tabular}{|c|c|c|c|}
\hline \multicolumn{2}{|c|}{ Gender } & Age \\
\hline 3 & & \\
\hline
\end{tabular}

Affiliations for the Equity Work Group members were cited on project documentation and interviews further identified specific interests of members. Some group members were specifically affiliated with community organizations, while others were referred by an organization. Group members had the option of formally representing a group or serving as an individual.

Figure 20. Equity Work Group Initial Mapping of Interests

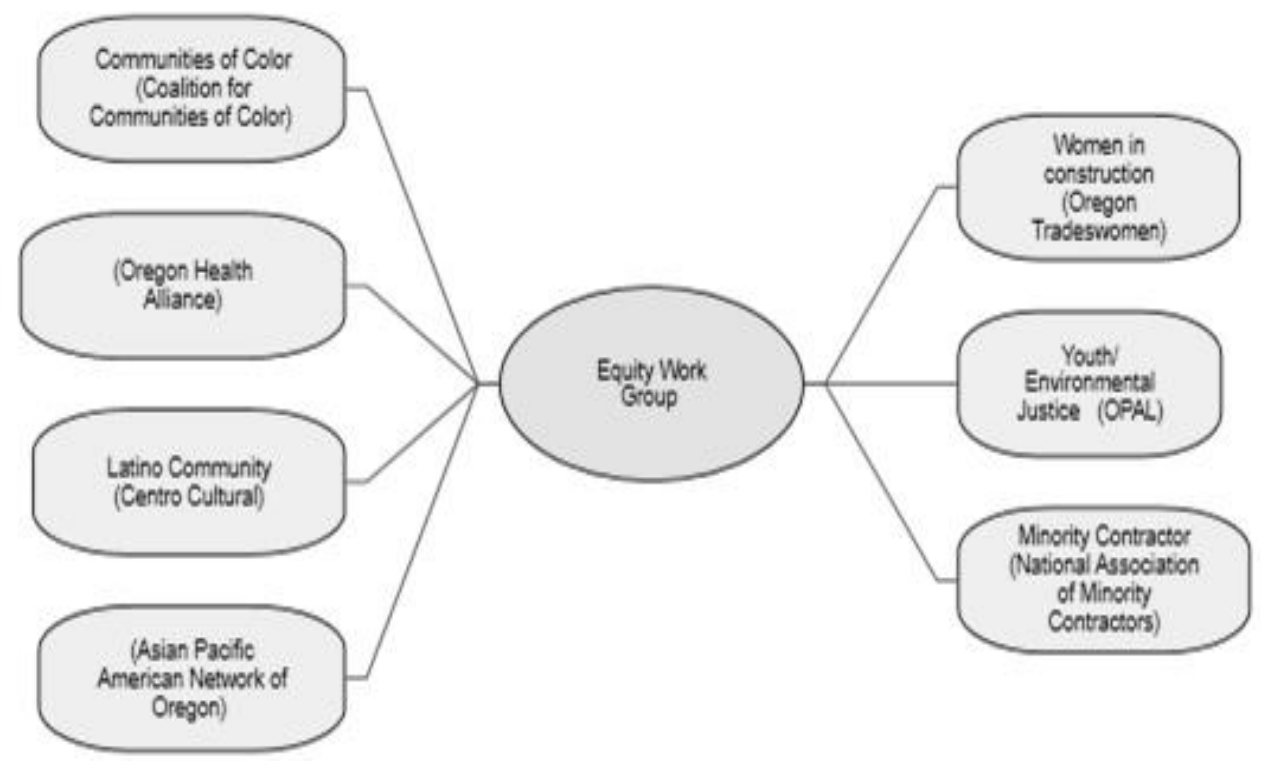


The self-identification and interests of the work group members reveals both diversity of interests and some lack of diversity in representation. In comparison to the selection criteria used for recruitment, the group members all identified with one of the broader categories of communities of color and historically marginalized communities. Within those categories of groups individuals identified with one of the following groups: young adults, environmental justice, immigrants, Oregon certified business owners in the garbage and recycling field. Although the group as a whole was diverse, the group lacked diversity in age. In Young's view the larger categories constructed for the Equity Work Group member selection connected with the one or more of her conditions of oppression. However, the selection process did not include an in-depth evaluation on historical impacts of the systems on social groups in the Portland metro area within the garbage and recycling system, which presents questions on how groups were prioritized for representation. In addition, the selection and recruitment process highlighted the authority and influence provided to staff in making the decisions on selection of individuals for group representation. This further highlights an additional decision making process that involved the power and influence of staff for deciding how different social groups are included in decision making that impacts the extent to which a planning process may address structural inequalities.

\section{Importance of group size}

An important consideration discussed by staff in the interviews was the size of the equity work group. The decision to limit the group membership to seven individuals was intentional and with the understanding of the implications to representation. Staff 
expressed a smaller size would be more productive and provide more space for dialogue on decisions. Staff commented:

One thing that we did identify is that we didn't want this group to be too big. You see other processes that have had an equity advisory group that's leading the conversation had a group of like 60 people on it. It's extremely representative of the community, but nothing gets done because it's just too big and there's too many voices to manage that makes it overwhelming.

Both staff and members of the work group commented that the group size allowed the group to have more in-depth discussions on issues. At the same time, staff noted the limitations of representation when forming a group with size limits and recognized there were there groups missing representation such as Tribal nations and seniors.

\section{Importance of tending to difference within social groups}

Both staff and equity work group members also expressed concern about the large categories used to group individuals and that those groupings do not account for differences within social groups and could operate to exclude. Specifically, within groups there are also differences that cut across identities such as disabilities, gender, age and income. An equity work group member commented:

I identify as a person of color, but underneath any individual identify there are additional identities like people with disabilities, queer people, and elders.

This calls to question the extent to which an individual can speak for an entire group and how to account for difference that cut across identities. As Young (2011) asserts, in affirming "a positive meaning of a group specificity people seek or try to enforce a strong sense of mutual identification, they are likely to reproduce exclusions similar to those they confront" (p.236). Staff also pointed out that within the larger category of 
communities of color there are differing social groups that experience different disparities. In the selection of the Equity Work Group membership, staff noted in project closure documents that there were gaps in representation for groups within communities of color that have experienced differing impacts related to the policies and programs within the 2030 Plan including seniors, Native American communities, rural communities, individuals with disabilities, low income communities and residents of communities that host garbage and recycling facilities. Further, as a part of the selection of groups for representation, there was no prioritization of social groups that were included in the larger categories of communities of color and historically marginalized.

\subsubsection{How does an equity lens influence the structural process of decision making?}

The study also investigated how an equity lens influences the structural process of decision making using Young's propositions and framework for structural justice. As discussed in Chapter 3, Young defines social justice as the elimination of institutionalized domination and oppression. Within the planning process, institutionalized oppression exists within decision making processes used to formulate policy that create structural inequalities where these processes may tend to privilege some social groups more than others. Young (1989) contends to address this inequality we must provide a means within institutional practices to recognize and ensure representation of politically marginalized groups. The Equity Work Group was established as a component of the equity lens to provide representation for perspectives that have previously been excluded from this type of planning process. Document review and interviews sought to determine how the views of the Equity Work Group were included in the decision making process and to what 
extent this influenced decision making and the representation of views and interests of oppressed groups in policy solutions. In particular, the study investigated how and when the Equity Work Group participated in the planning process, and how views and interests were communicated and considered in the decision making process.

Interviews revealed specific details on the timing and sequencing in which the Equity Work Group participated in the decision making. Interview data generated an overarching theme that explains views on how an equity lens influences the structural process of decision making. Participants constructed representation of distinct voices in a positive sentiment in relationship to the Equity Work Group participation within the planning process. The theme initial standing of the Equity Work Group explores the considering position of the equity work group within the planning process. The theme access to decision makers captures perceptions from participants as a factor that influenced decisions on policies within the plan. Time was viewed by participants as a constraint on the decision making process. Across these themes is the restructuring of the decision making process as a result of the equity lens. The major themes and sub themes generated in response to the research question are summarized the table below. Each subtheme is given special attention in the following sections.

Table 13. Restructuring the Decision Making Process

\begin{tabular}{ll}
\hline Theme Name & Theme Definition \\
\hline $\begin{array}{l}\text { Overarching theme: } \text { Restructuring the } \\
\text { decision making process }\end{array}$ & $\begin{array}{l}\text { Overarching theme that explains views on how an } \\
\text { equity lens influences the structural process of } \\
\text { decision making. Participants constructed } \\
\text { representation of distinct voices in a positive } \\
\text { sentiment in relationship to the Equity Work Group } \\
\text { within the planning process. The theme initial } \\
\text { standing of the equity work group explores the } \\
\text { considering position of the equity work group }\end{array}$ \\
voices & 119
\end{tabular}


- Initial standing of the Equity Work Group

- Access to decision makers

- Time constraints within the planning process. The theme access to decision makers captures perceptions from participants as a factor that influenced decisions on policies within the plan. Time constraints emerged as a theme that placed limitations on decision making. Across these themes is the restructuring of the decision making process as a result of the equity lens.

\section{Representation of distinct voices}

Interviews with the Equity Work Group members presented multiple views on representation of interests within the planning process. Individuals expressed a view of representing ones "own experience" and informally representing specific communities. Members commented:

I, as a person of color, represent my own experience. And then, just like experiences shared by others that I could communicate out. So, I think that was largely my identity.

I felt I represented the African-American community which I engage with the most and have my own personal and experience connection with, but was also mindful of the things that I was hearing from my Latinx leaders, Islamic leaders, Asian Pacific Islanders, Native Americans and African immigrants all of those voices you know inspired my approach. All of those communities have different, unique challenges and needs.

I represented myself and my views, but also the informed by my community. Because you need lived experience, you need people that can interpret and digest and make a make recommendations. The lived experience of those individuals who are actually answering questions makes a difference.

In all the interviews, how an individual self-identified or organizations they were affiliated with influenced their view of what perspectives and interests they represented as a part of the work group members. Although many called attention to the difficulty in being able to speak for an entire group or community, work group members accounted 
for a sense of responsibility of bringing in views of others from the community in which they self-identified with representing as part of the process. Discussion with interviewees also revealed accounts that called attention to the importance of an individual's personal experience and how this informed their worldview. Staff also recognized the position and view that the equity work group members brought to the discussion commenting:

I think they were representing communities of color and they brought their individual lens of those lived experiences. I think someone wasn't singularly representing the Latino community, but speaking about race generally and the impact of racism and exclusionary policies that prevented people from benefiting the system.

I believe they represented their own viewpoint that's based in their experience which is influenced by their community.

Young calls attention to the aims of modern normative political theory and practice to adopt an impartial view of the public that attains generality at the exclusion of a particularity (Young, 2011). This approach fails to recognize the differences of social circumstance. The perceptions by both staff and Equity Work Group members of the value of a situated point of view that acknowledges the personal and group affiliations that inform identities and provide perspectives on social life reject the ideal of impartiality. Young argues that just decision making structures must ensure voice to particular groups and just norms are most likely to arise from "the real interaction of people with different points of view who are drawn out of themselves by being forced to confront and listen to others" (Young, 2011, p.166). The Equity Work Group and dialogue that occurred between members and staff created a space to share perspectives that represented distinct voices and exchange on social issues. Thus, within Young's 
framework, the equity lens served as mechanism to ensure representation of oppressed groups within the decision making process that provided for this exchange of views.

\section{Initial Standing of Equity Work Group}

The project documentation indicates that discussions on the draft plan components occurred first with the Equity Work Group. Then, draft plan components were presented to the advisory committees for review and then to Metro Council for approval. Input from the Equity Work Group was summarized in reports by staff that went to both the advisory committees and Metro Council. The Equity Work Group had 14 meetings and participated in each phase of the plan development. Views of the work group were also represented in the staff reports that were presented to Metro Council during each phase of plan development. Using public records, a map of the decision process was constructed that is illustrated in the following figure.

Figure 21. Map of Decision Making

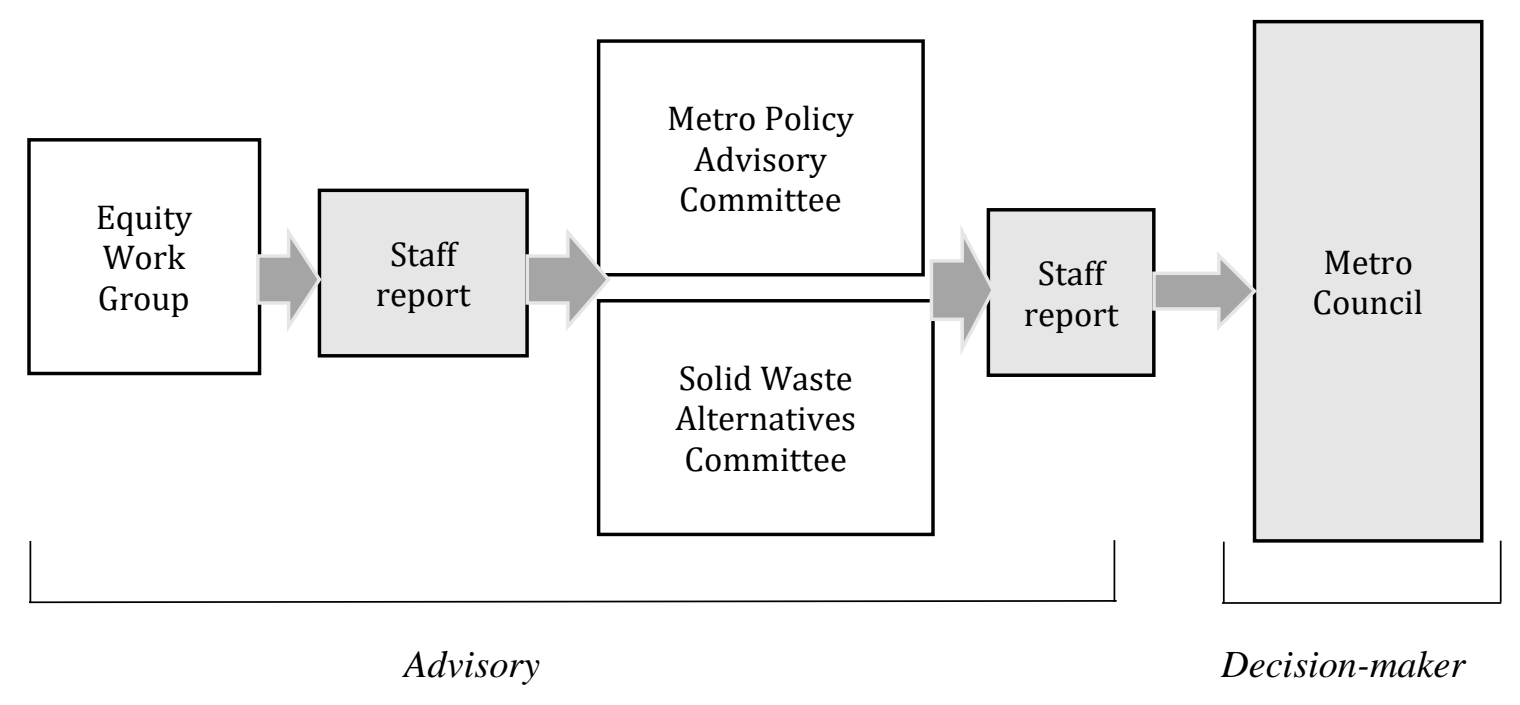


The initial standing of the Equity Work Group as it relates to the timing and sequence in which the Equity Work Group participated in the decision making process was specifically called out by staff and Equity Work Group members. In particular, both staff and Equity Work Group members called attention to the importance of allowing the individuals within the work group to "start the conversation rather than just review proposed policy actions.” A project team member stated:

One aspect of the equity lens was allowing this group to help set the foundational conversation. With this, I mean that in many cases you equity groups that are tagged onto a project, they tend to only receive things to weigh in on after conversations have already been had. So for example, let's say the Regional Waste Plan values as well as the goals were ready talked about by staff and other committee members and this established a set of goals and values were already kind of instilled, but they were still draft. Typically, you would take that draft and bring it to the equity group for them to review and weigh in on. The dynamic there is that they're already been given a set of parameters around what they can talk about. Whereas, we kind of flipped that, by allowing for that group to start the initial conversation. This broke down those parameters and allowed for a more open, healthy conversation around what equity is truly about. That in itself was pretty powerful because I think it did not limit what we were talking about.

Staff commented that by allowing the equity committee to initiate the conversation on the goals and values, they essentially framed how Metro staff and other committees and participants talked about the policy direction in the plan. With this approach, staff stated "It really flipped things around" from traditional planning process by shifting positions of influence.

Within Young's framework, this view accounts for attention to the considering position of a group or individual within the structural process of decision making. As noted previously, considering position is the initial standing of a group or individual in a 
given context that determines the range of possibilities of its action or interaction with other social groups or individuals (Young, 2011). This consideration is distinct from traditional decision making processes where advisory groups serve as a review body and their position in the decision making process is at a later stage in the planning process that limits the range of discussion on a particular issue. An Equity Work Group member also accounted for the ability to start the conversation on what equity meant within the context of the plan. Staff described the equity work group as "another planning team essentially to work in parallel with the Metro staff." The ongoing involvement of the members of the work group was different from past processes in that "staff started and ended conversations on the plan elements" before taking them to the advisory committees and Metro Council. Staff commented:

We wanted to and I would say they insisted rightly that we check in with them through the process and we touch base in every stage.

In each stage of the process, we were really paying attention to when we were plugging in this group to provide direction, so that they were actually creating influential decisions because we knew we were having to report back to them to tell them why their conversation was important.

I feel really thankful to have had the opportunity to work with them. Every time I interacted with a group it was eye opening to hear people who we don't usually hear from.

Despite the linear flow of decision making articulated in the project documentation, the interviews accounted for a more circular process of communication and decision making illustrated in the Figure 22. Staff engaged directly with the Equity Work Group meetings to deliberate and discuss the planning questions and options. Following the meetings, 
staff would circle back to the work group members on how their guidance was incorporated before the information was advanced to the decision making bodies. This flow of decision making occurred in each stage of the planning process as the work group engaged on each component of the plan.

Figure 22. Communication and Decision Making

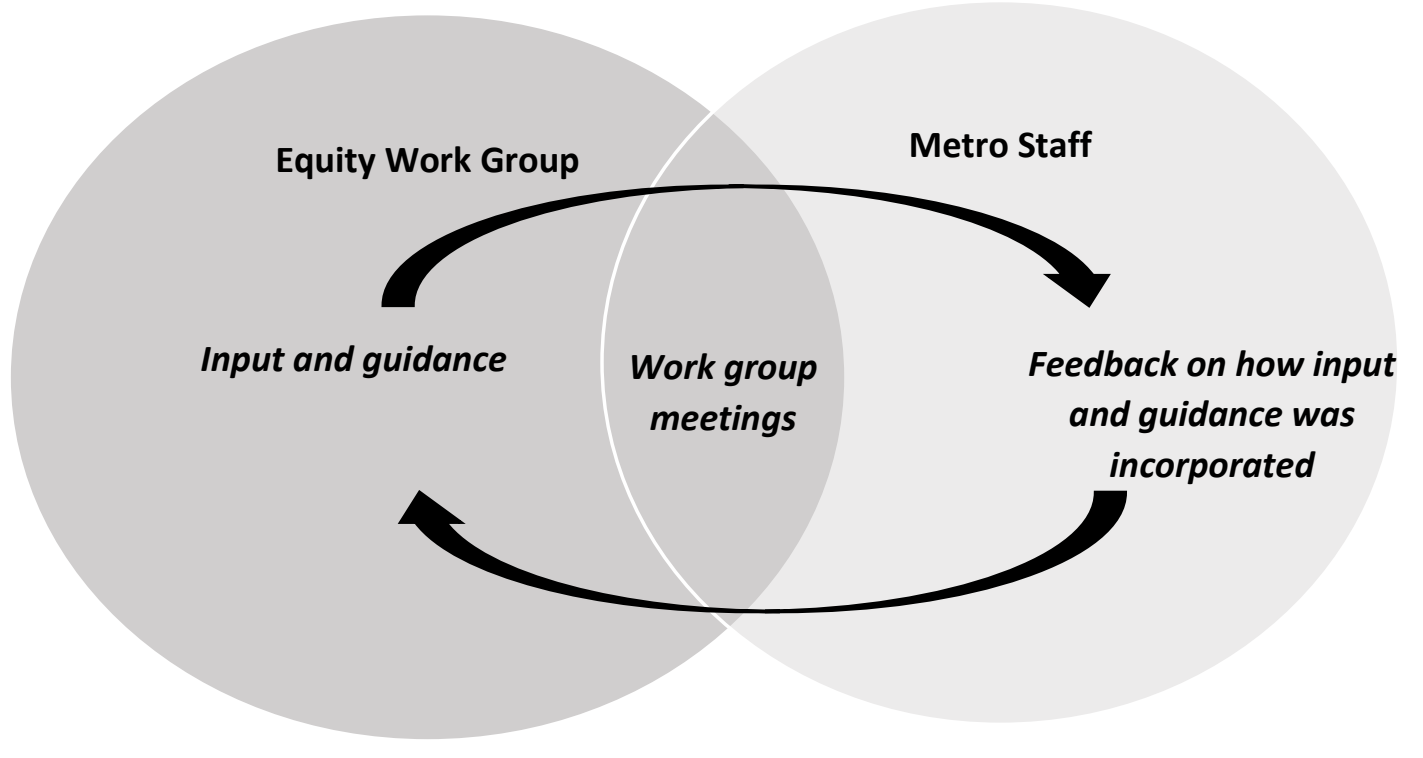

Key to Young's view is how the initial standing of the work group influenced the range of possibilities of actions within the plan development. The Equity Work Group's position at the onset of the planning process rather than being involved later in the process fundamentally altered the path of the development of the plan guidance. For example, Equity Work Group members and staff called attention to the plan principles that were not originally a part of the plan components, but were drafted by the work group members. Equity Work Group members felt the plan needed additional guidance related to racial equity to guide the development of the plan's goals and actions and future plan implementation and drafted the plan principles. The 2030 Regional Waste 
Plan states, “... principles were developed by the Equity Work Group in collaboration with Metro staff. Their purpose is to help address historical and disproportionate impacts of the waste system on marginalized communities and to define how the plan may advance racial equity" (p. 45). The complete principles are included in the table below. Table 14. 2030 Regional Waste Plan Principles

\section{Community restoration}

Take action to repair past harms and disproportionate impacts caused by the regional solid waste system. In practice, this means:

- Acknowledging historical impacts passed from generation to generation within communities.

- Actively including communities that have been historically marginalized from decision-making processes.

- Equitably distributing costs and benefits, taking into account historical and system impacts.

- Valuing indigenous and cultural knowledge about using resources sustainably.

- Committing to building a greater awareness of equity among providers of garbage and recycling services.

\section{Community} partnerships
Develop authentic partnerships and community trust to advance the plan's vision. In practice, this means:

- Prioritizing historically marginalized communities within the delivery of programs and services.

- Expanding voice and decision-making opportunities for communities of color.

- Supporting resilient community relationships by creating ongoing opportunities for leadership development.

\section{Community} investment
Emphasize resource allocation to communities of color and historically marginalized communities. In practice, this means:

- Making investment decisions in partnership with communities.

- Investing in impacted communities and youth through education and financial resources.

- Eliminating barriers to services and employment

Source: Metro, 2019. 
The plan's values and principles were endorsed by Metro Council prior to work being started on the vision, goals and actions. Therefore, the principles provided guidance in development of the remaining portions of the plan and would not have been generated without the involvement of the group members. Some viewed the principles as an extension of the equity lens:

Development of the principles was an element of the lens that I think really laid down a strong marker to ensure that the lens was applied throughout.

The equity work group helped craft a set of principles that were meant to guide our work in the planning process and plan implementation.

The principles were really to ensure the integrity of our application of the equity lens throughout. Because it's one thing to get started with good intentions and another to have good guidance.

We (equity work group) set the guiding principles for the plan. Staff used the principles in all the other stakeholder sessions, even when people didn't have a really deep understanding on racial equity. I feel like we were able to help keep the equity lens explicitly present and guiding through every single phase.

In viewing these accounts through a structural lens, the plan principles became something "produced in action" that established new conditions for positional rules and resources in which staff and the Equity Work group members would draw from for future actions. Thus, the plan principles set new rules or institutional conditions to direct future decision making. Both project staff and equity work group members called attention to the importance of the principles and timing of their development at the beginning of the planning process. The principles were also used by the Equity Work Group members and staff to identify specific actions in the plan that have the highest potential to advance 
equity. Forty of the 119 actions in the final plan were identified as focusing directly on advancing equity and reducing disparities.

\section{Access to decision makers}

The Equity Work Group's involvement in each phase of plan development that provided for ongoing discussions with staff on the plan components highlights another theme that emerged from the interviews concerning access to decision makers. As a part of the design of the planning process and engagement of the Equity Work Group, staff commented that they were intentional about creating lines of communication between staff and the final decision making authority of Metro Council. Staff and Equity Work Group members commented:

For the equity work group, there was unprecedented access (to decision makers).

There was increased access because they were able to talk directly to staff, which doesn't always happen. In addition, they had access to two directors. I feel like at the management level they had more interaction and more access than has been done before.

Without an intentional process you don't have to talk to any kind of community group and in this process the work group worked directly with staff.

The majority of increased access was accounted for at the staff and management level. Although some access to Metro Councilors did occur through staff reports and presentations by Equity Work Group members at council meetings, some individuals expressed there could have been more access to the councilors. A staff member commented:

One of the things we discovered from that debriefing is we may not have achieved the objective we intended for the Equity Work Group of connecting them more with Metro Council. 
In discussing the process and access to decision makers, individuals also accounted for the extent to which views of marginalized groups influenced the plan policy actions. Staff and Equity Work Group members commented that the plan's policy actions addressed existing disparities within the system for communities of color and marginalized groups. One staff member commented on goals related to jobs and increasing wages and career pathways within the garbage and recycling system where the lowest paying jobs are most often helped by people of color:

I felt like their (Equity Work Group) feedback was instrumental. For example, shared prosperity goals, we didn't even have a section for shared prosperity, but by the time we got through the planning process, we did. I felt like the Equity Work Group was instrumental because I don't think we would have had that without them.

Equity Work Group members commented that working with staff influenced the plan outcomes. Members commented:

The final product reflected I feel like almost every one of our views with very few exceptions.

I felt like I was represented (in the final plan) because we offered our ideas and there were different activities to allow us to participate in different ways to express our own opinions and views about certain aspects of the plan.

Within Young's conception of structural justice, increasing access to decision makers served to remove institutional constraints to provide the opportunity for the Equity Work Group members to express their views and interests within the planning. Further, Equity Work Group members confirmed that their views and interests were represented in the policy actions in the plan.

\section{Time constraints}


Both staff and the Equity Work Group members expressed concerns related to time constraints within the planning process. Many accounted for quick turnaround time for review and discussion of items and planning feeling "rushed at times." At the same time, Equity Work Group members understood the requirements around timelines and expressed an understanding of the need to operate within this constraint. Staff and equity work group members commented:

Timing was tough. I feel like we were given plenty of time to do the work. But, it was more of a question of $t$ how short of time we'd need. I felt like we were given enough information, but sometimes the turnaround was really, really tough.

I think the time constraints were really on the staff end. What I would have done differently, would be building in more time for staff to review, process and digest what was coming from the equity work group members.

New concepts, new materials, new ways of thinking, new worldviews mean that stuff just takes time to kind of walk through and figure out how do we incorporate this.

According to Young (1990), "social justice means the elimination of institutionalized domination and oppression" (p. 15). In this context, the process of decision making is subject to oppression and domination where some people are not able to exercise and develop their capabilities, express their own opinion and experience and participate in defining conditions for actions. The 2030 Regional Waste Plan's decision process was altered to address the considering position of individuals that represented social groups that are subject to oppression by providing the ability for these views to be represented at the onset of the process and within each stage of decision making. In Young's view, Metro's Racial Equity Strategy removed past objective constraints for oppressed groups 
by prioritizing specific groups for inclusion in decision making that worked to address institutionalized oppression.

\subsubsection{How does the institutional environment influence the use of the equity lens?}

The study also considered the institutional context within which the planning process was conducted including existing policies or practices that guide the planning process and influence organizational structures and processes. This provides important context by outlining the institutional environment in which the equity lens was implemented and to what extent these conditions may have influenced the how an equity lens was defined and used within the planning process. Young's concepts of social groups and social processes were key to interpreting these views.

The interview data generated an overarching theme that explains factors that influence the use of an equity lens with an institutional environment. Participants constructed policy guidance in a positive sentiment for influencing agency norms and values leading to new practices. Executive level leadership support also emerges as a means for introducing new practices that is intertwined with shifting agency norms and values. Young's attention to social norms and values underlying decision making process and view of a heterogeneous public are important in interpreting her data. The major themes and sub themes generated in response to the research question are summarized in the table below. Each sub-theme is given special attention in the following sections.

Table 15. Supports and Constraints of an Equity Lens within the Institutional environment 
Overarching theme: Support and constraints within the institutional environment

\section{Sub themes}

- Policy direction shifting norms and values

- Compensation for community members demonstrating value and removing barriers

- Executive level leadership providing support for advancing the equity lens
An overarching theme that explains factors that influence the use of an equity lens with an institutional environment. Participants constructed policy guidance in a positive sentiment for influencing agency norms and values leading to new practices. Executive level leadership support also emerges as a means for introducing new practices that is intertwined with shifting agency norms and values.

\section{Policy direction shifting norms and values}

At the elected official, management and staff level, individuals commented on the importance of Metro's Strategic Plan to Advance Racial Equity as a reason for why the 2030 Regional Waste Plan incorporated an equity lens in the design of the process. The strategic plan states:

Metro will concentrate on eliminating the disparities that people of color experience, especially in those areas related to Metro's policies, programs, services and destinations. By addressing the barriers experienced by people of color, Metro will also identify solutions and remove barriers for other disadvantaged groups. This strategic direction allows Metro the opportunity to make a difference in the lives of disadvantaged communities, while having a positive impact on the Portland region's overall quality of life. (Metro, 2018).

Metro staff referred to the plan as the basis for the lens and rationale for social groups that were prioritized for inclusion in the planning process. Staff commented:

I think the racial equity strategy in place already gave us an invaluable foundation.

The racial equity strategy really pushed the agency into creating an environment where this is possible.

Our agency has a strategic plan to advance racial equity and we have a robust internal diversity, equity and inclusion plan that staff, for the most part, are well grounded in. So, 
we were well poised to embark on such an effort, versus if we had not had those that level of understanding and ownership it would have been a much bigger fight.

Having a strategic plan to advance racial equity, I think allowed me to address any detractors and just opens the door to allow for this particular conversation to receive some standing.

The racial equity strategy was a primary impetus for both equity lens and the equity work group. I don't think it would have happened without that direction.

In many of the conversations with staff, there was a positive sentiment of ownership of the racial equity strategy signifying a shift in values and norms within the agency. A staff member commented:

The structures were being created to advance equity within the agency and people. There are passionate advocates for that work, so we're working not just on it within structures, but also on just advancing it culturally within the agency.

My other strong goal and interest which is both for work and personally is to support the use of the equity lens and ensuring that the plan serves community needs and helps to achieve the universal goal of all people having a good standard of health and access to resources.

In Young's view, staff are recognizing the need to address institutionalized oppression with the structures and processes within the agency. Project team staff highlighted training on institutional racism and implicit bias that had been conducted for Metro staff prior to and during plan development to support implementation of the agency's Strategic Plan to Advance Racial Equity. Staff accounted for a level of "momentum" around racial equity work. A staff member commented:

Part of the discussion in the organization for the last three years, combined with the training and education that ran in parallel to it, conveyed the importance of the work related to the 2030 plan. 
This provided some shared language in terms, however, some staff expressed their view that the agency as a whole "lacks shared understanding of racial equity and analysis."

I think you're starting to see that a little bit more here at Metro is as we start to dive into advancing racial equity is to ensure that what we're talking about is actually racial equity. I think you see a lot of programs that the perception of racial equity from a manager or a program manager or whoever can be a little skewed and not truly aligned with what racial equity truly is trying to get to.

Well when you say the word equity, if you have 25 people in the room, there'll be 25 definitions of what that means.

Despite some views of needing to further develop a shared understanding of racial equity, project team staff expressed a "responsibility to consider who is most impacted" and interest in working to determine how to best advance equity within their work. In staff considerations of who is most impacted, another theme emerged centered on the value of the "lived experience." A staff member commented:

Community members carry knowledge and expertise in different ways. And, just because they're not professional consultants or whatever that doesn't mean that we don't value what they have to say. And so that was sort of another way that I feel application of the equity lens is by really valuing the expertise that was brought to the room.

This value was not only expressed by staff, but also reinforced by Equity Work Group members. An equity work group member commented:

I always felt like you know my opinion was valued and that the information or suggestions that I provided were well taken and valued by staff and the group as a whole.

In Young's framework, staff acknowledgement of the "lived experience" and "who is most impacted" represents a shift from the universal view of the public to one that acknowledges social difference and places direct value on this point of view. 


\section{Compensation for Equity Work Group members demonstrating value and removing barriers}

Another theme that emerged was the importance of compensating Equity Work Group members for their participation in the planning process. Work group members were paid a $\$ 100$ hourly stipend for their participation in the group. Specific hour allocations were specified for meetings and work performed by members of the group. Metro Councilors, staff and equity work group members identified the importance of compensation. Metro Councilors and staff commented:

Compensation was a critical element. I think that was important in identifying privilege and power and removing barriers. I think that it shows that we value those perspectives.

I learned how valuable it is to compensate people that participate in these processes. It is just so transformational.

Equity work group members commented:

I felt like I was compensated fairly for the amount of time we were putting into it.

Stipends makes a lot of sense, so it's not just like hey let's give you like a 20 dollar gift card you know for Starbucks or Fred for attending a three hour long meeting.

I don't think it would have been possible without the stipend.

Individuals expressed that compensation was critical for removing barriers and expressing value for the time and expertise Equity Work Group members brought to the process. At the time, Metro had a precedence in the agency's charter that allowed for stipends to be paid to citizen representatives on advisory boards. However, rates and specific terms were not defined in policy. Project team staff conducted research on other 
similar types of processes and arrived on the rate based on similar practices that were being conducted in the agency. Within Young's framework, the use of compensation addresses some aspects of institutionalized oppression by addressing financial constraints on self-development. Within the planning process, the use of compensation become a critical factor for involving individuals representing groups historically marginalized from the political process. This mechanism responds to Young's proposition that new mechanisms are needed to ensure representation of oppressed groups in the decision making process.

\section{Executive level leadership providing support for advancing the equity lens}

The importance of executive level leadership support emerged as a theme throughout the staff interviews. For nearly all the staff on the project team, this was the first experience developing a long range plan at this scale and using an equity lens. Policies within Metro Charter established requirements for advisory committee review and public hearings for plan adoption. Beyond that, the general design of the planning process and level of engagement with individuals, communities, businesses and local governments was open to the discretion of the project team and their interpretation of general policy guidance and practices at Metro. This provided staff with opportunity to design the process and the ability to interpret how to best advance Metro's Racial Equity Strategy. However, staff commented that approval and support from the department and division level directors was necessary for the staff ideas to advance:

I think that leadership really matters. The executive level leadership made it possible for us to move forward with something that we thought was the right thing to do at the staff level. 
It helped that the director was on board and fully supportive and fully embraced the work. Without that, I do not think it would have been as successful as it was.

I think that it helped that we had a sponsor level support and that they were very consistent in their support of the concepts. They were willing to help us work through challenges that arose when so many times throughout the process I feared that it would crumble, but it never did.

Staff also commented that there were times when the department was questioned about the equity approach particularly by individuals "with power" such as Metro Council and private industry lobby groups. They viewed the department director's ability "to articulate the importance of the work as an advocate put to rest any questions or fears." This view reflects Young's emphasis on the power that is provided within hierarchical decision making. In this case, the authority at the leadership level influenced the value place on the equity lens and role of the Equity Work Group that allowed the process to move forward as structured. The theme centering on leadership support is also closely intertwined with shifting norms and values resulting from Metro's Strategic Plan to Advance Racial Equity.

\subsection{Summary}

This case study examines the equity lens utilized within the 2030 Regional Waste Plan planning process to gain a better understanding of how an equity lens may change the institutional planning process. The study builds upon structural theories of justice and provides new insights to further bridge theory and practice as it pertains to an equity lens. The study revealed that individuals involved in the application of the planning process have significant power and influence on how the equity lens is defined in practice. Consistently, participants viewed the equity lens within the planning process as a means 
of inclusion for individuals and social groups that have historically been marginalized in the political process. At the same time, the lens is also presented as a series of actions or steps to take when designing a process to identify who participates in the decision making and establishing appointed representation for historically marginalized groups. The selection of individuals for appointed representation provided a new mechanism for representation of distinct voices that focus on personal identity and attribute value to the "lived experience" in policy deliberation. A key aspect of the equity lens was the timing and sequencing in which participants were involved in the process of decision making. Departing from past planning models, individuals representing politically marginalized groups were placed at the onset of the planning process working in collaboration with staff rather than being involved later as a review body. In addition, participants had greater access to decision makers particularly at the staff and management level. The case study also highlighted factors within the institutional environment including policy direction shifting norms and values to adopt a view of a heterogeneous public that acknowledges and accounts for social difference. This translated into new practices of providing compensation to community members for participation and value of community expertise alongside technical expertise. Leadership from management was also identified as a factor for providing support for advancing the equity lens. In the next chapter, I will discuss the major findings of the case study in relationship to the existing literature and implications for future research. 


\section{Chapter 6. Discussion of Findings and Future Research}

"Just because we no longer have explicit rules about exclusion doesn't mean bias doesn't remain. We still have more work to do." -Julie Nelson, director of the Government Alliance on Race and Equity

\subsection{Introduction}

The case study revealed insights into the understanding of the equity lens in practice that support propositions outlined by Young and theories centered on structural racism, but also presents potential dilemmas for consideration. This chapter discusses the findings of the case study in relationship to existing literature, identifies considerations for future practice and research and provides a conclusion to the study.

\subsection{Discussion of Findings}

The practice of equity lenses is growing rapidly in the public sector as a means to reform institutional processes that perpetuate inequities. The purpose of this study was to gain a better understanding of how an equity lens can address the structures and processes within a government organization's planning process that perpetuate inequalities. The research explored perceptions of an equity lens in practice, methods for selecting groups for special representation, and how an equity lens addresses structural inequalities in the planning process. Investigation of these issues within the case study help address key gaps in the existing literature and elaborate on existing theories of structural justice. The discussion of findings presented in this section are structured around the key gaps in literature identified in Chapter 2. First, I describe the use of an equity lens within a planning process based on the 2030 Regional Waste Plan to address existing gaps on the 
use of an equity lens in practice. Then, I look specifically at the design of decision making structures and augment Fung's (2006) democracy cube to demonstrate how the equity lens can change specific dimensions within the institutional planning process. Next, I discuss the use of criteria for selecting groups for representation and consider the strengths and challenges to Young's propositions on appointed representation. Lastly, I consider the case study findings on the influence of the institutional environment in relationship to theories of structural racism.

\subsubsection{Equity Lens in Practice}

As presented in Chapter 1, cities and counties across the country are using forms of equity lenses to explicitly integrate racial equity in government practices. In many instances, the definitions of equity lenses call attention to the decision making processes, outline questions to consider including who benefits and who is burdened by policy decisions and prioritize the inclusion of politically marginalized specific communities in the policy process. However, limited research has been conducted on how an equity lens is used in practice by local government organizations. The 2030 Regional Waste Plan case study builds knowledge in this area by providing more in-depth understanding of what components and methods comprise an equity lens in the field of planning as revealed in this case and implications of these methods for planning models.

The 2030 Regional Waste Plan case study identified policy documentation that provided specific definitions and methods associated with an equity lens, however, participants in the planning process revealed the lens was perceived differently among the participants. In some instances, individuals perceived the lens as an intention to address social disparities, while others associated the lens with specific actions and methods. 
These methods were primarily defined by the actions of planning staff and the Equity Work Group members. Interviews provided a more specific level of detail on what was included in the practice of an equity lens and how it departed from traditional practices. Specifically, the case study revealed four distinct components and associated actions and methods of an equity lens as a part of a planning process as outlined in Table 16.

Table 16. Components of an Equity Lens for a Planning Process

\begin{tabular}{|c|c|c|c|}
\hline Component & Action & Method & Timing \\
\hline $\begin{array}{l}\text { Historical and } \\
\text { social analysis }\end{array}$ & $\begin{array}{l}\text { Considering who is positively and } \\
\text { negatively affected by the issue } \\
\text { taking into historical context and } \\
\text { level of influence and impact of the } \\
\text { issue under consideration }\end{array}$ & $\begin{array}{l}\text { Stakeholder } \\
\text { power analysis }\end{array}$ & $\begin{array}{l}\text { As the first step } \\
\text { in designing a } \\
\text { planning process }\end{array}$ \\
\hline $\begin{array}{l}\text { Appointed } \\
\text { representation }\end{array}$ & $\begin{array}{l}\text { Appointing individuals from } \\
\text { specific social groups who have the } \\
\text { least influence and are most } \\
\text { impacted to work directly with staff } \\
\text { to inform decision making }\end{array}$ & $\begin{array}{l}\text { Targeted } \\
\text { recruitment with } \\
\text { specific criteria } \\
\text { for participant } \\
\text { selection and } \\
\text { compensation for } \\
\text { participation }\end{array}$ & $\begin{array}{l}\text { As the second } \\
\text { step of designing } \\
\text { a planning } \\
\text { process }\end{array}$ \\
\hline $\begin{array}{l}\text { Considering } \\
\text { position in } \\
\text { process design }\end{array}$ & $\begin{array}{l}\text { In the design of the decision } \\
\text { making process, situating the initial } \\
\text { standing of individuals with } \\
\text { appointed representation at the } \\
\text { onset of each decision point within } \\
\text { the planning process such that they } \\
\text { are able to set the foundational } \\
\text { conversation in each decision point, } \\
\text { not just a "review" proposed policy } \\
\text { actions }\end{array}$ & $\begin{array}{l}\text { Concept mapping } \\
\text { for identifying } \\
\text { sequence of } \\
\text { decisions }\end{array}$ & $\begin{array}{l}\text { As the third step } \\
\text { of designing a } \\
\text { planning process }\end{array}$ \\
\hline $\begin{array}{l}\text { Deliberation and } \\
\text { transparency }\end{array}$ & $\begin{array}{l}\text { Deliberation with key decision } \\
\text { makers to respond to policy }\end{array}$ & $\begin{array}{l}\text { Proposed } \\
\text { questions and } \log \end{array}$ & $\begin{array}{l}\text { As an ongoing } \\
\text { process, at each }\end{array}$ \\
\hline
\end{tabular}




$\begin{array}{lll}\begin{array}{l}\text { questions with consideration of } \\ \text { benefits and burdens and }\end{array} & \begin{array}{l}\text { of input, decision } \\ \text { and response }\end{array} & \begin{array}{l}\text { decision point } \\ \text { within the }\end{array} \\ \text { transparency in final decisions } & & \text { planning process }\end{array}$

These four components included analysis, appointed representation, considering position in process design, and deliberation and transparency. Each of the components represented an aspect of the equity lens to be performed in a specific sequence and serve different purposes. First, historical and social analysis is completed as a first step to guide decision making for who is included in the process taking into account historical and social contexts and level of influence. Second, appointed representation is identified as a specific mechanism of participation for oppressed groups. Third, process design considers what position in the decision making process individuals are situated within the overall planning process. This takes into account the importance of considering position. As discussed previously within Young's (2011) framework, considering position is the initial standing of an individual or group in the decision making process that will later determine the range of possibilities of its action or interactions within a process. This must be accounted for at each decision point and within the larger stages of the planning process. Lastly, deliberation and transparency considers the participation and communication that occurs with each decision point within the planning process. This conceptualization of an equity lens within a planning model provides more specific direction on what steps and actions planners must take to restructure the process of decision making to address inequalities in the planning process. The case study also presented details on the order in which different actions and methods were used in the planning process. 
In comparison to the planning models discussed in Chapter 2 including rational, equity and deliberative approaches, a planning model with an equity lens adopts a structural approach with a focus on the decision making processes, power and social identity for who is included in the process and in the position to influence decisions. Underlying this approach is values centered on equality of opportunity to participate and a view of the public that accounts for social differences in power.

\section{Figure 23. Planning Model with an Equity Lens}

- Planning to address social disparities through a structural approach

- Planners as advocates of reforming structures and decision making processes to account for social group difference and power

- Public as heterogeneous recognizing individuals and groups by their social location and experience

- Special treatment for oppressed groups in the decision making process
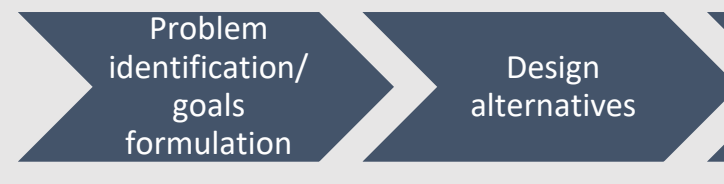

This model draws inspiration from the equity and deliberative planning models including a view of the public as heterogeneous, inclusion of marginalized groups in decision making processes, and planners as advocates. However, this model draws increased attention to the collection of decisions and processes that may impose institutional constraints on participation. A planning model with an equity lens aims to reform the structures, shift underlying values and focus on inclusion at each stage of the decision making process. This model stands in direct opposition of the rational planning model 
that views the pubic as a universal, planners as neutral analysts and provides for limited participation in decision making.

In sum, the case study provides new insights on the components and methods that comprise an equity lens within a planning process. These insights help to build

understanding for how an equity lens is used in practice. The case study also highlights a structural approach to planning that draws some similarities to planning models discussed in Chapter 2, but with increased focused on decision making structures. According to Young, it is the collection of decisions and processes that address structural injustices. Each action within the lens is associated with smaller decision making processes that influence how the equity lens is used in practice. Although the case study revealed participants conceptualized the equity lens as an intention to address social disparities, how the equity lens was defined and used in the planning process was ultimately determined by the planning staff with final approval by department leadership. This raises questions on potential inconsistencies of how an equity lens may be applied in practice and how the collection of decisions made by planning staff may either counteract or perpetuate inequities in the institutional planning process.

\subsubsection{Decision Making Structures and Processes}

A central concern of this study is how an equity lens may change the institutional planning process and how an equity lens addresses structural inequalities in decision making. The study revealed the equity lens influences dimensions of participation and position within decision making within the planning process. In restructuring these processes and practices, in this case, the equity lens also shifted underlying values of the dimensions. Augmenting Fung's (2006) framework on the democracy cube, provides the 144 
ability to look more closely at structural dimensions of the decision making process and highlight the attributes of Young's propositions that were supported in the case study.

As discussed in Chapter 2, Fung's (2006) framework for governance is built on the assumption that participation in governance contains three dimensions including who participates, how they participate in decision making and how their input is linked to policy outcomes. Different types of mechanisms for participation can be located in this space and may advance differing values of legitimacy, justice and effectiveness. Insights from the 2030 Regional Waste Plan case study suggest two changes to the framework. First, the consideration of who participates must also take into account the underlying history and current structure of particular social relations that provide for social differences in power. Second, the framework must be augmented with a fourth dimension that accounts for the considering position in decision making. These are each discussed in more detail in the following sections.

\section{Participant Selection Dimension: Who participates}

Fung's first dimension concerns who participates. He draws attention to the variety of participation processes that range from being open to all who wish to engage to others that invite only specific representatives. He suggests five common selection mechanisms for participation that range from more exclusive with less individuals participating to more inclusive with a complete open process to the public. The underlying values of his scale of participant selection assumes an impartial perspective that asserts a commitment to a homogenous public as being the most inclusive for participant selection (Habmermas, 1989, 1996). This works in contrast to notions of inclusion centered on the degree to which diverse individuals are able to participate fully 
in the decision making process within an organization. In this context, inclusion may be considered both "the process for improving terms for individuals and groups to take part in society, and the process of improving the ability, opportunity, and dignity of those disadvantaged on the basis of their identity to take part in society" (World Bank, 2020).

Therefore, his scale of participant selection must be revised to account for the history and current structure of particular social relations. These insights are drawn from the stakeholder power analysis process used in the 2030 Regional Waste Plan planning process to prioritize groups for participation based on level of impact and level of influence as a part of the equity lens. This approach rejects the concept of the "public sphere" where the ideal of activities of citizenship are reduced to generality and operate to exclude. Incorporating these attributes modifies Fung's scale on participant selection types and alters underlying values related to inclusion. The augmented dimension is highlighted in the figure below.

Figure 24. Participant Selection

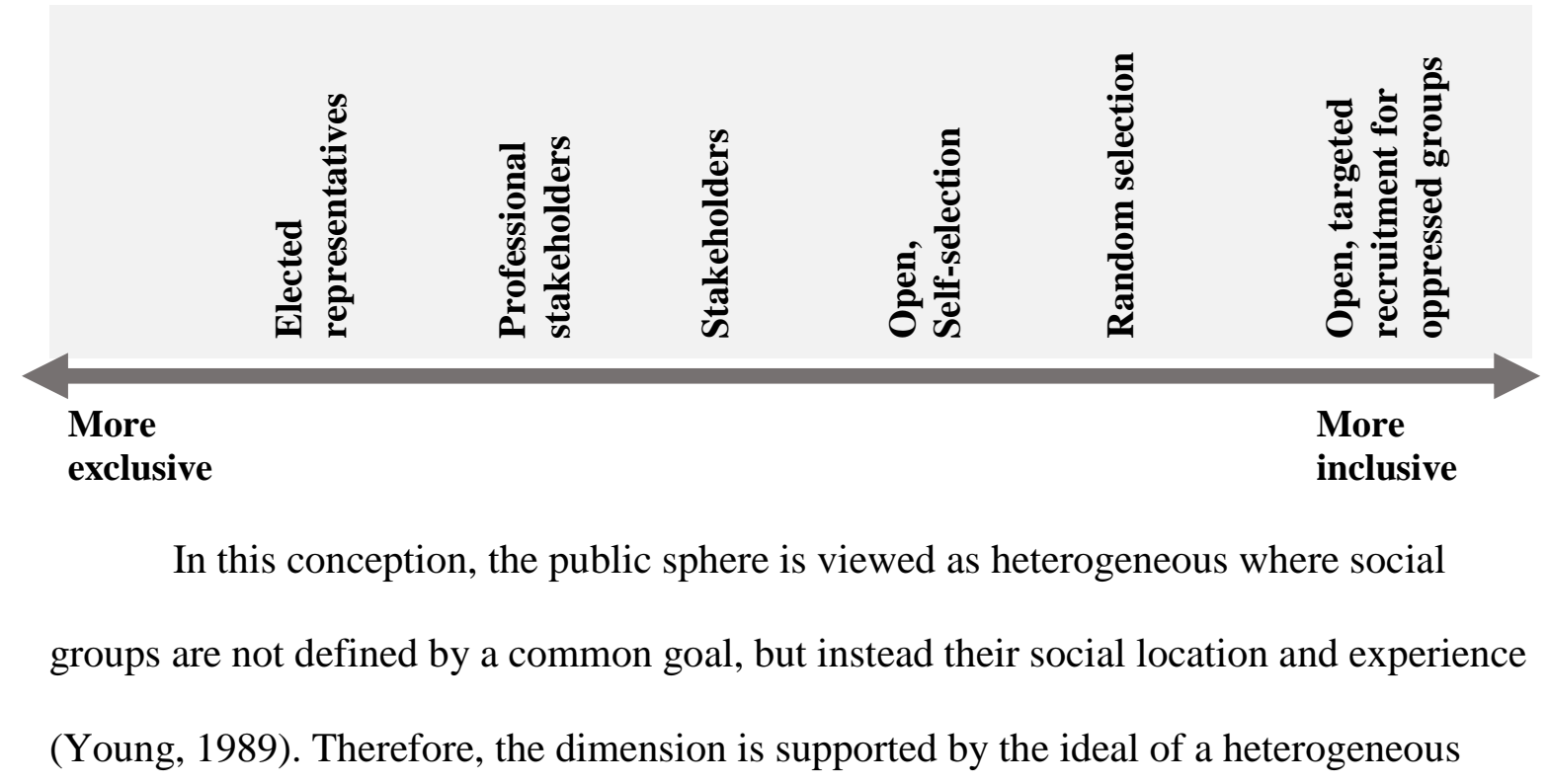


public "in which persons stand forth with their differences acknowledged and respected" (Young, 2011, p. 119). This explicitly rejects the universalist ideal of the civic republic that underpins Fung's approach and puts forth the ideal of full inclusion that is defined by representation of individuals or groups that have experienced exploitation, marginalization, powerlessness, cultural imperialism and random violence or harassment (Young, 2011). In relation to the institutional planning process, this alters the view and considerations of participant selection. Participants in the 2030 Regional Waste Plan planning process revealed a key aspect of the equity lens was the intent of inclusion of historically marginalized groups that was supported by the power analysis to identify and select groups that have been marginalized.

The case study also revealed that compensation was a significant factor in the participation of the members of the Equity Work Group. Not only did participants express that the compensation demonstrated value and recognition of their community expertise, but in many instances it was needed to allow the individuals to allocate their time to participate. Some of the work group members were paid as individuals not in affiliation for representing a particular organization. This also works in contrast to Fung's characterization of professional stakeholders who are compensated for their participation in affiliation with a particular organization and lay stakeholder who are unpaid stakeholders with a deep interest in a public concern. In the context of the Regional Waste Plan case study, the individuals were compensated for bringing their own individual view and community expertise, which represents a shift the underlying assumptions of Fung's definitions of who participates.

Considering position: Initial standing of participant in the decision making process 
Fung's (2006) framework accounts for dimensions of who participates, how participants communicate and make decisions and how discussions are linked with a policy or public actions. However, none of these dimensions account for the position of participants within the decision making process. This is particularly important for the authority and power dimension that highlights the different possibilities to influence public policy and action. Although this dimension accounts for level of influence of decision making, it does not account for at what stage individuals are included in the process of determining a public action. This dimension assumes participation at any point in the process will provide for the same level of influence on decision. However, the case study supported Young's proposition that the considering position, initial standing of a given social group or individuals in a given context determines the range of possibilities of its action or interaction with other groups, is a critical matter of justice. The 2030 Regional Waste Plan planning process demonstrated considering position of the Equity Work Group was critical in providing the ability to influence future actions and decision making on policy actions. This was a key aspect of reforming the decision making structures to address advantages and disadvantages that are provided to groups within the planning process. To address this deficiency, the following questions should be addressed when considering the value of participation in the institutional design space: Who participates and at what point or stage will they participate in decision making? Will they be placed in a position to influence how problems or goals are defined? Will they be in a position to influence policy actions or solutions before they are drafted and evaluated? As the case study revealed, the position within decision making is a key consideration both at the macro level of the process design that outlines the stages of planning process 
including problem definition or defining need, identifying policy solutions and alternatives through evaluation, but also at the micro level for the multiple decision points within each planning stage. Taking these changes together provides for an augmented democracy cube illustrated in Figure 25.

Figure 25. Augmented Democracy Cube Adapted from Fung (2006)

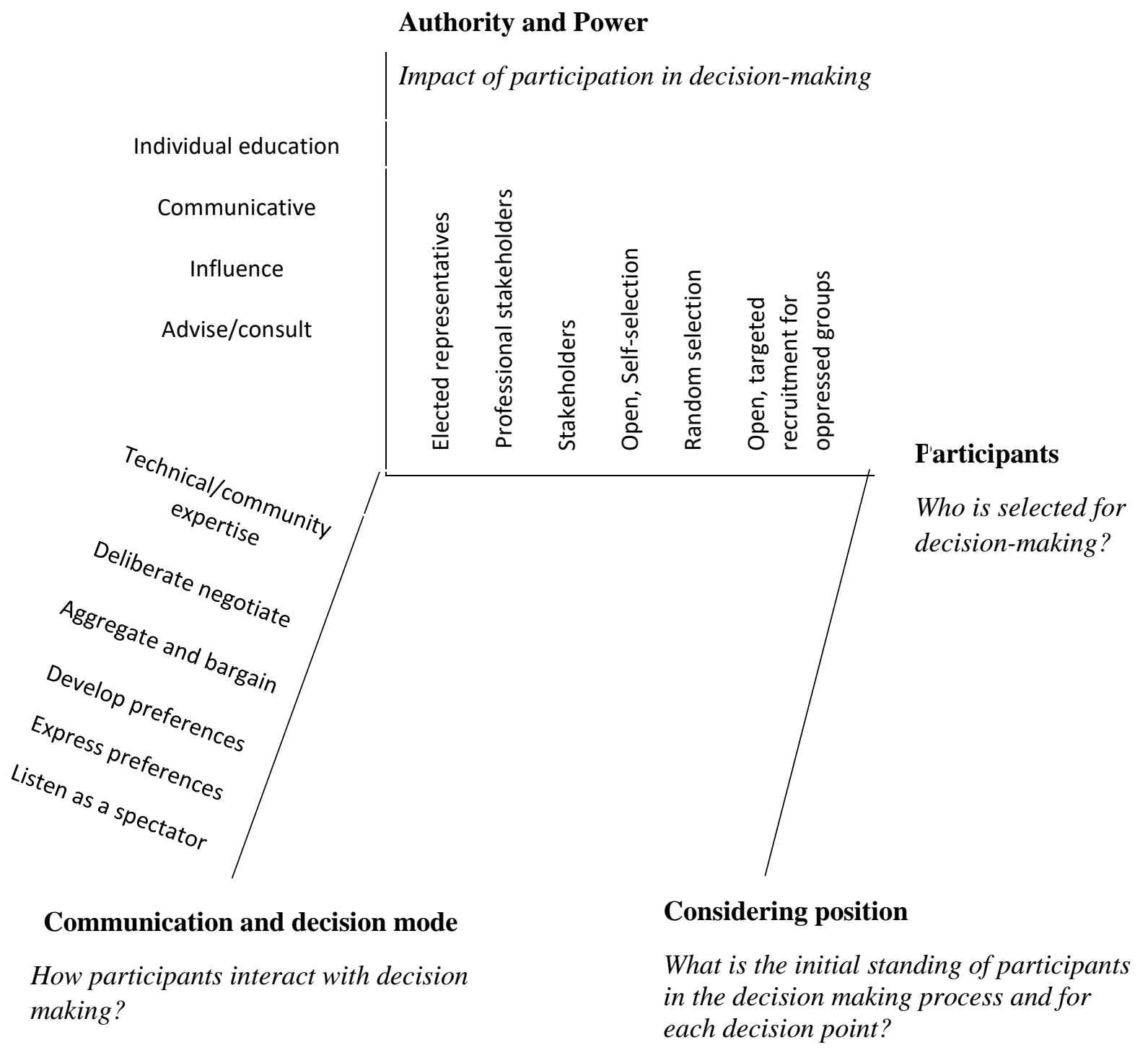


The updated cube maintains Fung's (2006) premise that participation serves the values of legitimacy, justice and effectiveness of action and no singular design is best suited to achieve all the values. However, the updated cube adopts a view of a differentiated citizenship and heterogeneous public that acknowledges the need for institutional mechanisms to support disadvantaged groups. Further, the new cube accounts for the embedded processes within decision making that advantage some groups over others in influencing policy outcomes. In summary, insights from the case study provide a fuller description on how the equity lens can change the institutional planning process by shifting underlying values and addressing structural inequalities in the decision making process. This supports Young's propositions and augments existing scholarship on the mechanisms of participation.

\subsection{Selection of Groups for Special Representation}

Another key aspect of the study concerned ongoing efforts by local governments to include social groups that have historically marginalized from the political process. Specifically, the study aimed to consider the use of appointed representation as part of an equity lens in the context of Young's view of oppressed groups. The study revealed both strengths and challenges to Young's propositions that provide new insights to the existing literature as well as considerations for future study and practice.

Within the 2030 Regional Waste Plan case study, policy guidance at the institutional level including Metro's Strategic Plan to Advance Racial Equity (2016), acknowledges the political marginalization of specific social groups and prioritizes inclusion of these groups in the decision making process. Under Young's framework, special representation is limited to groups that are oppressed or disadvantaged within 
society or particular institution. She distinguishes them by stating that in a heterogeneous public not any group of individuals that form an association may be a candidate for representation. Groups in a heterogeneous public are not defined by a common goal, but instead their social location and experience. The 2030 Regional Waste Plan planning process included three levels of priorities for the selection of groups: 1) affiliation with communities of color and historically marginalized groups; 2) expertise and skills and 3) prior government or policy experience. This is illustrated in the following figure.

Figure 26. Selection Criteria for Special Representation

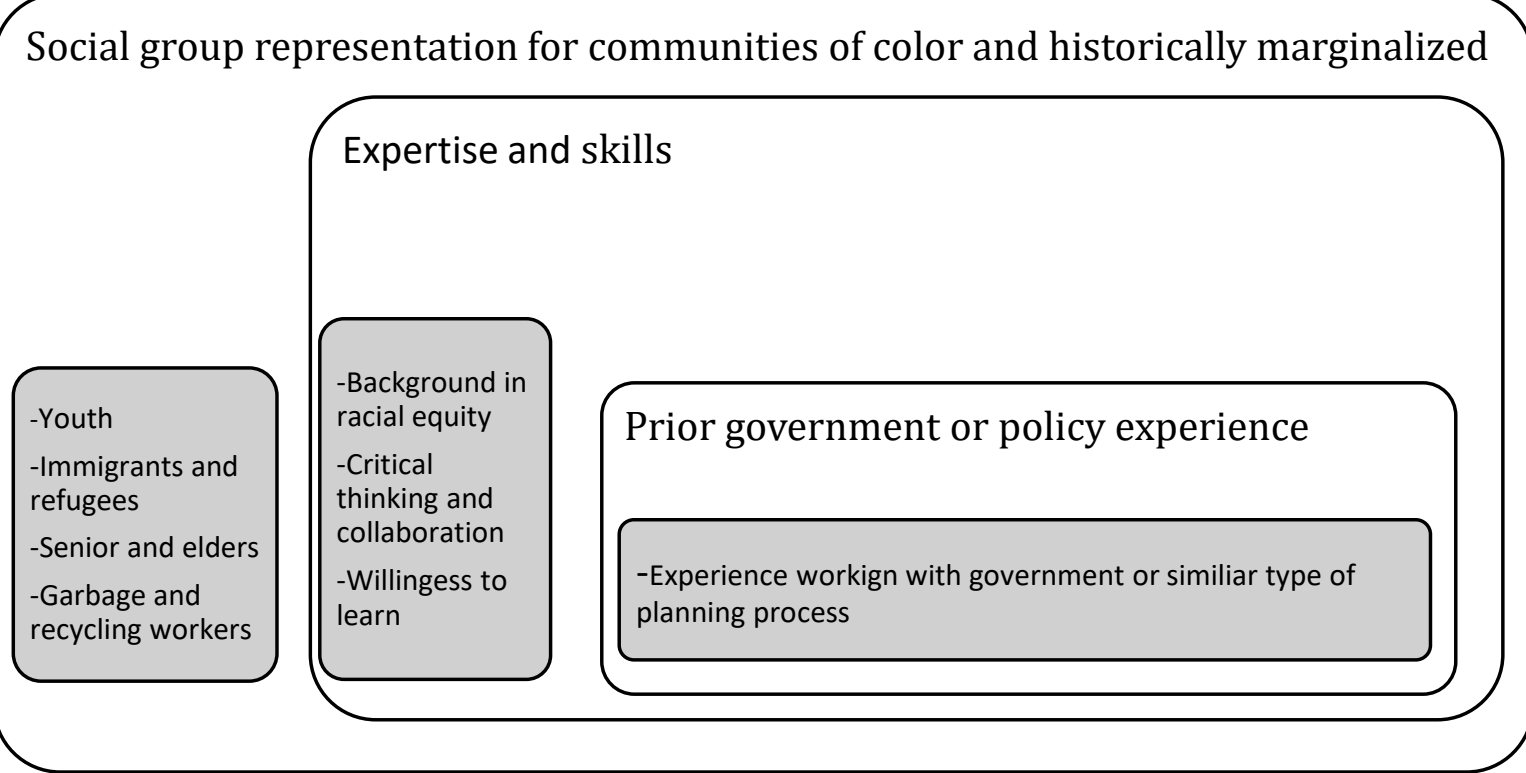

Representation was limited to individuals that self-identified with groups that experienced a disadvantage within the particular institution and historical context. The larger category definitions of communities of color and historically marginalized groups generally adhere to Young's criteria for disadvantaged groups that qualify for special representation and take into account their social location and experience. However, Young (1990) contends that her criteria for conditions of oppression may be used to 
compare oppressions and make plausible claims that one group is more oppressed than another without reducing all oppressions to a single scale. In the case of the 2030 Regional Waste Planning process, all groups identified as historically marginalized were considered at an equivalent standing point and no prioritization occurred among these groups. For example, the stakeholder power analysis tool placed all oppressed groups in one category and did not attempt to determine further difference among these groups. There was also no intentional historical analysis conducted to provide further insights on historical impacts to specific groups with regards to the policy field of the Regional Waste Plan. As a result, some groups, such as Tribal nations or groups that lived near a garbage or recycling facility that fell with the larger categories, were not represented on the Equity Work Group. This poses a dilemma given the intent of the Equity Work Group was to represent individuals that are most impacted by the plan's policies with the least amount of influence.

This draws attention to the need for public agencies to further distinguish and prioritize groups with the larger categories of communities of color and historically marginalized groups relative to the issue at hand taking into consideration the historical and present day impact. This support Young's (1989) argument that the way specific groups are oppressed must include an explanatory account that is particular and historical. This case identifies this area as a potential gap in current practice on the use of an equity lens for appointed representation. Further, the solicitation and selection process for the recruitment of the Equity Work Group members also presented some potential future dilemmas. Although the recruitment was posted publicly on the web and distributed to organizations that were in contact with Metro, these channels are limited to 
specific individuals and groups. This highlights a deficiency and potential for exclusion in current practices. In addition, the criteria around expertise and skills including government policy experience for participant selection may also pose a dilemma for exclusion. Lastly, the question of who holds the decision making authority on the selection of groups and individuals to serve on the group also present questions for future inquiry. In the case of the 2030 Regional Waste Plan, there was not an explicit effort to include individuals with different racial backgrounds on the selection committee. This begs the question of the consequence of biases and underlying values and norms of individuals making these decisions that may perpetuate inequities through decision making process in the selection of groups for special representation.

\subsubsection{Institutional environment}

Another key concern of the study was the institutional context of the planning process including polices, practices and procedures within the organization. Scholarship on structural racism calls attention to different forms of racial inequities that occur at individual, institutional and structural levels. Structural racism theory posits that analysis of racial disparity must look at all three levels (Grant-Thomas and powell, 2006). Although the study did not provide an in-depth analysis of all three levels, the case study revealed specific insights of behaviors at the institutional and individual levels.

The study revealed shifting values and behaviors at the institutional and individual level supporting propositions posed in scholarship. At the institutional level, new policies and practices at the agency level fundamentally shifted the agency's approach to policy and delivery of programs and services. Specifically, Metro's Strategic Plan to Advance Racial Equity, Diversity and Inclusion (2016) altered the agency's view 
of the public from a universal perspective to one that acknowledges social difference and drew attention to bias in policies and practices that play a role in perpetuating inequities. This agency level plan directed change within the practices and methods used within the organization for the design of planning processes, priorities for participation and introduced new language and values to the organization. At the individual level, this policy was supported by individual trainings for staff on implicit bias and institutional racism to support self-awareness on attitudes and beliefs and to reinforce shared language and vocabulary. The case study revealed that the combination of these efforts at the institutional and individual level influenced values and social norms within the organization supporting behavior change. Although the institutional level policy was critical in establishing racial equity goals and support for new practices, individual action and leadership presented as a critical factor from the view of participants in the case for advancing reform to current practices. Participants revealed individual actions were influenced by trainings and new knowledge and understanding around implicit bias and institutional racism. Perceptions from participants in the 2030 Regional Waste Plan planning process revealed the combination of these efforts at both levels supported how the equity lens was defined and prioritized for use as a part of the planning process. Figure 27 provides a conceptual model of the dynamics of the institutional and individual level that may be associated to changes in behavior.

The dynamic of actions at the institutional and individual level substantiates claims provided by theories of structural racism and institutional racism that highlight the reinforcing effects of multiple institution and individual norms that can change processes. This also supports Young's (2003) claim that responsibility for addressing structural 
injustice is distributed individually. Therefore, transforming structures that perpetuate inequalities requires many individuals to take responsibility in their individual and collective actions. The case study suggests interactions on both levels supported change in behavior.

Figure 27. Conceptual Model of Institutional and Individual Dynamics

\section{Formal Actions}

\section{Policies}

- Adopted racial equity goals

- Adopted policy for compensation for participation

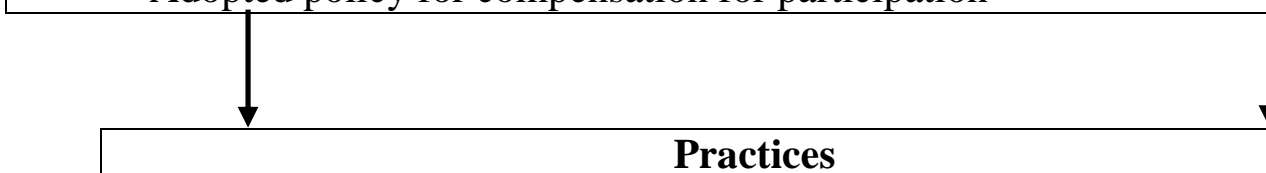

- Direction to use equity lens

- Direction to prioritize engagement communities of color and historically marginalized communities in decision making

- Individual training on implicit bias and institutional racism

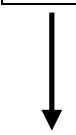

\section{Institutional and Individual Behavior}

\section{Institutional Processes}

- Methods for design of decision making process and mechanisms of participation that increase participation from marginalized groups in the planning process

- Shifting view of homogenous public to heterogeneous public

- Providing stipends for community participation

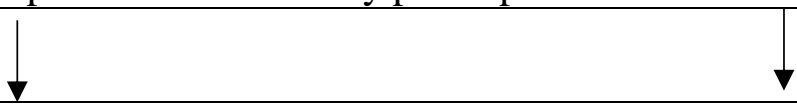

\section{Individual Actions}

- Staff ownership and "responsibility to consider who is most impacted" and designing planning processes to incorporate these views

- Attributing value to community expertise

- Individual leadership in prioritizing adoption of new practices 


\subsection{Summary of Equity Lens Considerations for Future Practice}

As both an academic and practitioner, one of the ultimate goals of the study was to provide insights to improve today's planning models and practices. Drawing from the study's findings and previous discussion in this chapter, this section summarizes key considerations for local governments considering the use of an equity lens as a part of planning processes within their organization. Key considerations for the use of equity lens include adoption of a formal definition of an equity lens, the use of policies for establishing organizational values and mechanisms of participation, and reforming decision making structures. The selection of considerations is influenced both by my experience working within government and designing planning processes. Each deserves specific attention.

First, the concept of an equity lens carries broad values, definitions and associated practices that may be understood and prioritized for use in different ways. The case study revealed the different ways an equity lens is conceptualized and perceived in practice from the view of participants in the planning process and the large degree of interpretation by planning staff in defining practices in using the lens. Given this, a key consideration for future practice is developing a common definition and understanding of an equity lens within an organization to ensure consistent understanding and use in practice. Drawing from the case study findings, a formal definition of an equity lens may include:

An equity lens is defined as an intention to address social disparities in planning, policy formulation and resource allocation. An equity lens is put into practice through changes to the structure of decision making processes by shifting 
underlying values to account for social differences in power, identity and experience and providing the opportunity for oppressed groups to influence decisions.

This definition provides a more specific level of detail as compared to other equity lens definitions in identifying the concepts of decision making structures, power and social identity that are fundamental to advancing justice as defined by Young (2011).

A second consideration yielded from the case study is the institutional environment and the role of policies within an organization that influence the use of an equity lens. The case study revealed that organizational policies helped influence underlying values and culture within the organization and provided direction in determining what groups were prioritized for inclusion in the planning process. At the same time, the remaining practices related to the lens were largely defined by planning staff. Given that the equity lens is a normative concept and construct, establishing and acknowledging these values is a key consideration in building shared understanding within an organization to change decision making practices and limit the level of interpretation by staff. Specific values highlighted in the case study included the view of the public, ideal of impartiality, and the ideal of inclusion. In the case study, these values were associated with transforming decision making structures and removing institutional constraints. The values may be considered in contrast to more traditional values that underpinned the rational planning model as illustrated in Figure 28. First, the case study revealed the shifting view of the public as a result of the equity lens from the public as a generality to a view of the public that differentiated among social groups by their social location and experience. 
Figure 28. Embedded Values of Decision Making

\section{Shifting Values \\ Rational Planning Model}

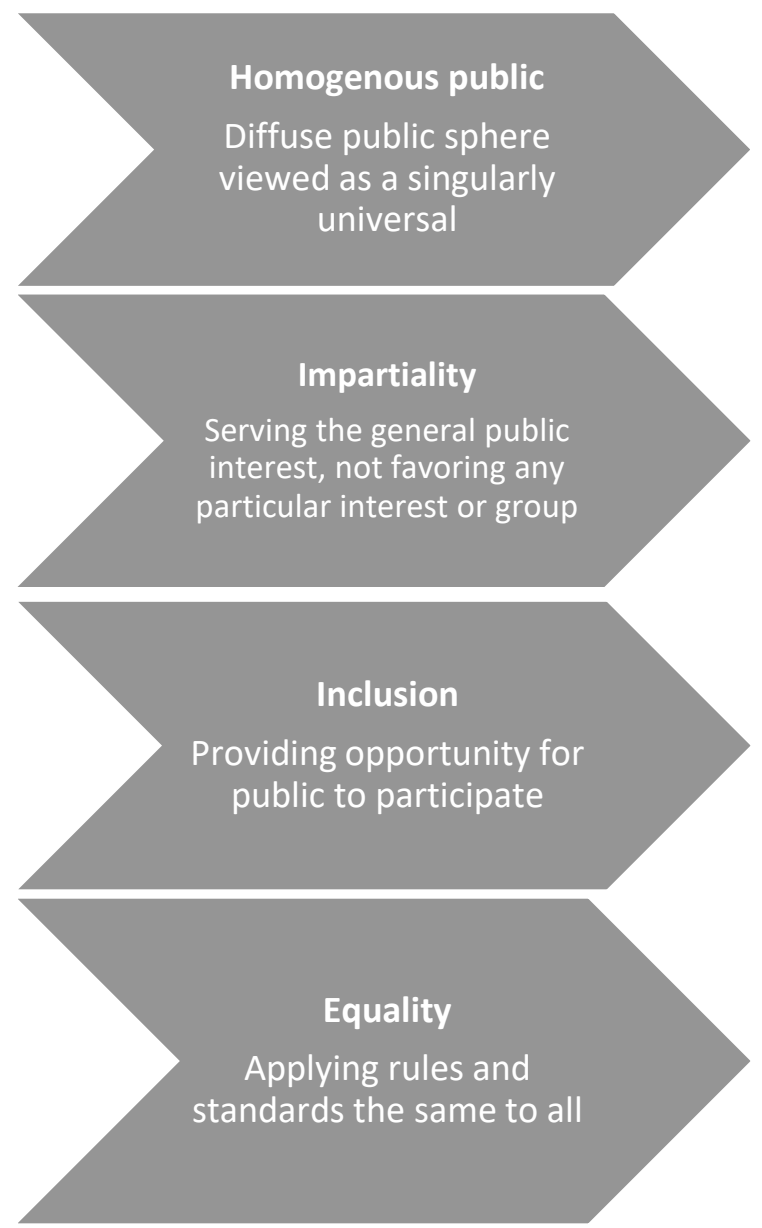

Planning Model with Equity Lens

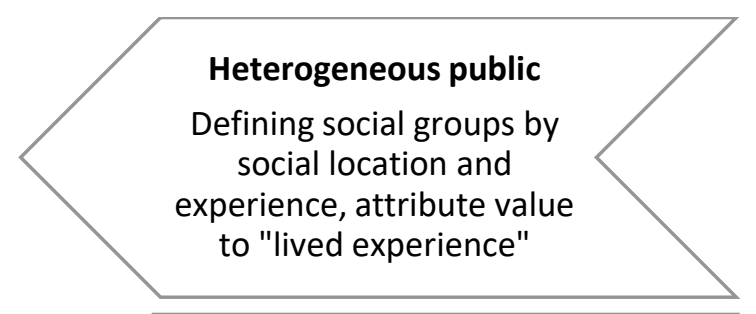

Rejection of impartiality

Adopting a situated point of view that acknowledges social difference and disporportinate impacts of policy desicions

\section{Full Inclusion}

Ensuring voice and vote to oppressed individuals and social groups in desicion making

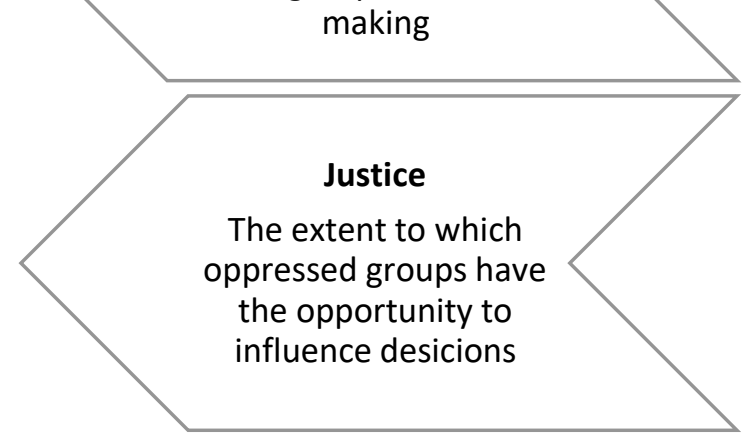

\section{Key policies for removing institutional constraints}

$>$ Recognizing and naming oppressed social groups for inclusion in decision making

Defining specific mechanisms for participation to provide special treatment for select social groups to influence decision making including appointed representation and paying stipends for community member participation

Defining methods and criteria for prioritizing groups for inclusion and representation

This shift in view was attributed to the policy guidance that named and defined specific social groups that have been marginalized from the political process. This was a key 
factor in providing special treatment to specific individuals and social groups in the planning process. The second value that underlies decision making procedures highlighted in the case study as a part of the rational approach to planning was the ideal of impartiality. As discussed previously, this ideal supported decision making centered on the view of the public as universal and public administrators and planners as neutral, impartial agents. The case study revealed the use of an equity lens was supported by the rejection of impartiality by acknowledging that no decisions are neutral and all decisions have some impact whether it be positive or negative and may benefit or impact some social groups more than others. Rejection of this ideal supports a situated point of view and supports the ideal of full inclusion. In the rational planning approach, inclusion in a political process assumes everyone has equal opportunity to participate in the policy process. In contrast, the ideal of full inclusion is defined by representation of individuals or social groups that have experienced exploitation, marginalization, powerlessness, cultural imperialism and random violence or harassment. This again requires policies that identify and define these specific social groups. In the case study, the larger categories of communities of color and marginalized groups were identified within institutional policies. This provided specific direction to staff on groups to prioritize for inclusion in decision making. However, as discovered in the case study, policy direction may also be needed to further prioritize social groups within these larger categories. Given the level of interpretation and influence that may occur at the staff level, more detailed guidance at the institutional level for this form of participation is a key consideration.

Lastly, the case study highlighted a key aspect of the equity lens was reforming decision making structures to account for social difference and power. This requires 159 
participation mechanisms that provide for special treatment and inclusion at each stage of decision making that accounts for what stage individuals are included in the process of determining a public action. To advance justice within Young's (2011) framework, individuals or groups must be positioned in the stages of decision making to influence future actions and decisions.

These considerations address potential challenges for practitioners working to understand what an equity lens means in practice by highlighting the shift in values that underlie decision making processes and opportunities to remove institutional constraints.

Figure 29. Equity Considerations in Brief

\section{Equity Lens Considerations in Brief}

Equity Lens Definition: The concept carries broad values, definitions and associated practices that may be interpreted and prioritized in different ways. An important consideration is adopting a formal definition and defined practices to build common understanding within an organization.

Removing Institutional Constraints: Institutional policies are needed to provide specific direction including establishing common definitions for the use and practice of equity lenses, recognition and naming of oppressed groups, adopting participation mechanisms for the special treatment of oppressed groups in the political process, and paying stipends for community participation. These policies build shared understanding and practices and limit the level of interpretation needed by individuals to apply the lens in practice.

Inclusion at each stage of decision making: The level of authority and influence of individuals within each stage of decision making is a key consideration. Initial standing of an individual or group within a decision process influences the extent to which they may define and influence outcomes. Therefore, the design of decision making processes must account for power and social identity for who is included and in the position to influence decisions.

The case study brought to light the level of interpretation required by participants in the planning process to use the equity lens in practice. Although the case study suggests policy guidance directly influenced how the lens was used, there was insufficient guidance to address all aspects of the equity lens. Therefore, providing more 
specific guidance including clear definitions, defined values and practices that may be adopted within an organization may assist in the intent of an equity lens to advance justice.

\subsection{Future Research}

The use of an equity lens is gaining increasing attention as a new and innovative method for addressing growing social, economic and environmental inequities. This method is rapidly being adopted in the public sector with limited research on how the equity lens changes existing structures and processes and operates within specific disciplines. This case study provides a first step in providing a more in-depth understanding on the use of an equity lens in the field of planning and provides evidence supporting propositions put forward in literature on how to address structural inequalities in the planning process. However, additional investigation is needed.

First, more research is needed on how the equity lens is continuing to evolve in practice in specific contexts. This study provides specific insights into the actions and methods that comprised the equity lens as a part of a planning process for a large scale urban system plan. Documentation reviewed as a part of the case study showed that most definitions and guides that provide instructions for the use of equity lenses are very broad and not specific to a particular discipline. Rich descriptions of the use of an equity lens with in-depth details is necessary for practitioners to fully understand how to apply an equity lens in practice. This also needs to be coupled with attention to underlying values in decision making practices and the adoption of policies to remove institutional constraints. More work is needed to build understanding on the similarities and differences between the methods being adopted as a part of an equity lens and how they 
may or may not increase representation of oppressed groups in the policy process.

Attention must also be paid to who is given the decision making power for defining and using the lens. Further study on how equity lenses are used in practice by individuals within specific disciplines would provide valuable insights for practitioners in defining and using an equity lens.

A second area for future inquiry includes investigation on how groups are selected and prioritized for special representation in policy formulation. Two potential dilemmas were identified within this case study. First, how public agencies further distinguish and prioritize groups within the larger categories of communities of color and historically marginalized groups. Within the case study, there was no additional prioritization within the larger categories of communities of color and historically marginalized groups relative accounting for historical and present day impact. Second, the process by which individuals are solicited for participation presents potential for exclusion. In the case study, recruitment was posted publicly on the web and distributed to organizations that were in contact with Metro. These channels are limited to specific individuals and groups that poses potential for exclusion. An in-depth study examining the policies and practices within institutions that establish guidance for selection of individuals and groups in the policy process and who makes these decisions is needed. This could further augment the findings of this study and provide additional insights in these two areas.

Finally, the literature review and case study suggest racial equity has become a major concern of public institutions. The case study revealed that adopting this view shifts underlying values within institutions and presents implications for reforming existing structures and systems. This includes bringing consistency between values and 
practice and adopting new language and concepts. The concepts and definitions related to equity lenses, racial equity analysis tools, and community engagement are all being used in different ways with different understandings. How will these terms continue to evolve in practice and relationship to theory? How do the varying interpretations of these concepts impact intent and outcomes of these practices? Are agencies adopting new policies to define these terms and practices? More research on how agencies are interpreting and applying these concepts in practice may lead to more consistent understanding and shared practices among government agencies.

\subsection{Conclusion}

This study provides an in-depth look at use of an equity lens using Young's theoretical propositions of structural justice. This case study is not an attempt to generalize findings, but to draw knowledge from one particular context. The findings help fill research gaps on the lack of knowledge and use of an equity lens in local government organizations and provides valuable insights on how the lens addresses structural inequalities in the planning process for a large scale urban system plan. The study provides important understandings into how the equity lens addresses structures within decision making and supports existing theories of structural justice. Lastly, the study informs how an equity lens is used in practice with a rich level of detail including the explicit actions, sequencing of methods within the institutional design space and the level of influence of practitioners interpreting and using the lens. The case study provides a significant step forward in advancing knowledge in this area and providing an opportunity for future research. 


\section{References}

Amalia Duţu \& Mihaela Diaconu. (2017). Community participation for an open public administration: Empirical measurements and conceptual framework design. Cogent Business and Management, 4(1).

Arnstein, Sherry R. (1969). A Ladder of Citizen Participation. Journal of American Planning Association, 35(4), 216-24.

Bayor, Ronald H. (1988). Planning the City for Racial Segregation: The Highway Street Pattern in Atlanta. Journal of Urban History, 15, 3-21.

Bevir, Mark (2013). Governance: A Very Short Introduction. Oxford: Oxford University Press.

Bevir, M. (2011). The SAGE Handbook of Governance. M. Bevir (Ed.). Thousand Oaks, CA: SAGE Publications.

Bingham, L. B. (2011). Collaborative governance. In M. Bevir (Ed.), The SAGE Handbook of Governance (pp. 386-401). Thousand Oaks, CA: SAGE Publications.

Bonilla-Silva, Eduardo. (1994). Rethinking Racism: Towards a Structure Interpretation. Center for Research on social Organization, Working Paper Series.

Box, Richard (1998). Citizen Governance: Leading American Communities into the $21^{\text {st }}$ Century. Thousand Oaks, CA: Sage Publications

Bonilla-Silva, Eduardo. (2003). Racism without Racists: Color-Blind Racism and the Persistence of Racial Inequality in the United States. Lanham: Rowman \& Littlefield

Braun and Clarke. (2013). Successful Qualitative Research: A practical guide for beginners. Thousand Oaks, CA: SAGE Publications. 
Braun and Clarke. (2018). Introduction to Thematic Analysis. University of West England. https://www.youtube.com/watch?v=5zFcC10vOVY

Bronstein, Elliott; Harris, Genn; Harris-White, Ron; and Nelson, Julie. (2011) Eliminating Institutional Racism within Local Government the City of Seattle Race and Social Justice Initiative. In C. King. (Eds), Government is Us 2.0. M.E. Sharpe Corporation: New York

Campbell, Scott and Fainstein, Susan. (1996). Readings in Planning Theory. Blackwell Publishers: Oxford.

Calmore, J. (1995). Critical race theory, Archie Shepp, and fire music: Securing an authentic intellectual life in a multicultural world. In K. Crenshaw , N. Gotanda , G. Peller , \& K. Thomas (Eds.), Critical race theory: The key writings that formed the movement (pp. 315-329). New York: New Press.

California Reinvestment Coalition. (2010). From Foreclosures to Re-redlining: How America's largest financial institutions devastated California communities. http://www. calreinvest.org/publications.

Cathart, Faith.(2019). Metro Council Adopts Regional Waste Plan. Metro. https://www.oregonmetro.gov/news/metro-council-adopts-2030-regional-wasteplan

Cathart, Faith.(2019). Council to Consider Proposed 2030 Regional Waste Plan. Metro. https://www.oregonmetro.gov/news/council-consider-proposed-2030-regionalwaste-plan

Cathart, Faith.(2019). Comment Now On Draft 12-Year Plan for Garbage and Recycling. Metro. https://www.oregonmetro.gov/news/comment-now-draft-12-year-plangarbage-and-recycling

Clark, Brian (2018). Planning With An Equity Lens: Making Cities More Fair. https://www.nar.realtor/on-common-ground/planning-with-an-equity-lensmaking-cities-more-fair 
Cogan Owens Cogan. (2004). Regional Solid Waste Management Plan Update: Summary Report of Stakeholder Meetings. Portland, OR.

Corbin, J. \& Strauss, A. (1990). Grounded theory method: Procedures, canons, and evaluative criteria. Qualitative Sociology, 13, 3-21.

Davidoff, Paul (1965). Advocacy Pluralism in Planning. Journal of American Institute of Planners.

Denhart and Denhart. (2015). The New Public Service: Serving Not Steering. Routledge: New York

Fainstein, Susan. (2010). Just City. United States: Cornell University

Federal Housing Administration. (1947). Underwriting Manual, Washington. DC: U.S. Government Printing Office.

Forester, John (1999). The Deliberative Practitioner: Encouraging Participatory Planning Processes. MIT Press: Cambridge, MA

Fisher, R., Ury, W., \& Patton, B. (1991). Getting to Yes: Negotiation Agreement Without Giving In. New York: Penguin

Flyvbjerg, B. (2006). Five Misunderstandings about Case-Study Research. Qualitative Inquiry, 12(2), 219-245. https://doi.org/10.1177/1077800405284363

Flyvbjerg, B. (2011). Case study. In N. K. Denzin \& Y. S. Lincoln (Eds.), The SAGE Handbook of Qualitative Research (4th ed, pp. 301-316). Thousand Oaks, CA: Sage.

Fung, Archon. (2006). Varieties of Participation in Complex Governance. Public Administration Review, 66 (S1), 66-75.

Fraser, Nancy (2000). Rethinking Recognition. New Left Review,3. 
Gewirth, Alan (1996). The Community of Rights. Chicago: University of Chicago Press

Giddens, Anthony. (1976). Central Problems of Social Theory. Berkeley: University of California Press

Government Alliance on Racial Equity. (2015). Advancing Racial Equity and Transforming Government. https://racialequityalliance.org/wpcontent/uploads/2015/02/GARE-Resource_Guide.pdf

Gulati-Partee, Gita. (2013). (2019). A Case Study of the Equity Initiative of

Montgomery County Department of Health and Human Services with Technical Assistance from Common Health Action. Montgomery Count.y http://www.consumerhealthfdn.org/wp-content/uploads/2016/02/case-study.pdf

Grant-Thomas, Andrew and powell, john a. (2006). Toward a Structural Racism Framework. PRRAC. Connecting Research to Advocacy. https://prrac.org/toward-a-structural-racism-framework/

Haggard, Derek R. (1994). [Book Review] Justice and the Politics of Difference. Iris Marion Young. Princeton University Press, 1990. Feminism and the Women's Movement. Barbara Ryan. Routledge, 1992. We Gotta Get Out of This Place: Popular Conservatism and Postmodern Culture. Lawrence Grossberg. Routledge, 1992. A Journal of Social Theory: 3(18).

http://uknowledge.uky.edu/disclosure/vol3/iss1/18

Hampton, Jean. (1997). Political Philosophy. Boulder: Westview.

Harvey, David. (1996). Justice, Nature and the Geography of Difference. Oxford: Blackwell.

Honneth, Axel. (1995). The Struggle for Recognition: The Moral Grammar of Social Conflicts. Cambridge, MA: MIT Press 
Huls, Mary E. (1985). Exclusionary and Inclusionary Zoning: A Bibliography. Monticello: Vance.

Insua, David Rios and French, Simon (2010). E-democracy: A Group Decision and Negotiation Perspective. London: Spring Dordrecht Heidelberg

Innes, Judith. (2013) A Turning Point for Planning Theory? Overcoming Dividing Discourses. University of California.

Jacobs, Jane. (1961). The Death and Life of Great American Cities. New York: Random House.

Kaiser, Edward; Goschalk, David; Chapin, Stuart (1995). Urban Land Use Planning. Chicago: University of Illnois Press

King, Cheryl Simrell. (2011). Government is Us 2.0. M.E. Sharpe Corporation: New York

Krumholz, Norman. (1982). A retrospective view of equity planning: Cleveland 19691979. Journal of the American Planning Association, 48 (2),163-74.

Krumholz, Norman and Pierre Clavel. (1994). Reinventing Cities: Equity Planners Tell Their Stories. Philadelphia: Temple University Press.

Krumholz, Norman and Forester, John. (1990). Making Equity Planning Work: Leadership in the Public Sector. Philadelphia: Temple University Press.

Kweit, Robert W. and Kweit, Mary G.(1987). The politics of policy analysis: the role of citizen participation in analytic decision making. In Jack DesSario and Stuart Langton, editors. Citizen Participation in Public Decision making. Westport, CT: Greenwood Press.

Lipsky, Michael (1980). Street-Level Bureaucracy: Dilemmas of The Individual in Public Services. New York: Russell Sage Foundation. 
Lucio, Joanna (2009). Customers, Citizens, Residents: The Semantics of Public Service Recipients. Administration and Society. 41, 878-899.

Marciano, R., Goldberg, D., \& Hou, C-Y. (2019). Los Angeles 1939 Redlining Map. Retrieved http://salt.unc.edu/T-RACES/mosaic.html

Merriam, Sharan B. (2009). Qualitative Research: A Guide to Design And Implementation. San Francisco: Josey-Bass.

Melillo, Jerry M., Terese (T.C.) Richmond, and Gary W. Yohe, Eds. (2014). Climate Change Impacts in the United States: The Third National Climate Assessment. U.S. Global Change Research Program.

Metro. (1986). Ordinance No. 89.207. For The Purpose of Defining the Planning Procedure for Designating Areas and Activities in Need of Functional Planning. Metro.

Metro. (1987). Ordinance No. 87-740. For the Purpose of Designating Solid Waste as an Area and Activity Appropriate for Development of a Functional Plan and has a Significant Impact Upon the Orderly and Responsible Development of a Metropolitan Area. Metro.

Metro. (1988). Ordinance No. 88-266B. For the Purpose of Adopting the Regional Solid Waste Management Plan as Functional Plan and Rescinding the Prior Solid Waste Plan Provisions.

Metro. (2008). Regional Solid Waste Management Plan. Portland, OR

Metro. (2013). Public Engagement Guide. Portland, OR. Metro. https://www.oregonmetro.gov/public-engagement-guide

Metro. (2016). Strategic Plan to Advance Racial Equity. Portland, OR. Metro. https://www.oregonmetro.gov/sites/default/files/2016/11/15/Strategic-planadvance-racial-equity-diversity-inclusion-exec-summary-17063-20160613.pdf

Metro. (2017). Equity Work Group Recruitment Announcement. Portland, OR 
Metro. (2017). Equity Work Group meeting Agenda May 31, 2017. Portland, OR

Metro. (2017). Equity Work Group meeting Agenda June 5, 2017. Portland, OR

Metro. (2017). Equity Work Group meeting Agenda July 25, 2017. Portland, OR

Metro. (2017). Equity Work Group Meeting Agenda August 9, 2017. Portland, OR

Metro. (2017). Equity Work Group Meeting Agenda October 23, 2017. Portland, OR

Metro. (2017). Equity Work Group Meeting Agenda November 6, 2017. Portland, OR

Metro. (2017). Equity Work Group Meeting Agenda March 7, 2018. Portland, OR

Metro. (2017). Equity Work Group Meeting March 14, 2018. Portland, OR

Metro. (2017). Equity Work Group Meeting Agenda June 5, 2018. Portland, OR

Metro. (2017). Equity Work Group Meeting Agenda October, 2018. Portland, OR

Metro. (2017). Equity Work Group Meeting Agenda November 27, 2018. Portland, OR

Metro. (2017). Metro Council Work Session Worksheet on Work Plan to Develop the 2030 Regional Waste Plan. Portland, OR

Metro. (2017). Metro Council Work Session Worksheet on 2030 Regional Waste Plan Values. Portland, OR.

Metro. (2017). Metro Council Work Session Worksheet on 2030 Regional Waste Plan Vision and Goals. Portland, OR. 
Metro. (2018). Metro Council Work Session Worksheet on 2030 Regional Waste Plan Vision and Goals. Portland, OR

Metro. (2018). Metro Council Work Session Worksheet on 2030 Regional Waste Plan Actions and Indicators. Portland, OR

Metro. (2017). Metro Policy Advisory Committee February 9, 2017 Meeting Minutes. Portland, OR

Metro. (2017). Metro Policy Advisory Committee July 12, 2017 Meeting Minutes. Portland, OR.

Metro. (2018). Metro Policy Advisory Committee January 10, 2018 Meeting Minutes. Portland, OR.

Metro. (2018). Metro Policy Advisory Committee October 10, 2018 Meeting Minutes. Portland, OR.

Metro. (2019). Metro Policy Advisory Committee January 23, 2019 Meeting Minutes. Portland, OR.

Metro (2019). Project Closure Summary. Portland OR

Metro. (2017). Solid Waste Alternatives Advisory Committee July 12, 2017 Meeting Minutes. Portland, OR.

Metro. (2018). Solid Waste Alternatives Advisory Committee January 10, 2018 Meeting Minutes. Portland, OR.

Metro. (2018). Solid Waste Alternatives Advisory Committee October 10, 2018 Meeting Minutes. Portland, OR. 
Metro. (2018). Solid Waste Alternatives Advisory Committee December 12, 2018 Meeting Minutes. Portland, OR.

Metro. (2017). 2030 Regional Waste Plan Development Project Work Plan. Portland, OR

Metro. (2018). 2030 Regional Waste Plan Engagement Summary Phases 1-4 Retrieved from: https://www.oregonmetro.gov/sites/default/files/2018/11/20/RWP_Engagement_ Report_20181120.pdf

Metro. (2019). Metro Code. Retrieved from: https://www.oregonmetro.gov/metro-code.

Metro. (2019). 2030 Regional Waste Plan. Retrieved from:

https://www.oregonmetro.gov/sites/default/files/2019/03/22/2030_Regional_Waste_Plan _03222019.pdf

Mohl, Raymond A. (1993). Race and Space in the Modern City: Interstate-95 and the Black Community in Miami.In Arnold Hirsch and Raymond Mohl, ed., Urban Policy in Twentieth-Century America. New Brunswick: Rutgers University Press.

Nelson, Julie and Brooks, Lisa. (2016). Racial Equity Toolkit: An Opportunity to Operationalize Equity. https://racialequityalliance.org/wpcontent/uploads/2015/10/GARE-Racial_Equity_Toolkit.pdf

Osbourne, D and Gaebler, T. (1992). Reinventing Government. New York: Penguin Press.

Patton, M. (1990). Qualitative Evaluation and Research Methods. Beverly Hills, CA: Sage.

Pew Research Center. (2017). How U.S. Wealth Inequality Has Changed Since Great Recession. https://www.pewresearch.org/fact-tank/2017/11/01/how-wealthinequality-has-changed-in-the-u-s-since-the-great-recession-by-race-ethnicityand-income/

powell, john a. (2007). Structural Racism: Building Upon the Insights of John Calmore, 86 N.C. L. Rev. 791 
powell, john a. (2013). Deepening Our Understanding of Structural Marginalization. Poverty \& Race 22(5),3-4, 13.

powell, john a and Heller, Connie Cagampang. (2011). Systems Thinking And Race: Workshop Summary. The California Endowment. https://www.racialequitytools.org/resourcefiles/Powell_Systems_Thinking_Struct ural_Race_Overview.pdf

Rawls, John (1971). A Theory of Justice. Cambridge, MA: Harvard University Press.

Rabin, Yale. (1989). Expulsive Zoning: The Inequitable Legacy of Euclid, in Charles Harr and Jerold Kayden, ed. Zoning and the American Dream: Promises Still to Keep. Washington, D. C.: American Planning Association Press.

Ross, Catherine and Leigh, Nancy Green (2000). Planning, Urban Revitalization, and the Inner City: An Exploration of Structural Racism. Journal of Planning Literature, $14,367-380$

Reardon, S.F., \& Bischoff K. (2016). The Continuing Increase in Income Segregation, 2007-2012. Stanford Center for Education Policy Analysis. http://cepa.stanford.edu/content/continuing-increase-income-segregation-20072012

Ritzdorf, Marsha. (1997). Family Values, Municipal Zoning, and African American Family Life.” In June M. Thomas and Marsha Ritzdorf, ed. Urban Planning and the African American Community: In the Shadows. Thousand Oaks: Sage Publications.

Ritzdorf, Marsha. (1997). Locked out of Paradise: Contemporary Exclusionary Zoning, the Supreme Court, and African Americans, 1970 to the Present. In June M. Thomas and Marsha Ritzdorf, ed. Urban Planning and the African American Community: In the Shadows. Thousand Oaks: Sage Publications. 
Saez, Emmanuel and Zucman, Gabriel. (2014). Wealth Inequality in the United States Since 1913 Evidence From Capitalized Income Tax Data. Cambridge, MA: National Bureau of Economic Research.

Scott, Richard W. (1995). Institutions and Organizations. Thousand Oaks, CA: Sage Publications.

Stake, R. E. (1995). The Art of Case Study Research. Thousand Oaks, CA: Sage Publications.

Stake, R.E. (1998). Case studies. In N. K. Denzin \& Y. S. Lincoln (Eds.), Strategies of Qualitative Inquiry 2, 86- 109. Thousand Oaks, CA: Sage.

Stoker, G. (1998). Governance as Theory: Five Oropositions. Oxford: Blackwell Publishers

Sellers, J. (2011). State-Society Relations. In M. Bevir (Ed.), The SAGE Handbook of Governance (pp. 124-141). London: SAGE.

Taylor, Charles. (1994). Multiculturalism and the Politics of Recognition. Princeton: Princeton University Press.

Thomas, June Manning. (1997). Race, Racism, and Race Relations: Linkage with Urban and Regional Planning Literature. Michigan State University.

U.S. Census Bureau (2012). Census of Governments. Retrieved from: www.census.gov/programs-surveys/cog.html.

Van Fleet, Toby (2017). Local Apartments Face Unique Challenges, Research Finds. Metro. https://www.oregonmetro.gov/news/local-apartment-residents-faceunique-recycling-challenges-research-finds

Yin, Robert k. (2002), Case Study Research: Design and Methods. Thousand Oaks, CA: SAGE publications 
Young, Iris Marion. (1989). Polity and Group Difference: A Critique of the Ideal of Universal Citizenship. Ethics, 99 (2), 250-274.

Young, Iris Marion. (1990). Justice and the Politics of Difference. Princeton, New Jersey: Princeton University Press.

Young, Iris Marion (2001). Equality of Whom? Social groups and judgments of injustice." The Journal of Political Philosophy, 9(1), 1-18

Young, Iris Marion. (2002). Inclusion and Democracy. Oxford: Oxford University Press,

Young, Iris Marion. (2007). Structural Injustice and the Politics of Difference, in Multiculturalism and Political Theory, eds. Anthony Simon Laden and David Owen, Cambridge, Massachusetts: Harvard University Press, 2007

Young, Iris Marion. (2011). Responsibility for Justice. Oxford: Oxford University.

World Bank (2020). Understanding Poverty and Social Inclusion. https://www.worldbank.org/en/topic/social-inclusion

Weingroff, Richard F. (2017). The Greatest Decade 1956-1966 - Interstate System Highway History. Federal Highway Administration. https://www.fhwa.dot.gov/infrastructure/50

Williams-Rajee, Desiree and Taren, Evans. (2016). The Integration of Equity in the Portland/Multnomah County 2015 Climate Action Plan. City of Portland (OR). https://www.portlandoregon.gov/bps/article/583501

Zapata, Marisa A and Bates, Lisa K. (2015). Equity Planning Revisited. Journal of Planning Education and Research, 35(3) http://works.bepress.com/lisa_bates/19/ 


\section{Appendix A. Positionality Statement}

\section{Researcher Positionality}

In relation to this study and qualitative research approach, the issue of my positionality is a critical consideration. Stake (1995) notes that the researcher "perceives what is happening in key episodes or testimonies, represents happenings with their own direct interpretation and stories" (p. 40). As such, presenting my own philosophical, personal and professional background become an important aspect of the study to understand how my perceptions may influence the study approach and findings.

\section{Philosophical orientation}

As a social constructionist, I believe reality is constructed inter-subjectively through meanings and understandings developed socially and experientially by individuals interacting in their social worlds. I reject the notion of neutrality and objectivity in the research of social phenomenon as I believe the researcher is a part of the social context in which they study. I believe it is necessary to understand the lived experience of individuals in context and to examine social conditions in order to expose hidden structures. Thus, the design of my study is specifically oriented to this world view and influenced my selection both Young's theoretical framework and Merriam's approach to case studies. I bring to this study the willingness to critique the status quo and investigate the structures in place that may oppress individuals and groups.

\section{Personal background}

My personal background also influences how I experience the world, approach my research and how I evaluate and interpret others and their experiences. As a daughter 
of a mixed race couple, I self-identify as a female person of color. I identify with the races and ethnicities of both of my parents and do not associate myself with one singular social group category. The recognition of my own race as being different than others was something that I gained awareness of at an early age and something that has been continually acknowledged by others throughout my life. My mother is Hispanic and was born in the United States. Both her parents were immigrants, her mother born in Mexico and her father born in Panama who arrived in America as teenagers. My mother's lived experience of being a daughter of immigrants, encountering barriers to education and being stereotyped based on her social identity has heavily influenced my worldview and understanding of embedded values, norms and assumptions within social structures and processes and the reality of social difference. In my life experience, being mixed race, has allowed me to navigate between social groups throughout life, but also never allowed me to fit into just one group. This directly influences my resistance to generalizing categories and my interest in understanding the lived of experience of individuals in context. I believe this life experience directly influenced my selection of Young's framework for my study. Young's approach looks beyond one singular category to consider systems of oppression. This approach relies more heavily an individual's or social groups' lived experience rather than how they may be classified through socially constructed singular categories such as race and class.

\section{Professional and educational background}

My professional and education background provides me with intimate knowledge and insights into the decision making processes, communication practices and organization behavior within a government organization. My decision to pursue a 
career in public policy dates back to my high school years, during which I had the opportunity to work with my father, an environmental health and safety engineer, conducting air quality testing at steel mills. The daily operations of a steel mill provided me with a vivid example of the impact industry can have on the environment. Through that work, I learned about federal and state regulations that monitor air quality and manage pollution, which gave me an early introduction to environmental policy. From that point on, I knew that I wanted to pursue a career in a field that would affect positive environmental change. This led me to pursue my bachelor's degree in environmental communications and master's degree in urban and regional planning from Portland State University. This guided my pathway into my practical experience, working nearly the last two decades as a planner for the Metro regional government. In this work, I have had the opportunities to participate in all aspects of program and policy development and evaluation as well as designing processes for participation.

In addition, I served two terms as a planning commissioner and as member of the citizen involvement board at City of Wilsonville. This experience allowed me to cross disciplines from being solely focused on environmental policy and looking a policy development in other areas including land use and transportation. It also provided me a wider view of decision making processes at a local city level in addition to decisionmaking that crosses levels of government.

My professional work at Metro and experience as a commissioner has driven a lot of curiosity and interest in me on critically evaluating how government develops policy and who participates. The pursuit of my doctorate degree has further developed my knowledge and understanding of policy making process, administrative theory, and 
theories of justice. This interest has led me into a path of inquiry that focuses on the decision making processes within a government organization and new methods that are being adopted with the intention of increasing social justice. This study is my first endeavor in applying a critical lens to my path of inquiry.

My experience as a practitioner and participant in the Regional Waste Plan helped inform and shape the research design. I selected this case to study based both on my interest and access to information and contacts that other researchers may not have. As an employee of Metro for the last twenty years, I have in-depth knowledge of the organization, institutional environment and individuals that provides me unique perspective into the social and political conditions of the case under study. Further, as a participant in the development of the Regional Waste Plan, I have an insider view of how the planning process was conducted, who was involved, and developed relationships with a number of participants in the study. I believe my connection to this study serves an opportunity to provide insights that others may not have to contribute. I also believe my relationship with participants in the planning process and may increase their willingness to talk openly about their experiences. At the same time, I recognize that this relationship may also influence individual's response as well as my assumptions for the study. The study will include a range of individuals that will elicit multiple perspectives to help answer the study questions. I will be transparent about my past experience and role in the Regional Waste Plan project with all participants involved and will continuously engage in the process of reflexivity throughout the research process. A research journal will be utilized to keep track of my observations and speculations. In addition, analytical memos will be produced at each phase of the data 
collection and analysis process and may be used an audit trail to track the analysis from raw data through interpretation and findings. My intention for the study is not only to address the existing gaps in the literature, but to also identify considerations to improve future methods and practices adopted by government organizations. I plan to share the study results with the organization and participants. 


\section{Appendix B: Consent Form}

\section{The Portland State University Consent to Participate in Research A case study of applying an equity lens to greater Portland's Regional Waste Plan}

You are being asked to participate in a research study conducted by Marta McGuire, a doctoral student with Portland State University as a part of her dissertation. Your participation in this study is entirely voluntary. Please read the information below and ask questions about anything you do not understand, before deciding whether or not to participate.

You have been asked to participate in this study because of your involvement in the 2030 Regional Waste Plan.

\section{Study Purpose}

The primary purpose of this research is to describe and analyze the current practice of an equity lens with particular attention to how the lens is defined and what factors within the institutional environment influence the application of the equity lens. Through an indepth case study analysis of the 2030 Regional Waste Plan adopted by metro, I will investigate how an equity lens may counteract policies and practices that maintain inequities in the planning process to inform the future use and study of this method.

\section{Study Procedures}

If you volunteer to participate in this study, you will be asked describe your role and experience in development of the 2030 Regional Waste Plan project in an interview. The interview that will last no more than one hour. During the interview, you may choose to refuse to answer any question, or end the interview at any time. If you decide after the interview that you do not wish your interview to be included in the study, you can contact me and have your interview deleted. The interview will be recorded, per your approval. If you wish to not be recorded, that will in no way effect your participation in the interview process. You will also be asked to complete a short survey to provide demographic information that is optional.

\section{Confidentiality}

We will take measures to protect the security of all your personal information, but we cannot guarantee confidentiality of all study data. Confidentiality will be maintained by removing names and other references that could identify individuals following data collection. Each interviewee will be given a code number to which their comments are assigned. I will be the only individual with access to consent forms, the participant list 
and the assigned codes. The key code list will be kept in a secure location in which I only have access.

\section{Participation and Withdrawal}

You can choose whether or not to be in this study. If you volunteer to be in this study, you may withdraw at any time without consequences of any kind or loss of benefits to which you are otherwise entitled. You may also refuse to answer any questions you do not want to answer. There is no penalty if you withdraw from the study.

\section{Questions or Concerns}

If you have any questions or concerns about this research, please contact:

\begin{tabular}{|c|c|}
\hline Investigator: & $\begin{array}{l}\text { Marta McGuire } \\
\underline{\text { mmarta@pdx.edu }}\end{array}$ \\
\hline & $503-544-5753$ \\
\hline Faculty Advisor: & Jennifer Allen \\
\hline & $\frac{\text { jhallen@pdx.edu }}{503.725 .3921}$ \\
\hline
\end{tabular}

If you have questions regarding your rights as a research participant, you may call the PSU Office for Research Integrity at (503) 725-2227 or 1(877) 480-4400. The ORI is the office that supports the PSU Institutional Review Board (IRB). The IRB is a group of people from PSU and the community who provide independent oversight of safety and ethical issues related to research involving human participants. For more information, you may also access the IRB website at https://sites.google.com/a/pdx.edu/research/integrity.

\section{Consent}

You are making a decision whether to participate in this study. Your signature below indicates that you have read the information provided (or the information was read to you). By signing this consent form, you are not waiving any of your legal rights as a research participant.

You have had an opportunity to ask questions and all questions have been answered to your satisfaction. By signing this consent form, you agree to participate in this study. A copy of this consent form will be provided to you.

\footnotetext{
Name of Adult Subject (print) Signature of Adult Subject $\quad$ Date
} 


\section{Investigator Signature}

This research study has been explained to the participant and all of their questions have been answered. The participant understands the information described in this consent form and freely consents to participate.

Name of Investigator (type or print)

(Signature of Investigator)

Date 


\section{Appendix C: Recruitment Materials}

\section{Recruitment Guide}

The following script will be used to recruit participants by e-mail.

You are being invited to participate in a research study examining the use of an equity lens in the development of the 2030 Regional Waste Plan. This study is being conducted by myself as a part of my dissertation at Portland State University. Specifically, I will be investigating how an equity lens may counteract policies and practices that maintain inequities in the planning process to inform the future use and study of this method. You were selected as a possible participant in this study because of your involvement in the 2030 Regional Waste Plan

If you volunteer to participate in this study, you will be asked to participate in an interview that will last no more than an hour and fill out a short survey. The interview will be recorded, per your approval. If you wish to not be recorded, that will in no way effect your participation in the interview process. The study will not include any personal identifiers in the presentation of the results. If you would like to receive research and interview results, I am happy to provide those to you upon request.

Again, your participation is voluntary. Attached is the consent form for your review that goes into greater detail on the information that I have just provided to you. I'm happy to answer any additional questions you may have about the study and your participation.

Please let me know your interest in participating by responding to this email or contacting me by phone at 503-544-5753.

Sincerely,

Marta McGuire 


\section{Appendix D: Data Collection Instruments}

\section{Interview Guide}

\section{Introduction}

Hello, and thank you for agreeing to an interview. As you know, my name is Marta McGuire and I am a doctorate student at Portland State University.

As you may recall from my phone call/email, participation in this interview is voluntary. This means you may choose now not to participate, refuse to answer any question, or end the interview at any time. If you decide after the interview that you do not wish your interview to be included in the study, you can contact me and have your interview deleted. I will leave my contact information for you.

Additionally, this interview will be recorded, per your approval. Recording the interview will help me ensure that I capture your answers more fully, but if you wish to not be recorded, that will in no way effect your participation in the interview process.

Here is the consent form for your review that goes into greater detail on the information that I have just provided to you. Please check the boxes accordingly and sign.

Thank you again for participation. Next, I am going to ask questions about your role and experience in the 2030 Regional Waste Plan

Please feel free to expand on any questions you find interesting. Any information and details you can provide is valuable to my research.

\section{Part I: Introduction}

1. Please tell me about your role and involvement in the Regional Waste Plan?

2. Can you tell me about your background and past experience participating in planning processes?

3. What interests do you and/or your organization represent?

\section{Part II: Equity Lens}

4. Are you aware that the Regional Waste Plan is using an equity lens? If so, how would you define it?

5. Did the equity lens change the planning process? If so, how?

6. Are there existing policies that define or provide direction on the use of an equity lens? If so, can you describe? How did this influence the use of the equity lens in the planning process?

7. In your view, did you observe any other factors that influenced the how the equity lens was defined and used equity lens? 


\section{Part III: Representation and Participation}

8. Who participated in the planning and decision making process?

9. How were equity work group members identified and selected?

10. In your view, did the equity lens influence representation of oppressed and marginalized groups in the planning process? If so, please describe how.

11. Did you feel you the equity lens influenced who was able to set priorities and solutions identified in the plan? If so, can you explain and provide some examples?

\section{Part II: Decision making}

12. How were decisions made in this process? Did this differ from past processes? If so, how?

13. Did the equity lens influence how decisions were made? If so, how?

14. Did the equity lens provide increased access to decision makers for historically marginalized groups? If so, how?

\section{Part IV: Lessons Learned}

15. In your view, what have been the successes and challenges with applying an equity lens to the regional waste plan?

16. Can you share some lessons learned by participating in this process?

\section{Part V: Other thoughts}

17. Is there anything else you would like to share?

This concludes the interview. As a last step, I will also ask you take a few minutes to fill out this brief optional survey. 


\section{Participant Survey}

Participants will be asked to complete this short survey following their interview.

About you

This survey is optional. You may skip any question you prefer not to answer.

\begin{tabular}{|c|c|c|c|c|}
\hline Age & $\begin{array}{l}0 \\
0 \\
0\end{array}$ & $\begin{array}{l}18-24 \\
25-34 \\
35-44\end{array}$ & $\begin{array}{l}0 \\
0 \\
0 \\
0 \\
0\end{array} \quad-\quad n$ & $\begin{array}{l}45-54 \\
55-64 \\
65-74 \\
75 \text { and older } \\
\text { Prefer not to answer }\end{array}$ \\
\hline Gender identity & $\begin{array}{l} \\
0 \\
0 \\
0 \\
0\end{array}$ & $\begin{array}{l}\text { Female } \\
\text { Male } \\
\text { Trans } \\
\text { Genderqueer or gender } \\
\text { non- conforming }\end{array}$ & $\begin{array}{l}0 \\
0\end{array}$ & $\begin{array}{l}\text { Other } \\
\text { Prefer not to answer }\end{array}$ \\
\hline $\begin{array}{l}\text { Racial/ethnic } \\
\text { identity (pick all } \\
\text { that apply) }\end{array}$ & O & $\begin{array}{l}\text { American Indian/Native } \\
\text { American or Alaskan } \\
\text { Native } \\
\text { Asian or Asian } \\
\text { American } \\
\text { Black or African } \\
\text { American }\end{array}$ & $\begin{array}{l}0 \\
0 \\
0 \\
0\end{array}$ & $\begin{array}{l}\text { Hispanic, Latino, or } \\
\text { Spanish origin } \\
\text { Pacific Islander } \\
\text { White } \\
\text { Other } \\
\text { Prefer not to answer }\end{array}$ \\
\hline $\begin{array}{l}\text { Education } \\
\text { (highest degree } \\
\text { or level of school } \\
\text { completed) }\end{array}$ & $\begin{array}{l}0 \\
0\end{array}$ & $\begin{array}{l}\text { No schooling completed } \\
\text { Nursery school to } \\
\text { 8th grade } \\
\text { Some high school, no } \\
\text { diploma } \\
\text { High school graduate, } \\
\text { diploma or the } \\
\text { equivalent (for example: } \\
\text { GED) }\end{array}$ & $\begin{array}{l}0 \\
0 \\
0 \\
0 \\
0 \\
0\end{array}$ & $\begin{array}{l}\text { Some college credit, no } \\
\text { degree } \\
\text { Trade/technical/vocational } \\
\text { training } \\
\text { Associate degree } \\
\text { Bachelor's degree } \\
\text { Master's degree } \\
\text { Professional degree } \\
\text { Doctorate degree } \\
\text { Prefer not to answer }\end{array}$ \\
\hline
\end{tabular}

\section{Occupation}

\section{Residence zip} code

Thank you again for your time and for participating in this research study. I am happy to provide you with a copy of the research and interview results at your request. Please notify me if you choose not to have your interview included in the final report. In addition, I may contact you in the next few weeks to clarify any information I collected in the interview. 